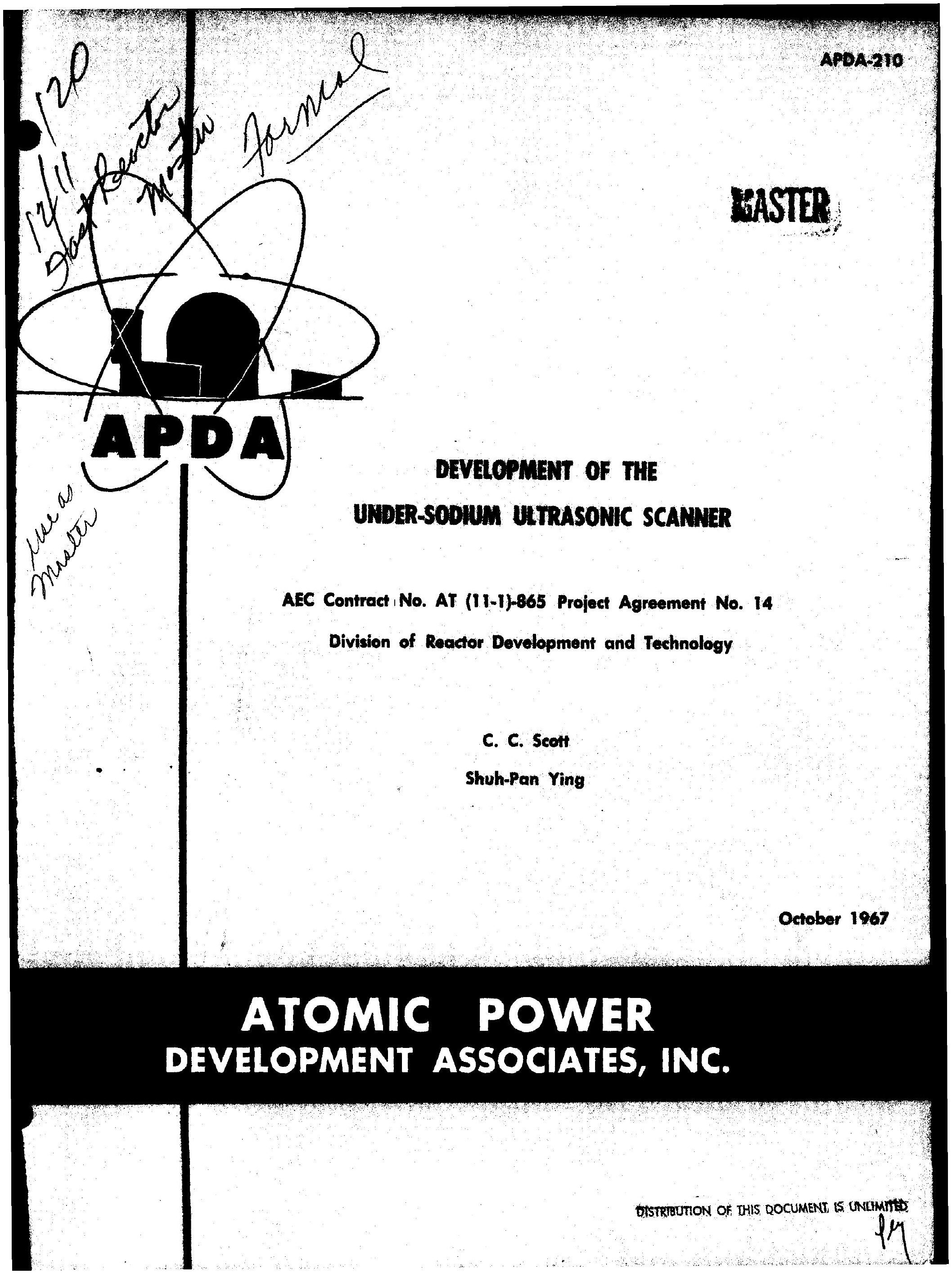




\section{LEGAL NOTICE}

This report was prepared as an account of Government sponsored work. Neither the United States nor the Commission, nor any person acting on behalf of the Commission:

A. Makes any warranty or representation expressed or implied, with respect to the accuracy, completeness, or usefulness of the information confained in this report, or that the use of any information, apparatus, method, or process disclosed in this report may not infringe privately owned rights; or

B. Assumes any liabilities with respect to the use of, or for damages resulting from the use of any information, apparatus, method, or process disclosed in this report.

As used in the above, "person acting on behalf of the commission" includes any employee or contractor of the Commission, or employee of such contractor, to the extent that such employee or contractor of the Commission, or employee of such contractor prepares disseminates, or provides access to, any information pursuant to his employment or confract with the Commission, or his employment with such contractor. 


\section{DISCLAIMER}

This report was prepared as an account of work sponsored by an agency of the United States Government. Neither the United States Government nor any agency Thereof, nor any of their employees, makes any warranty, express or implied, or assumes any legal liability or responsibility for the accuracy, completeness, or usefulness of any information, apparatus, product, or process disclosed, or represents that its use would not infringe privately owned rights. Reference herein to any specific commercial product, process, or service by trade name, trademark, manufacturer, or otherwise does not necessarily constitute or imply its endorsement, recommendation, or favoring by the United States Government or any agency thereof. The views and opinions of authors expressed herein do not necessarily state or reflect those of the United States Government or any agency thereof. 


\section{DISCLAIMER}

Portions of this document may be illegible in electronic image products. Images are produced from the best available original document. 


\title{
DEVELOPMENT OF THE UNDER-SODIUM ULTRASONIC SCANNER
}

\author{
AEC Contract, No. AT (11-1)-865 Project Agreement No. 14 \\ Division of Reactor Development and Technology
}

\author{
C. C. Scott
}

Shuh-Pan Ying

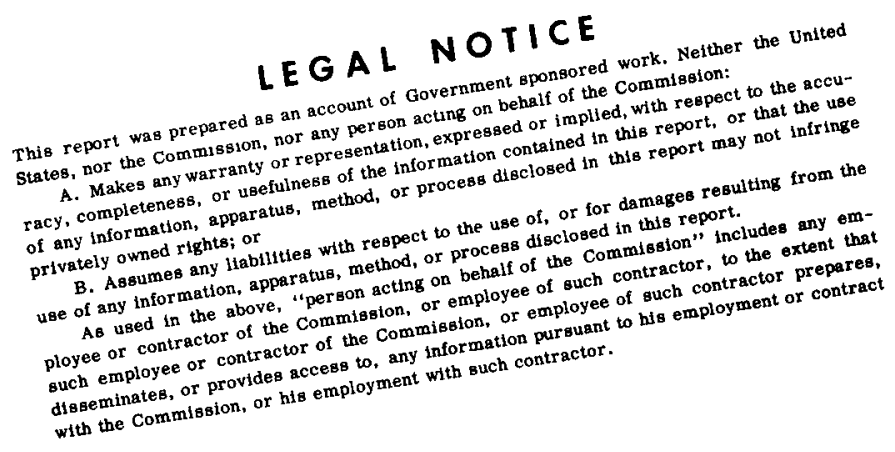




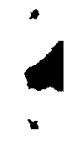

0 


\section{$\underline{\text { ABSTRACT }}$}

A scanning system that employs a focusing transducer for producing a single narrow ultrasonic beam for locating and discerning objects in hightemperature opaque media, such as $600 \mathrm{~F}$ liquid sodium, has been developed. In this report, the feasibility studies that preceded development of the system and the developmental work involving acoustic parameters, design and analysis of the mechanism, experimental results, and practical demonstrations are discussed. The focusing transducers were operated at frequencies of 2.25 and $5 \mathrm{Mc} / \mathrm{sec}$ with lead zirconate-titanate piezoelectric ceramic disks at distances from $1 / 4$ inch to approximately 3 feet from the targets. The zirconium planospherical lenses of the focusing transducers not only provided single focusing points but also, suppressed side lobes radiated from the transducers at distances far beyond the focal points. The direction and the range of a target were read from the orientation of the transducer and the cathode ray oscilloscope, respectively. For display of images of targets, a currentsensitive helix wire recorder was used. The scanner resolution for both distance and orientation was found satisfactory. 
TABLE OF CONTENTS

$\underline{\text { Page }}$

LIST OF ILLUSTRATIONS ..................... vi

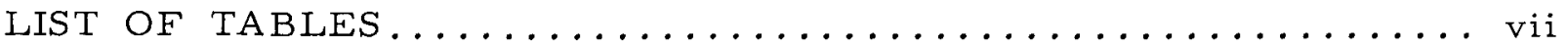

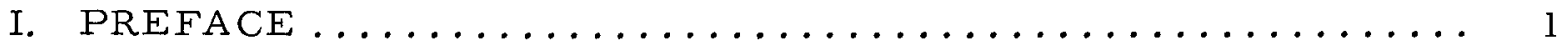

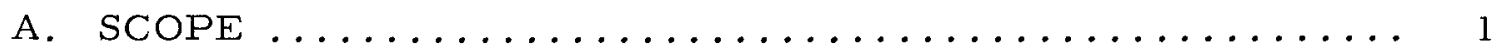

B. RELATIONSHIP TO OTHER PROJECTS ............ 1

II. INTRODUCTION $\ldots \ldots \ldots \ldots \ldots \ldots \ldots \ldots \ldots \ldots \ldots \ldots \ldots \ldots \ldots$

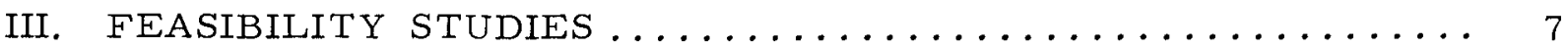

A. THEORY OF ULTRASONIC ATTENUATION IN LIQUIDS ... 7

B. ULTRASONIC ABSORPTION IN LIQUID SODIUM ......... 8

C. ACOUSTIC VELOCITY, COMPRESSIBILITY, AND

SPECIFIC HEAT OF LIQUID SODIUM ............ 8

D. CLASSICAL CALCULATION OF ABSORPTION

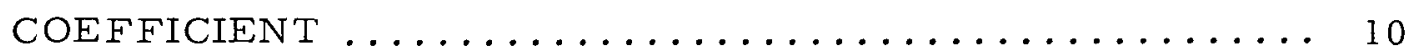

E. SUMMARY OF EXPERIMENTAL RESULTS ........... 12

IV. ULTRASONIC SCANNING SYSTEM COMPONENTS . . . . . . 13

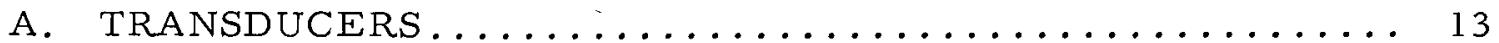

B. ELECTRONIC SYSTEM ................... 18

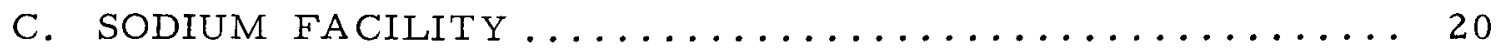

D. SCANNING MECHANISM ................. 20

V. EXPERIMENTAL INVESTIGATIONS OF TRANSDUCERS ..... 25

VI. OPERATION OF UNDER-SODIUM SCANNER ........... 33

A. LOCATING OBJECTS WITH A-SCAN SYSTEMS ......... 33

B. DISCERNING OBJECTS WITH C-SCAN SYSTEMS ....... 35

VII. CONCLUSIONS .......................... 39

REFERENCES .......................... 41

APPENDIX A: SCHEMATIC DRAWINGS OF UNDER-SODIUM SCANNER SYSTEM COMPONENTS AND TEST

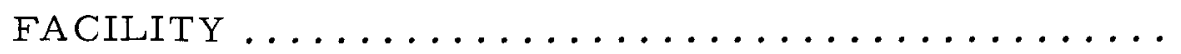




\section{LIST OF ILLUSTRA TIONS}

Figure

$\underline{\text { Page }}$

1 Intensity Attenuation in Liquid Sodium ............... 4

2 Ultrasonic Absorption in Liquid Sodium .............. 9

3 Velocity of Sound in Liquid Sodium .................. 9

4 Narrow-Beam Transducer Components ............... 15

5 Focusing Transducer with Metal Lens ............... 16

6 A Typical Ray Path in Backing Block............... 17

7 Block Diagram of Electronic System ................. 19

8 Under-Sodium Test Facility ......................... 21

9 Sodium Facility Glove Box Interior Showing Mounted

C-Scan Mechanism.......................... 22

10 Intensity Distribution at Focal Plane $\ldots \ldots \ldots \ldots \ldots \ldots \ldots$

11 Reflection Pattern Obtained by Focusing Transducer

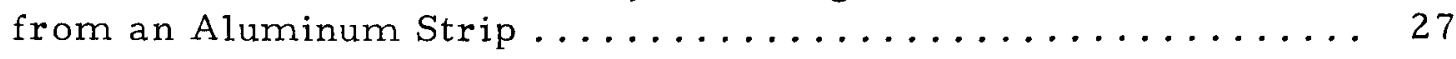

12 Calculated Radiation Pattern from Theory of Piston Transducer. 27

13 Beam Width at Focal Point for Various Focal Lengths with Fixed Diameter Piezoelectric Disks ................. 29

14 Beam Width at Focal Point for Various Focal Lengths with

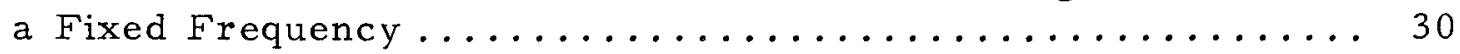

15 Beam Width at Focal Point as a Function of the Diameter of the Piezoelectric Disk .................... 31

16 Beam Width at about 16 Inches as a Function of the Radius of Curvature of the Lens ........................ 32

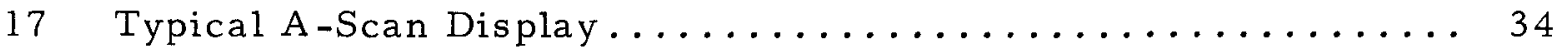

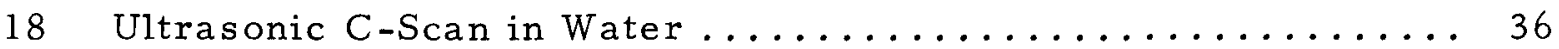

19 C-Scan Reproduction of Target in $600 \mathrm{~F}$ Sodium .......... 37

20 Stainless Steel Target for C-Scan Testing ............ 38 


\section{LIST OF TABLES}

$\underline{\text { Table }}$

$\underline{\text { Page }}$

1 Compressibility and Specific Heat of Liquid Sodium ....... 11

2 Ultrasonic Absorption Coefficient and Bulk Viscosity of Liquid Sodium ......................... 11

3 Acoustic Parameters of Focusing Transducer Materials ...... 14

4 Dimensions of Zirconium Lenses and Their Calculated

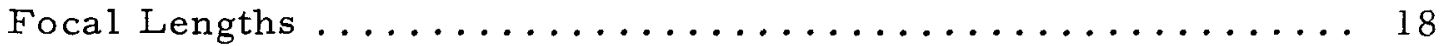




\section{PREFACE}

\section{A. SCOPE}

The scope of the under-sodium scanner test program is to develop and evaluate devices for locating and discerning objects in liquid sodium. With the determination of ultrasonic attenuation in liquid sodium and with the evolution of transducers operating at high temperatures, ${ }^{l}$ the concept of the utilization of ultrasonics for general-purpose under-sodium scanning systems has been established and documented. 2 The present phase of the work includes the following objectives:

1. To develop and evaluate narrow-beam transducers for operation in $600 \mathrm{~F}$ sodium that will be used as search units for scanning systems.

2. To engineer, design, fabricate, and initiate testing of undersodium single transducer scanning systems that will provide locations and images of objects in sodium.

\section{B. RELATIONSHIP TO OTHER PROJECTS}

A general-purpose scanning system will have application to projects in which liquid metals are used as the heat transfer media. Such a system will permit objects in liquid sodium to be discerned by means of sound waves and will, therefore, simplify maintenance and fuel handling procedures for nuclear reactors. 
$v$ 


\section{INTRODUCTION}

The major problem in using ultrasonics for under-sodium scanning is that transducers are not commercially available which can operate in such a medium at high temperatures. To overcome this problem, the conceptual designs of two methods for viewing objects immersed in liquid sodium have been formulated: the single narrow-beam transducer and the electronic acoustic image conversion system. The developmental work for the former, including the results of tests, is discussed in this report. The second method, although promising, is still being developed.

Ultrasonic detection methods are already being used in industry, and applications for such methods are steadily increasing as time continues. For example, ultrasonic nondestructive testing, which is based on the same fundamental principles as the single transducer scanner, is well established in ferrous metallurgical plants and in the machinery and transportation industries. In many instances only ultrasonic detection can be used for control purposes. This is true in the inspection of steam turbine rotors, which frequently are three feet in radius, because neithe $X$ rays, gamma rays, nor other electromagnetic waves can penetrate the thickness of the metal. Metal penetration is the basic reason why the ultrasonic method was selected for the under-sodium scanner.

The use of ultrasonic energy for testing was first suggested by Sokolov, ${ }^{3}$ who used the continuous ultrasonic wave method; however, this method was found to have limited applicability. The use of pulsed ultrasonics 4,5 though, has largely eliminated most of the problems intrinsic to the continuous - wave method. The pulse technique, in conjunction with recently de loped electronic devices, is used in the under-sodium scanner.

Prior to developing the single narrow-beam transducer, both theoretical and experimental results indicated that the attenuation in liquid sodium is sufficiently low for ultrasonic scanning. As can be seen from Figure l, beams can be transmitted up to 10 feet and more with no significant loss in intensity when transducer frequencies are between 1 and $3 \mathrm{Mc} / \mathrm{sec}$. At higher frequencies (up to $10 \mathrm{Mc} / \mathrm{sec}$ ) transmitted intensity can be sufficient up to one foot.

When sound waves are traveling in a medium, such as liquid sodium, they will be reflected from and refracted by the surface of an object if that object is large compared to the wave length. Surface reflection and refraction occur because of the discontinuity of acoustic impedances or because of an abrupt change in the elastic properties at the boundary of the medium. For the case of a stainless steel target immersed in liquid sodium, $83 \%$ of 


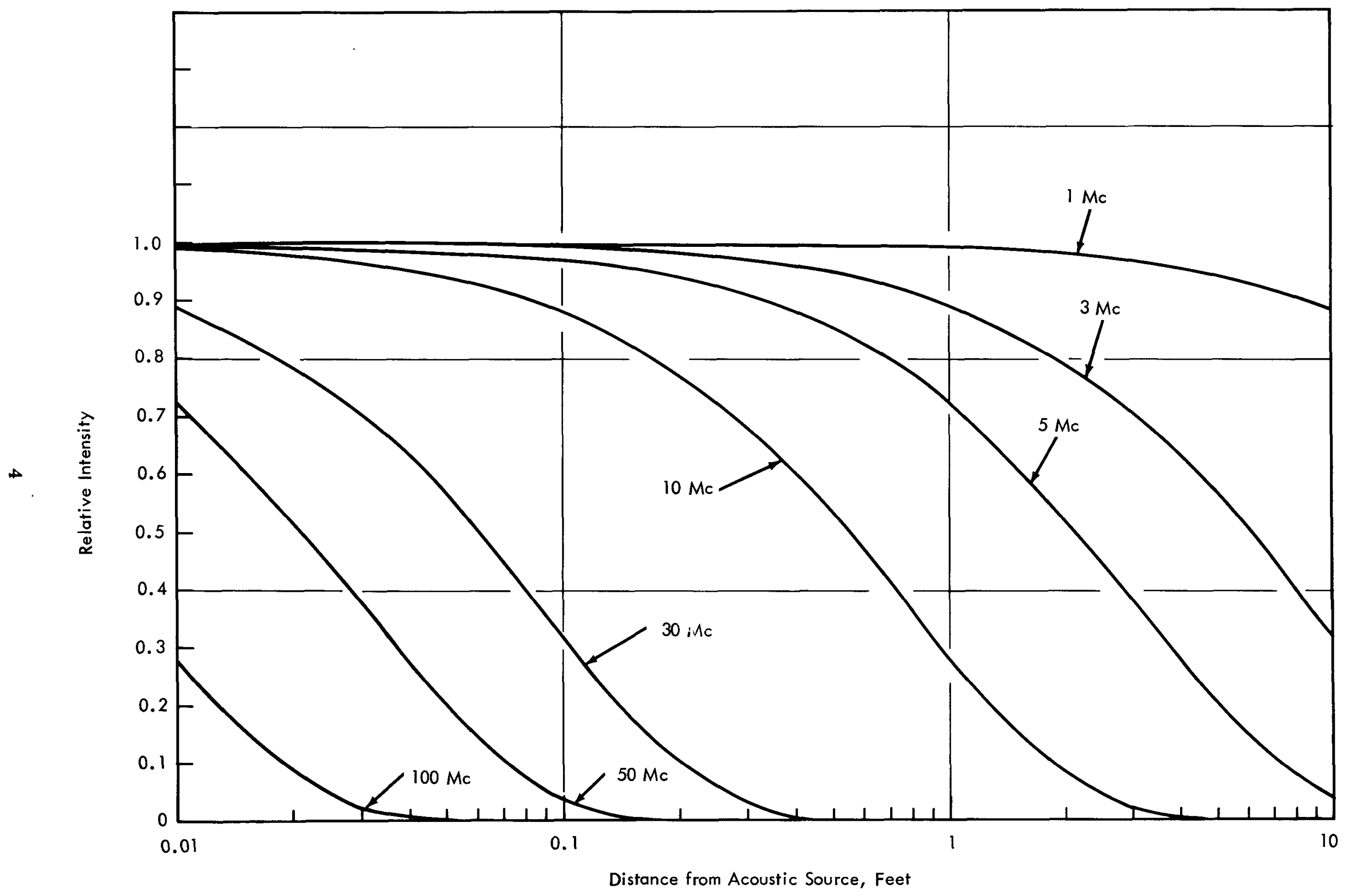

FIG. I INTENSITY ATTENUATION IN LIQUID SODIUM 
the normal incident intensity will be reflected from the target's surface. ${ }^{2}$ This is sufficient reflection for an ultrasonic scanner to locate and discern such objects in that medium. The determination of the direction and dis tance of an object is based on the directivity of the ultrasonic transducer and on the velocity of sound in liquid sodium. (As the temperature of sodium varies from its melting point to $600 \mathrm{~F}$, the velocity of sound ranges from $2.526 \times 10^{5}$ to $2.412 \times 10^{5} \mathrm{~cm} / \mathrm{sec}$.)

In the course of developing the under-sodium scanner discussed in this report, two modes of operation were used: the A-scan and the C-scan. The former was used to locate objects and to determine their distances from the transducers, and the latter was used to define objects through line-byline scanning. Both modes of operation worked satisfactorily in liquid sodium at temperatures as high as $600 \mathrm{~F}$. 
•.

- 


\section{FEASIBILITY STUDIES}

A. THEORY OF ULTRASONIC ATTENUATION IN LIQUIDS

Whenever sound waves propagate through a fluid medium, there is a loss of acoustic energy. The sources of this loss may be divided into two general categories: those associated with conditions at the boundaries of the medium and those due to the dissipation of acoustic energy in the medium itself. The first type of loss is of particular significance when the volume of the fluid is small in comparison with the area of the boundary walls. In an unbounded medium, the intensity of a plane wave decreases in accordance with the equation 6

$$
I=I_{0} e^{-2 a x}
$$

where the intensity $I_{O}$ falls to a value $I$ after traveling a distance $x$, and $a$ is the intensity absorption coefficient of a plane wave. The common explandtion of the second type of loss, the absorption of ultrasonic energy in the medium itself, is that it is due to the shear viscosity $\eta_{S}$, the bulk viscosity $\eta_{B}$, and the thermal conductivity $K$ of the fluid. The shear viscosity and thermal conductivity contribute to the so-called "classical absorption" of ultrasonic energy in the medium

$$
a_{\text {class }}=a_{S}+a_{T}
$$

The absorption due to shear viscosity, given by Stokes, ${ }^{7}$ is

$$
a_{S}=8 \pi^{2} f^{2} \eta_{S} / 3 p c^{3}
$$

where

$$
\begin{aligned}
& f=\text { frequency of the sound wave } \\
& \rho=\text { mean density of the medium } \\
& c=\text { velocity of sound in the medium }
\end{aligned}
$$

And the absorption due to thermal conductivity, given by Kirchoff, 8 is

$$
a_{T}=\left(\frac{2 \pi^{2} f^{2}}{\rho c^{3}}\right)\left(\frac{\gamma-1}{c_{p}}\right) K
$$

where 


$$
\begin{aligned}
\boldsymbol{Y} & =\mathrm{c}_{\mathrm{p}} / \mathrm{c}_{\mathrm{v}} \\
\mathrm{c}_{\mathrm{p}} & =\text { specific heat at constant pressure } \\
\mathrm{c}_{\mathrm{v}} & =\text { specific heat at constant volume } \\
\mathrm{K} & =\text { thermal conductivity }
\end{aligned}
$$

In most liquids, as a result of various relaxation processes, the measured absorption is greater than the classical value. The excess absorption is formally accounted for by the introduction of a bulk viscosity leading to an absorption 9

$$
a_{B}=2 \pi^{2} f^{2} \eta_{B} / \rho c^{3}
$$

The expression for the commonly observed absorption can be expressed by

$$
a_{\text {obs }}=a_{S}+a_{T}+a_{B}
$$

B. ULTRASONIC ABSORPTION IN LIQUID SODIUM

Ultrasonic absorption in liquid sodium has been measured in the temperature range of 220 to $600 \mathrm{~F}$ with frequencies of 4 and $5 \mathrm{Mc} / \mathrm{sec}$. As the distance of travel for sound waves increases, the intensity decreases exponentially; this agrees with the case of Eq (1). From Eqs (3) through (6), the absorption coefficient and the frequency have the relation

$$
\frac{a}{f^{2}}=\frac{2 \pi^{2}}{\rho c^{3}} \quad\left[\frac{4}{3} \eta_{S}+\eta_{B}+\left(\frac{\gamma-1}{c_{p}}\right) K\right]=\text { constant }
$$

at constant temperature.

For almost all liquids, Eq (7) is satisfied experimentally over a wide range of frequencies, i. e., the experimental results agree with this relation. The experimental data which are the average value of the comparable results for the measurements at each temperature are presented in Figure 2 . The solid line was obtained by the method of least squares from experimental data. At the temperature of $600 \mathrm{~F}$, the experimental data of $a / f^{2}$ is $21 \times$ $10^{-17} \mathrm{sec}^{2} \mathrm{~cm}^{-1}$. This is lower than that of water where a/f $\mathrm{f}^{2}$ is $24 \times 10^{-17}$ $\sec ^{2} \mathrm{~cm}^{-1}$ at $59 \mathrm{~F} \cdot 10$

\section{ACOUSTIC VELOCITY, COMPRESSIBILITY,} AND SPECIFIC HEAT OF LIQUID SODIUM

From Eq (7), the absorption coefficient is inversely proportional to the cube of the velocity of sound. Therefore, it was necessary to determine the velocity of sound in liquid sodium in the temperature range of attenuation measurements to investigate experimental data. Figure 3 shows the velocity of sound in liquid sodium measured at various temperatures. The results are in good agreement with data obtained by Pochapsky. 11 


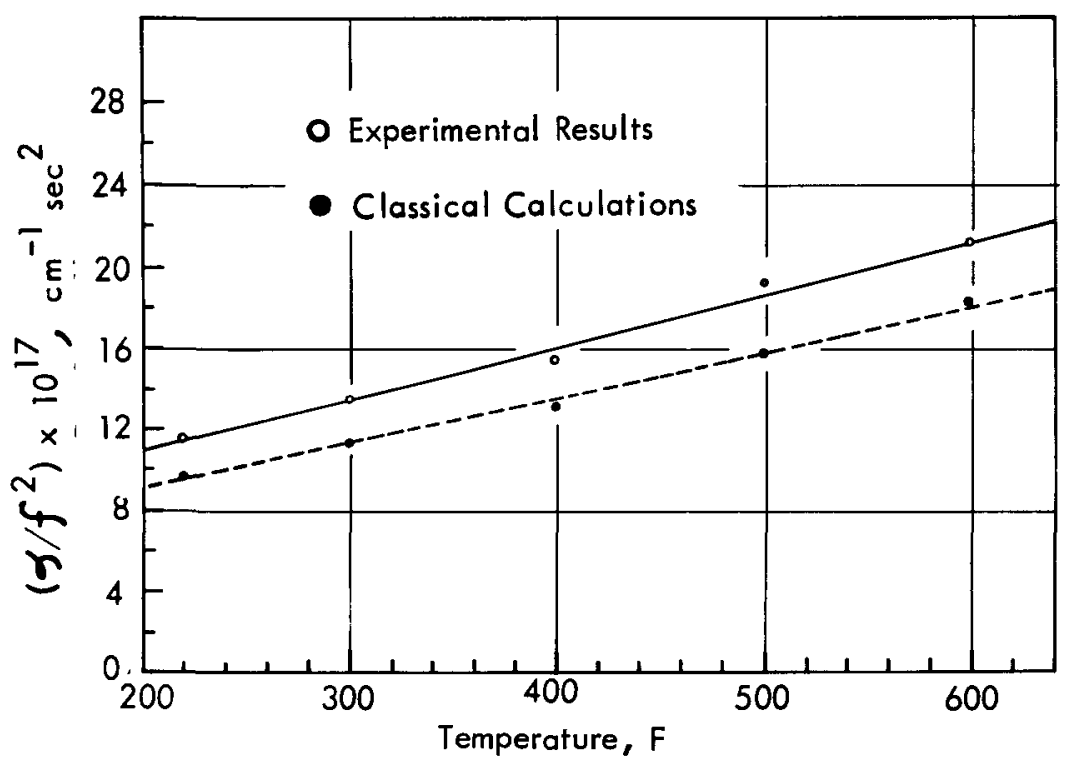

FIG. 2 ULTRASONIC ABSORPTION IN LIOUID SODIUM

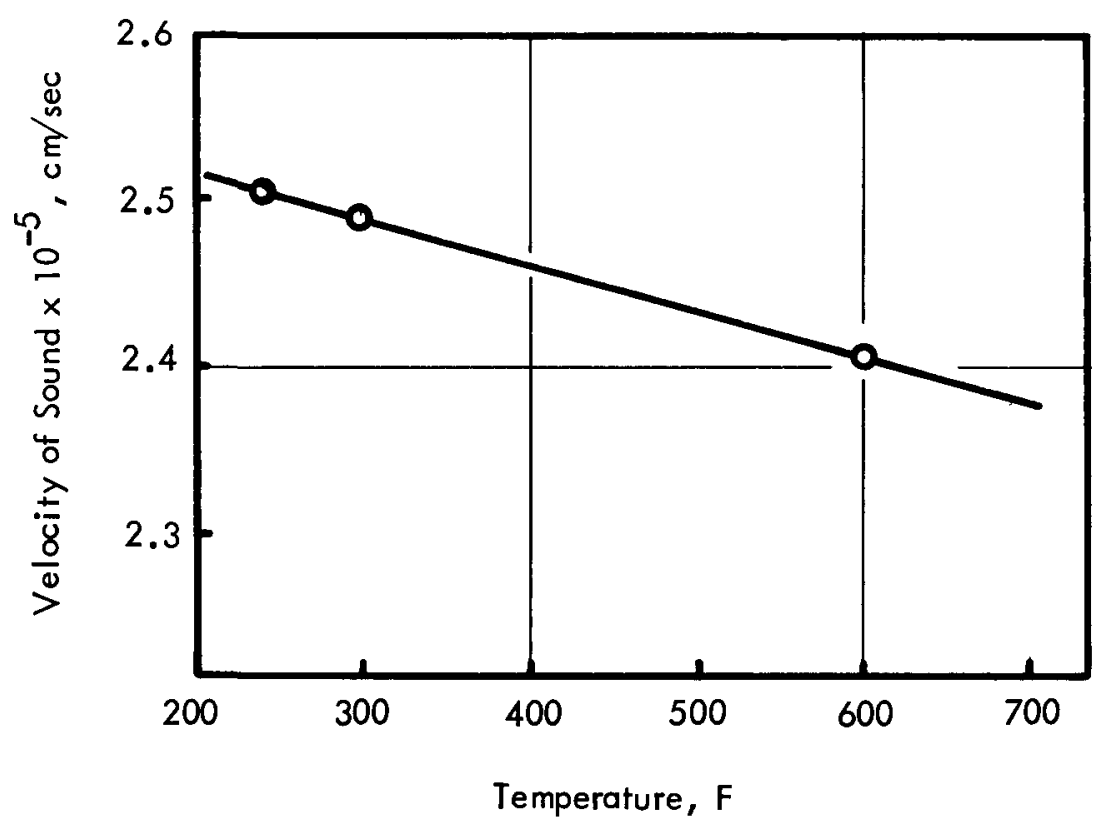

FIG. 3 VELOCITY OF SOUND IN LIQUID SODIUM 
The specific heat at constant volume $c_{v}$ in Eq (4) can be calculated from values obtained from the measurements of acoustic velocity. Since adiabatic compressibility $\mathrm{K}_{\mathrm{S}}$ is given by

$$
K_{S}=1 / \rho c^{2}
$$

where

$$
\begin{aligned}
S & =\text { constant entropy } \\
\rho & =\text { density } \\
c & =\text { velocity of sound }
\end{aligned}
$$

the isothermal compressibility $K_{T}$ can be calculated from

$$
K_{T}-K_{S}=T \beta^{2} / \rho c_{p}
$$

where

$$
\begin{aligned}
\beta & =\text { coefficient of volume expansion } \\
\mathrm{T} & =\text { temperature, oK } \\
\mathrm{c}_{\mathrm{P}} & =\text { specific heat at constant pressure }
\end{aligned}
$$

It follows, then, that specific heat at constant volume $c_{v}$ can be obtained from

$$
c_{v}=K_{S} c_{p} / K_{T}
$$

Data are available at temperatures below $522 \mathrm{~F}^{12}$ therefore, $\mathrm{K}_{\mathrm{S}}, \mathrm{K}_{\mathrm{T}}$, and $\mathrm{c}_{\mathrm{v}}$ are calculated only at $600 \mathrm{~F}$ from the results of the acoustic velocity measurements at this temperature. The results are listed in Table 1, together with data at lower temperatures.

\section{CLASSICAL CALCULATION OF ABSORPTION COEFFICIENT}

To obtain a comparison between the experimental data of ultrasonic attenuation and the values derived from classical theory, values for the relation $a_{\text {class }} / \mathrm{f}^{2}$ were calculated from 220 to $600 \mathrm{~F}$, using Eqs (2), (3), and (4). A part of the data for the calculations is listed in Table 2; other data were obtained from Sittig. ${ }^{12}$ The results are shown in Figure 2. The dotted line, which was obtained by the method of least squares from the results of classical calculations, can be represented by the following equation:

$$
\frac{a_{\text {class }}}{f^{2}} \times 10^{17}=(4.68867+0.0219582 t)\left(\mathrm{sec}^{2} \mathrm{~cm}^{-1}\right)
$$

where

$$
t=\text { temperature of liquid sodium, } F
$$


TABLE 1 - COMPRESSIBILITY AND SPECIFIC HEAT OF LIQUID SODIUM

\begin{tabular}{|c|c|c|c|c|c|c|}
\hline $\begin{array}{c}\text { Temperature, } \\
\mathrm{F} \\
\end{array}$ & $\begin{array}{l}\mathrm{c} \times 10^{-5}, \\
\mathrm{~cm} / \mathrm{sec} \\
\end{array}$ & $\begin{array}{c}\rho, \\
\mathrm{gram} / \mathrm{cm}^{3}\end{array}$ & $\begin{array}{c}\mathrm{K}_{\mathrm{S}} \times 10^{5} \\
\mathrm{~atm}-1 \\
\end{array}$ & $\begin{array}{l}\mathrm{K}_{\mathrm{t}} \times 10^{5} \\
\mathrm{~atm}^{-1} \\
\end{array}$ & $\begin{array}{c}\mathrm{c}_{\mathrm{p}}, \\
\mathrm{cal} / \mathrm{C} \text { gram } \\
\end{array}$ & $\begin{array}{c}\mathrm{C}_{\mathrm{V}}, \\
\mathrm{cal} / \mathrm{C} \text { gram } \\
\end{array}$ \\
\hline 208.1 & 2.526 & 0.9270 & 1.713 & 1.888 & 0.33088 & 0.30025 \\
\hline 300 & 2.499 & 0.9155 & 1.771 & 1.986 & 0.32517 & 0.29001 \\
\hline 400 & 2. 471 & 0.9028 & 1.836 & 2.095 & 0.31970 & 0.28008 \\
\hline 500 & 2.441 & 0.8898 & 1.911 & 2.225 & 0.31479 & 0.27041 \\
\hline 600 & 2.412 & 0.8770 & 1. 986 & 2.356 & 0.31065 & 0.26160 \\
\hline
\end{tabular}

TABLE 2 - ULTRASONIC ABSORPTION COEFFICIENT AND BULK VISCOSITY OF LIQUID SODIUM

\begin{tabular}{|c|c|c|c|c|}
\hline $\begin{array}{c}\text { Temperature, } \\
\mathrm{F} \\
\end{array}$ & $\begin{array}{l}\left(a \operatorname{class} / \mathrm{f}^{2}\right) \times 10^{17}, \\
\sec ^{2} \mathrm{~cm}^{-1}\end{array}$ & $\begin{array}{c}\left(a \text { obs } / f^{2}\right) \times 10^{17}, \\
\sec ^{2} \mathrm{~cm}^{-1}\end{array}$ & $\begin{array}{c}\eta_{S}, \\
\text { Centipoise } \\
\end{array}$ & $\begin{array}{c}\eta_{\mathrm{B}} \text { ' } \\
\text { Centipoise } \\
\end{array}$ \\
\hline 208.1 & 9.258 & 11.365 & 0.690 & 1.587 \\
\hline 300 & 11.276 & 13.294 & 0.545 & 1.460 \\
\hline 400 & 13.472 & 15.392 & 0.445 & 1.325 \\
\hline 500 & 15.668 & 17.490 & 0.376 & 1.195 \\
\hline 600 & 17.864 & 19.587 & 0.329 & 1.075 \\
\hline
\end{tabular}


E. SUMMARY OF EXPERIMENTAL RESULTS

A comparison of the results of ultrasonic attenuation derived from classical calculations and those obtained from measurements indicates that liquid sodium exhibits relatively little excess absorption. The excess absorption is mainly due to the bulk viscosity $\eta_{B}$ which is ignored in the classical calculation of ultrasonic attenuation. Since the bulk viscosity of a monatomic fluid, such as a liquid metal, can possibly be caused by a structural relaxation process, and since $\partial \eta_{B} / \partial T$ is usually negative, ${ }^{13} \eta_{B}$ of liquid sodium derived from experimental results and classical calculations have similar values at temperatures below $500 \mathrm{~F}$. From 500 to $600 \mathrm{~F}$, experimental results indicate an excess absorption of $7 \%$, which is possibly caused by an increase in impurities in the sodium. Experimental results applying this correction can be expressed by the following equation, using the method of least squares:

$$
\frac{a_{o b s}}{f^{2}}=(6.99836+0.0209836 t)\left(\mathrm{sec}^{2} \mathrm{~cm}^{-1}\right)
$$

where

$$
\begin{aligned}
a_{\text {obs }} & =\text { measured absorption coefficient } \\
f & =\text { frequency } \\
t & =\text { temperature of liquid sodium, } F
\end{aligned}
$$

Therefore, from Eqs (11) and (12) the excess absorption of liquid sodium can be obtained for various temperatures, and the bulk viscosity can be calculated from the excess absorption and Eq (5)

$$
\eta_{B}=\frac{\rho c^{3}}{2 \pi^{2}} \quad\left(\frac{a_{o b s}-a_{c l a s s}}{f^{2}}\right)
$$

The values obtained from Eqs (11), (12), and (13) are listed in Table 2 which indicates $\partial \eta_{\mathrm{B}} / \partial \mathrm{T}$ is negative. The ratio of $\eta_{\mathrm{B}} / \eta_{\mathrm{S}}$ is 3 at $400 \mathrm{~F}$, and changes approximately $20 \%$ for temperature changes between 208.1 and $600 \mathrm{~F}$. 


\section{ULTRASONIC SCANNING SYSTEM COMPONENTS}

\section{A. TRANSDUCERS}

To obtain high resolution of an image from an ultrasonic transducer, such as the transducer shown disassembled in Figure 4, a narrow radiation beam is very desirable. The selection of a planospherical lens material is difficult, however, because it is necessary to have a good acoustic impedance match between the lens and the piezoelectric disk (lead zirconate-titanate) and between the lens and the sodium into which the ultrasonic waves are transmitted. At the same time, it is necessary to have a velocity of sound in the lens that is different from that in the sodium. The requirements for index of refraction and acoustic impedance may be stated as follows:

$$
\begin{aligned}
\mathrm{n} & =\mathrm{c}_{1} / \mathrm{c}_{2} \neq 1 \\
\mathrm{r}_{12} & =\mathrm{c}_{1} \rho_{1} / \mathrm{c}_{2} \rho_{2} \simeq 1
\end{aligned}
$$

where

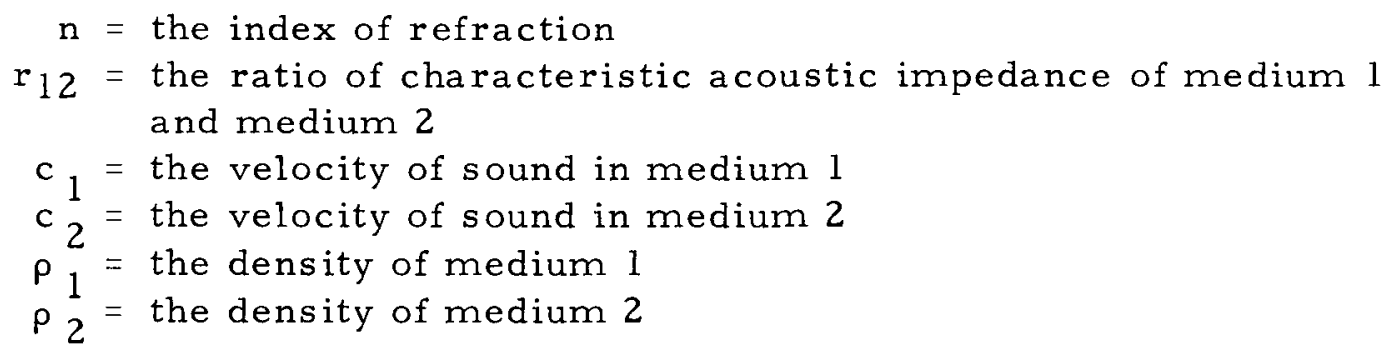

Although materials can be found that satisfy these requirements, many of them cannot be used in high-temperature liquid sodium. For example, Ernst 14 and Sette ${ }^{15}$ have pointed out the suitability of two plastics, Plexiglas and polystyrene, for use as converging lenses for sound waves. However, neither of these materials can be used in $600 \mathrm{~F}$ liquid sodium. Of those materials that can be used in such an environment, zirconium was found to possess the best overall qualities for a planospherical lens. As can be seen from Table 3, zirconium, when compared to other focusing trans ducer materials, exhibits satisfactory acoustic matching with both sodium and lead zirconate-titanate (commercially known as PZT-5). Also indicated in Table 3 is a list of the indexes of refraction of various focusing transducer materials--the metals with respect to sodium and the plastics with respect to water. From this list, it can be seen that zirconium has a slightly higher but still quite acceptable index of refraction when compared to those of the two plastics. 


\section{TABLE 3 - ACOUSTIC PARAMETERS OF FOCUSING} TRANSDUCER MATERIALS

Characteristic

Acoustic Index of

Material

\begin{tabular}{ccc}
$\begin{array}{c}\text { Acoustic } \\
\text { Impedance } \times 10^{-6}, \\
\mathrm{~g} / \mathrm{cm}^{2}-\mathrm{sec}\end{array}$ & $\begin{array}{c}\text { Index of } \\
\text { Refraction, } \\
\mathrm{n}\end{array}$ & $\begin{array}{c}\text { Surrounding } \\
\text { Medium }\end{array}$ \\
\hline
\end{tabular}

Sodium

0.2131

1.000

$\begin{array}{lrcl}\text { Polystyrene } & 0.26 & 1.60 & \text { Water } \\ \text { Plexiglas } & 0.33 & 1.90 & \text { Water } \\ \text { Zirconium } & 2.98 & 1.92 & \text { Liquid Sodium } \\ \text { Nickel } & 4.85 & 1.97 & \text { Liquid Sodium } \\ \text { Steel } & 4.67 & 2.39 & \text { Liquid Sodium } \\ \text { Tungsten } & 10.00 & 2.25 & \text { Liquid Sodium } \\ \text { Lead Zirconate- } & & & \\ \text { Titanate, PZT-5 } & 2.80 & & \end{array}$

The focal length of a planospherical concave lens is dependent upon the radius of curvature of the lens and upon the acoustic index of refraction of the lens in a given medium. The relation among the focal length $f$, index of refraction $n$, and radius of curvature $R$ is given by

$$
f=R\left(1-\frac{1}{n}\right)^{-1}
$$

Twelve zirconium lenses with various diameters and radii of curvature were procured for evaluation. The diameters, radii of curvature, and focal lengths of the lenses were calculated from Eq (16) for both liquid sodium and water environments. Table 4 is a compilation of the calculated values. Since the cross section of the beam width at the focal plane is related to the physical size of the lens, the lenses that were procured provided different focal lengths with various beam widths. The results of the evaluation of the lenses operating in both liquid sodium and water were obtained analytically and are presented in Section $V$ of this report.

To reduce the effect of multiple reflections from the bounda ry of the lens and sodium medium, a backing block should be attached to the back face of the piezoelectric disk, as is shown in Figure 5. Several geometrical shapes of the backing block were investigated to obtain optimum attenuation. By using the ray theory of reflection, the transmission paths can be easily found. A typical normal incident ray path in a backing block is shown in Figure 6. As can be seen from Figure 6, the geometry of the block consists 


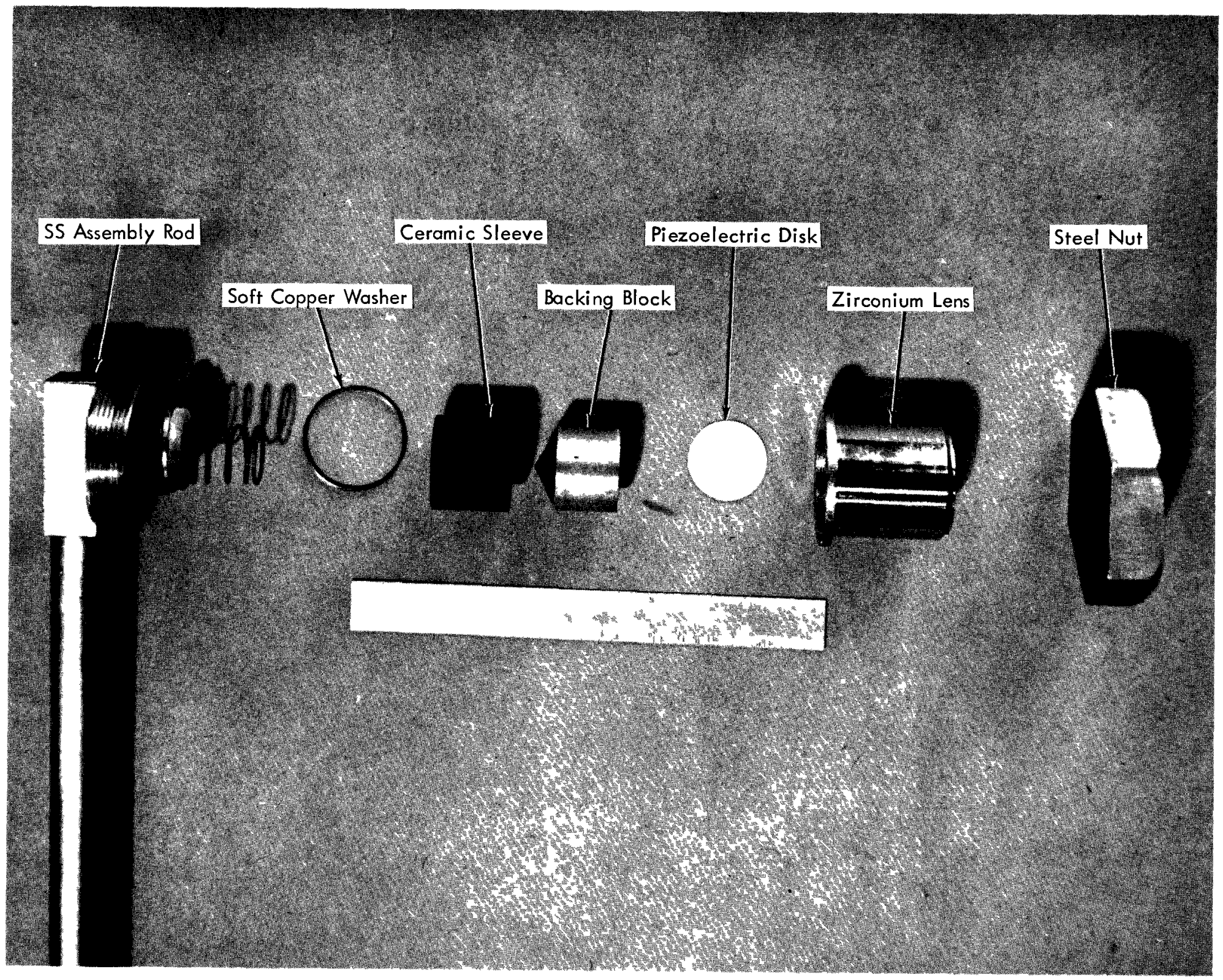

FIG. 4 NARROW-BEAM TRANSDUCER COMPONENTS 


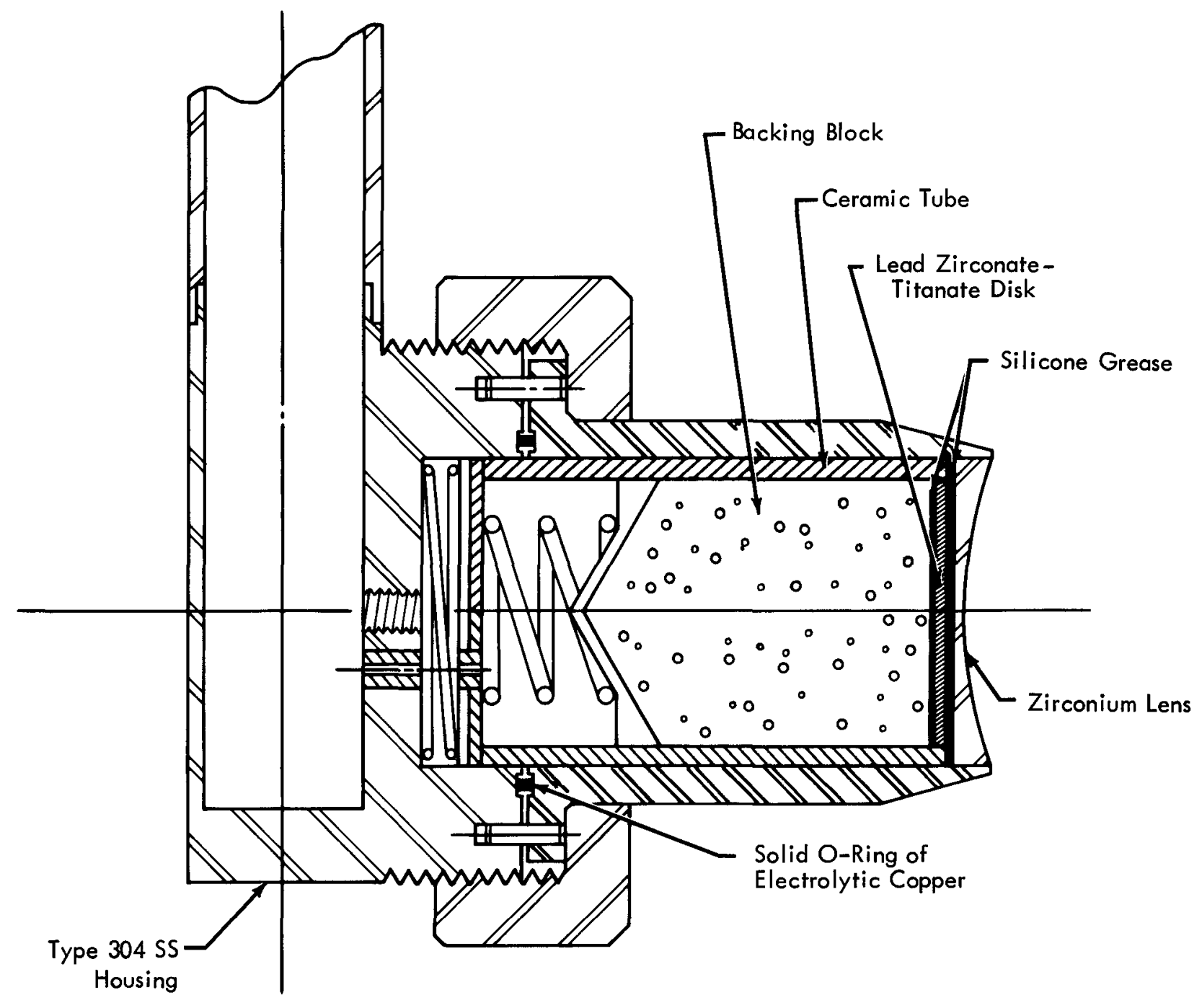

FIG. 5 FOCUSING TRANSDUCER WITH METAL LENS 


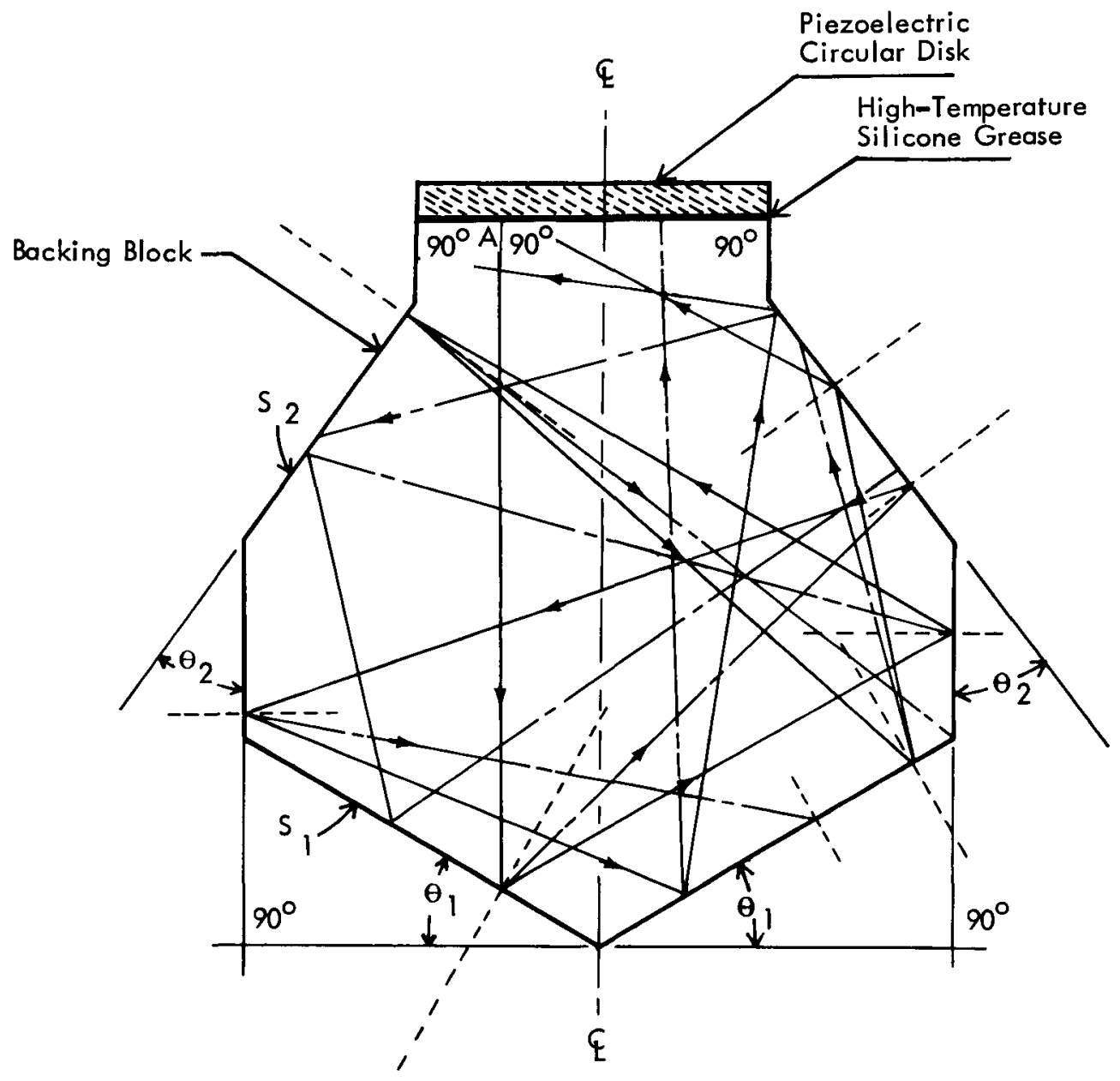

Path of Longitudinal Wave
$--\ldots$ Path of Transverse Wave
$---\quad$ Normal Line of Surface

FIG. 6 A TYPICAL RAY PATH IN BACKING BLOCK 
of two cones $\left(\theta_{1}, \theta_{2}\right)$ and two cylinders. The ray will not return to the incidence point $A$ on the piezoelectric disk if the angle $\theta_{2}$ is slightly greater than the angle $\theta_{1}$. In the present design $\theta_{1}=30^{\circ}, \theta_{2}=35^{\circ}$, and surface $\mathrm{S}_{1}$ is a convex cone. Evidently, either a concave conical surface or a concave spherical surface can be used to obtain optimum attenuation. In either case, the reflection rays from the back surface $S_{1}$ will transmit divergently into the backing block.

\section{TABLE 4 - DIMENSIONS OF ZIRCONIUM LENSES AND THEIR CALCULATED FOCAL LENGTHS}

\begin{tabular}{|c|c|c|c|c|}
\hline \multirow[b]{2}{*}{$\begin{array}{c}\text { Lens } \\
\text { No. }\end{array}$} & \multirow[b]{2}{*}{$\begin{array}{c}\text { Diameter, } \\
\text { Inches } \\
\end{array}$} & \multirow{2}{*}{$\begin{array}{c}\text { Radius } \\
\text { of Curvature, } \\
\mathrm{R} \text {, Inches } \\
\end{array}$} & \multicolumn{2}{|c|}{ Focal Length, f, Inches } \\
\hline & & & $\begin{array}{l}\text { in Liquid Sodium } \\
(\mathrm{n}=1.92) \\
\end{array}$ & $\begin{array}{l}\text { in Water } \\
(\mathrm{n}=3.14) \\
\end{array}$ \\
\hline 1 & 1.250 & 4.000 & 8.36 & 5.88 \\
\hline 2 & 1.250 & 2.500 & 5.25 & 3.68 \\
\hline 3 & 1.250 & 1.500 & 3.14 & 2.21 \\
\hline 4 & 1.000 & 2.000 & 4.18 & 2.94 \\
\hline 5 & 1.000 & 1.250 & 2.67 & 1.84 \\
\hline 6 & 1.000 & 0.750 & 1.57 & 1.10 \\
\hline 7 & 0.750 & 3.000 & 6.27 & 4.41 \\
\hline 8 & 0.750 & 1.000 & 2.09 & 1. 47 \\
\hline 9 & 0.688 & 0.375 & 0.78 & 0.55 \\
\hline 10 & 0.625 & 0.500 & 1.04 & 0.735 \\
\hline 11 & 0.625 & 0.375 & 0.78 & 0.55 \\
\hline 12 & 0.563 & 0.250 & 0.52 & 0.368 \\
\hline
\end{tabular}

\section{B. ELECTRONIC SYSTEM}

A block diagram of the electronic system used in the test and evaluation program is shown in Figure 7. Pulses used to synchronize the pulse transmitter, the gating system, and the oscilloscope were provided by a pulse generator. Pulse widths of 1 usec or less were often used. A receiver, a Transigate E550, and a Type S digital amplifier were used to accept the signals from the transducer. The electronic equipment had carrier frequencies of $2.25,5$, and $10 \mathrm{Mc} / \mathrm{sec}$, and the output of the pulse transmitter with a load was greater than $1 \mathrm{kv}$ peak-to-peak. A coaxial cable RG$63 \mathrm{~B} / \mathrm{U}$ with low distribution capacitance to reduce distortion of the narrow high-frequency pulses was used for the transmission line between the electronic receiver and the ultrasonic transducer. The receiver had sufficient gain and excellent signal-to-noise ratio. Its maximum output to the Transigate was about 7 volts peak-to-peak. 


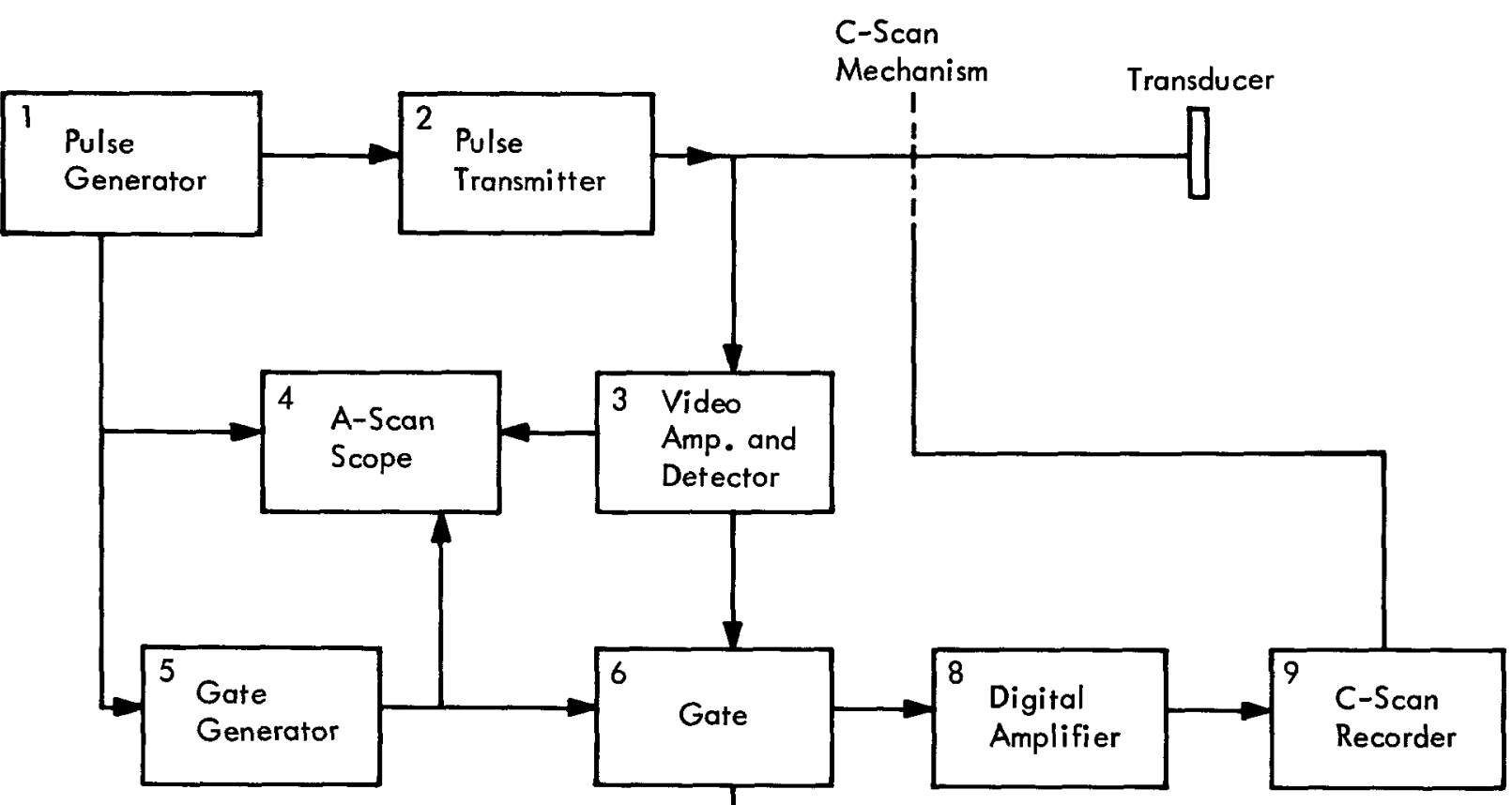

1. Hewlett-Packard Model 212A

2. Sperry Products Co., Pulser Model 10N

3. Sperry Products Co., Receiver Model 10N

4. Tektronic Type RM564 or 535A

5. Sperry Products Co., Transigate Model E550

6. Sperry Products Co., Transigate Model E550

7. Sperry Products Co.. Transigate Model E550

8. Sperry Products Co., Transigate Model E550

9. Alden Electronics Co., Model 3IIDA 
The Transigate was used for both the gate generator and the gate. It established specific, controllable gated areas or zones within the detection distance. Reflection signals appearing within the gate were monitored automatically to operate visual and/or audible alarms. Simultaneously, the Transigate also provided a digital signal of constant amplitude ( -10 volts $D C$ ) that was used for solenoid operation of the C-scan recorder pin. The gate starting point and the gate length could be varied over a range from 2 to 3000 $\mu$ sec, which corresponded to a range in sodium of 0.2 inch to 23 feet. The output of the digital amplifier was adjustable from 0 to 60 volts at 200 ohms impedance, and maximum current was $0.30 \mathrm{amp}$. Automatic short circuit protection was provided.

The output of the receiver was also fed into channel A of a dual trace oscilloscope which, in turn, indicated the time separation between the transmitted pulse and the echo from a target to form an A-scan. Channel B of the oscilloscope accepted the signal from the gate generator and indicated the gate waveform on the screen. With this display, the gate starting point and the gate length could be adjusted properly for the echo of interest.

\section{SODIUM FACILITY}

The tank for conducting the under-sodium scanning tests was made from Type 304 stainless steel. The tank, whose dimensions were 42 inches long, 19.25 inches wide, and 20.5 inches deep, was designed for installation under a dry box (Figure 8) in which argon was circulated to provide the liquid sodium with a dry cover gas. The design of the facility made it possible to adjust the separation of the transducer, reflector, and target up to a maximum distance of 30 inches. In addition, the design permitted easy adjustment of all three in azimuth or elevation. A cover gas purification system, model HE-93, manufactured by the Vacuum/Atmospheres Corporation, was installed on the facility, and during the experiments, this system maintained an atmospheric purity of $1 \mathrm{ppm}$ of oxygen and $0.1 \mathrm{ppm}$ moisture. DuPont reactor grade sodium, with impurities listed by volume at 50 ppm chlorides and $400 \mathrm{ppm}$ calcium, was used in the experiments. The sodium was first melted in the original shipping container and then transferred to the test tank through a filter and a stainless steel tube by pressurizing the shipping container with argon. Once in the test tank, the sodium was heated to $600 \mathrm{~F}$ by electric resistance heaters that were controlled by a manual and automatic temperature control system.

\section{SCANNING MECHANISM}

The primary function of the scanning mechanism (Figure 9) is to provide a means by which an ultrasonic scanner type of spatial mapping can be investigated in a liquid sodium environment. The mechanis $\mathrm{m}$ is comprised of three main units, which are as follows: 


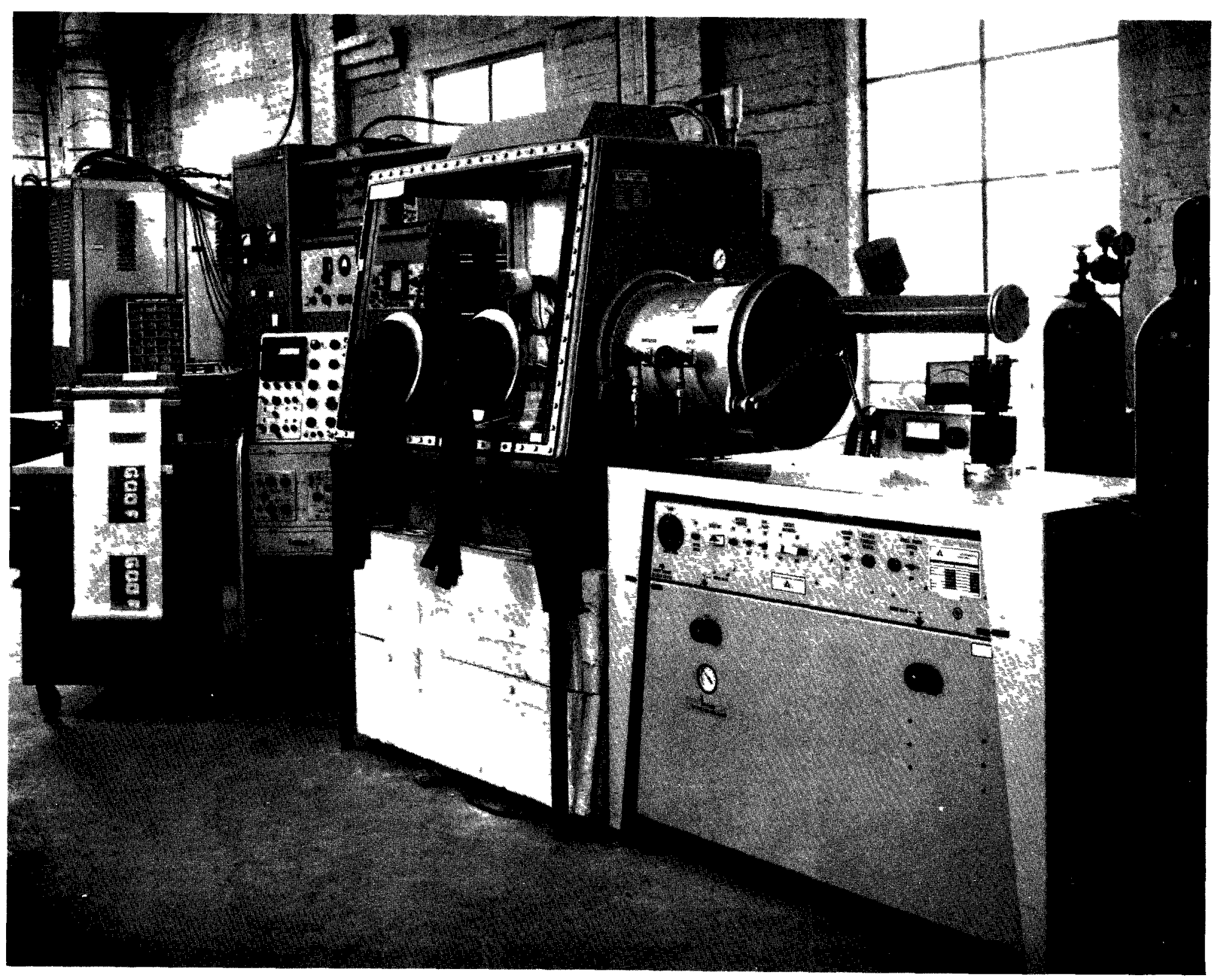

FIG. 8 UNDER-SODIUM TEST FACILITY 


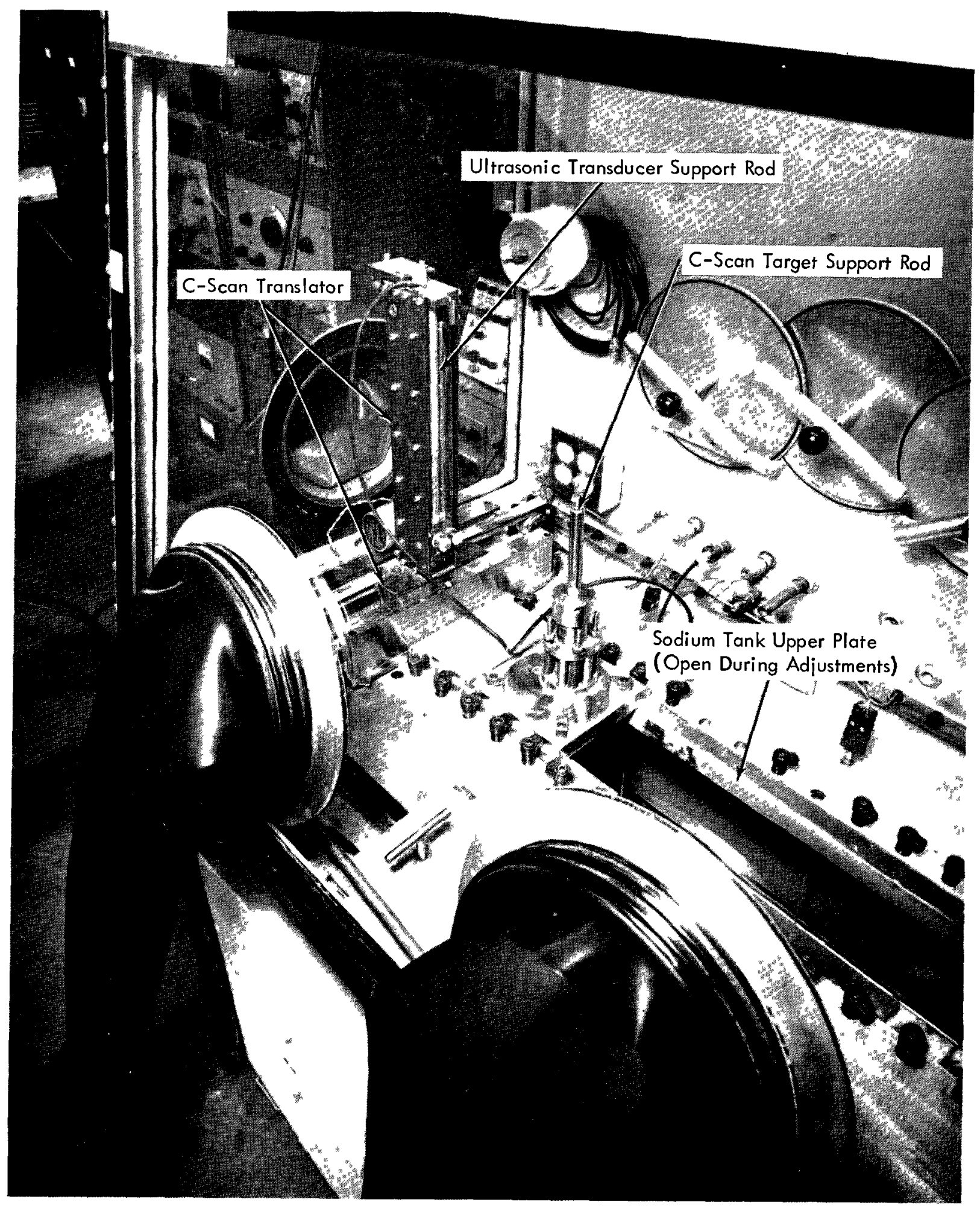

FIG. 9 SODIUM FACILITY GLOVE BOX INTERIOR SHOWING MOUNTED C-SCAN MECHANISM 
- The first unit is an X-Y positioning system that is driven by stepping motors. Mounted on the positioning system is the transducer for C-scan mapping. The transducer is capable of traversing an area of 9.25 by 9.25 inches.

- The second unit is a recording system that is positioned by stepping motors. This system accepts the output current of the digital amplifier from the electronic receiving system when the transducer, which moves synchronously with the recording system, receives reflection signals from the target. This current provides modulation intensity to the recorder pen. The recorder paper utilized, made by Alfax Paper \& Engineering Company, is current sensitive. The Alden Electronics Company helix wire recorder, Model 311 DA, can thus be used to provide, with appropriate probe signal ranging, a quasi-three-dimensional picture of the volume scanned.

- The third unit is a central control system. This system contains all the control functions and indicating devices for automatic operation. The basic scan rate of the system in the horizontal X direction is $1-1 / 2$ inches per second. With the recorder system resolution set at $0.010 \mathrm{inch}$, the levels of vertical $\mathrm{Y}$-direction increments are $0.025,0.050,0.100$, and 0.200 of an inch. 
-

- 


\section{EXPERIMENTAL INVESTIGATIONS OF TRANSDUCERS}

The resolution of an object that can be obtained by an ultrasonic scan is a function of the cross section of the ultrasonic beam at the object. Ultrasonic beam cross sections were measured in water to obtain a knowledge of the beam patterns radiated from the zirconium lenses. This was essential because no technical information on zirconium lenses was available. Measurements made in liquid sodium at $600 \mathrm{~F}$ later in the program confirmed that transducer characteristics in room-temperature water and $600 \mathrm{~F}$ liquid sodium are similar.

The ultrasonic beams were measured at their calculated focal planes by fixing the transducers in stationary positions and moving 0.187 -inch stainless steel targets perpendicularly to the principal axes of the beams. The distances between transducers and targets were determined from the calculated focal points shown in Table 4. While the targets were being moved, the echoes of different amplitudes were read from an oscilloscope screen. Target positions were read from an indicator with a resolution better than 0.001 inch.

A typical experimental result is shown in Figure 10. The experiment was conducted with a transducer having a concave zirconium lens and a lead zirconate-titanate piezoelectric disk that operated at $2.25 \mathrm{Mc} / \mathrm{sec}$. The focal point for the transducer in water, calculated from Eq (16), was 5.86 inches. It should be noted that the cross section of the ultrasonic beam at an intensity of $-3 \mathrm{db}$ is 0.088 inch when the distance between the lens and the target is 5.3 inches.

An experiment was conducted to determine the acoustic beam diameter at a distance well beyond the focal point of the transducer. A 1/8-inch-wide aluminum plate was positioned at a distance of 16 inches from the transducer. The transducer was rotated on an axis that was perpenducular to the direction of sound propagation, and the intensities of the echoes were measured at various transducer angles. Figure 11 is a measured radiation pattern from a transducer with a $1 / 2$-inch-diameter lead zirconate-titanate piezoelectric disk and a 1 -inch-diameter zirconium lens with a 3 -inch radius of curvature. The piezoelectric disk was operated at a frequency of $2.25 \mathrm{Mc} / \mathrm{sec}$ and generated wave lengths of 0.0262 inch in water at room temperature. The beam width, as shown in Figure 11 , was $1.67^{\circ}$ at the $-3 \mathrm{db}$ intensity level, and there were essentially no side lobes above the -50db level. In Figure 12, a calculated acoustic pattern for a similar transducer is shown. It should be noted that the beam width is $2.94^{\circ}$ at the $-3 \mathrm{db}$ intensity level, with strong side lobes of $4.93^{\circ}$ and $8.2^{\circ}$ at relative intensities of $-16.3 \mathrm{db}$ and $-31 \mathrm{db}$, respectively. The experimental results indicate that the acoustic beam from the piezoelectric disk can be collimated by the spherical concave lens, and 


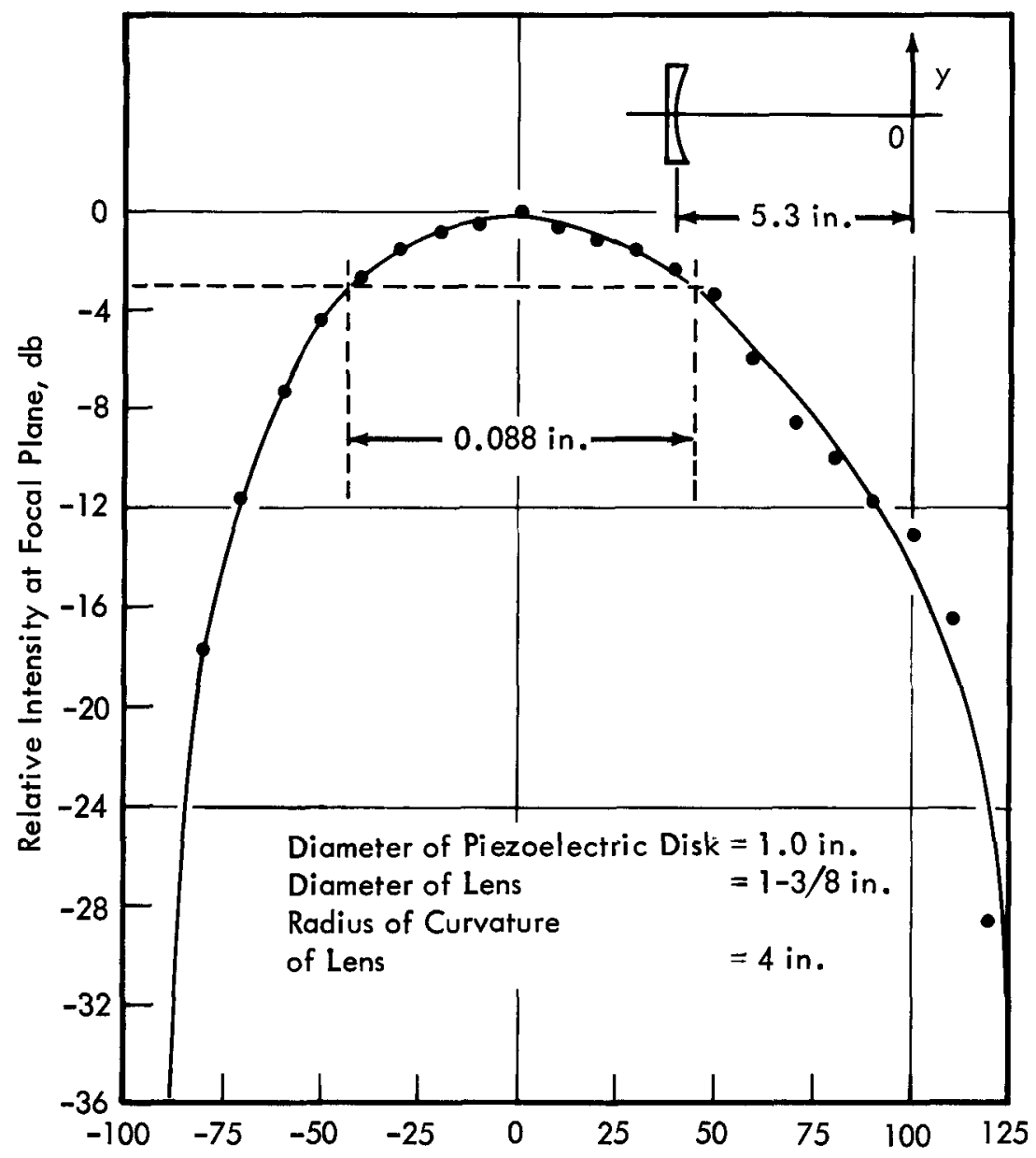

Distance from Center of Beam - $y$, Inches $\times 10^{-3}$

FIG. 10 INTENSITY DISTRIBUTION AT FOCAL PLANE 


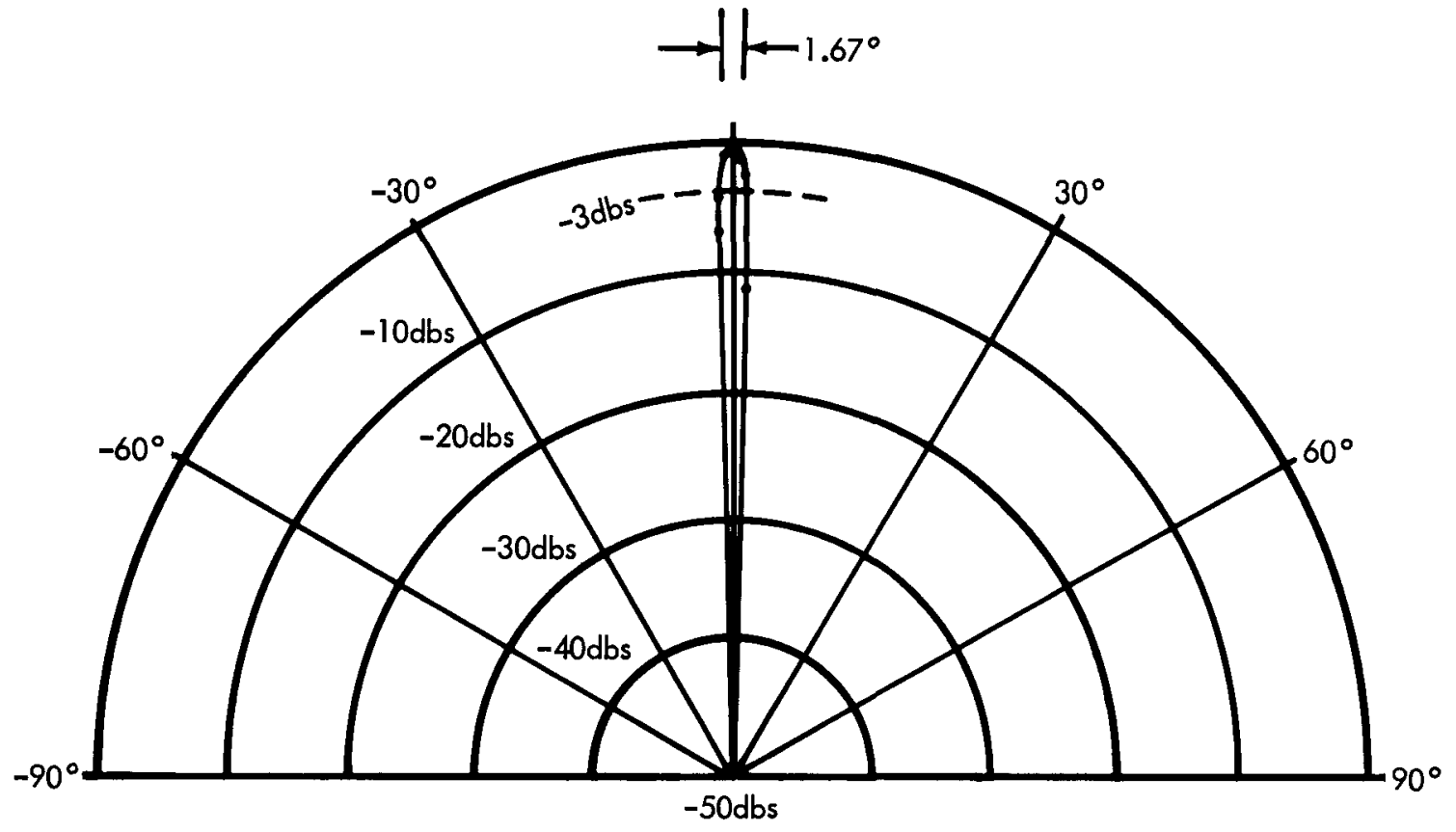

FIG. 11 REFLECTION/PATTERN OBTAINED BY FOCUSING TRANSDUCER FROM AN ALUMINUM STRIP

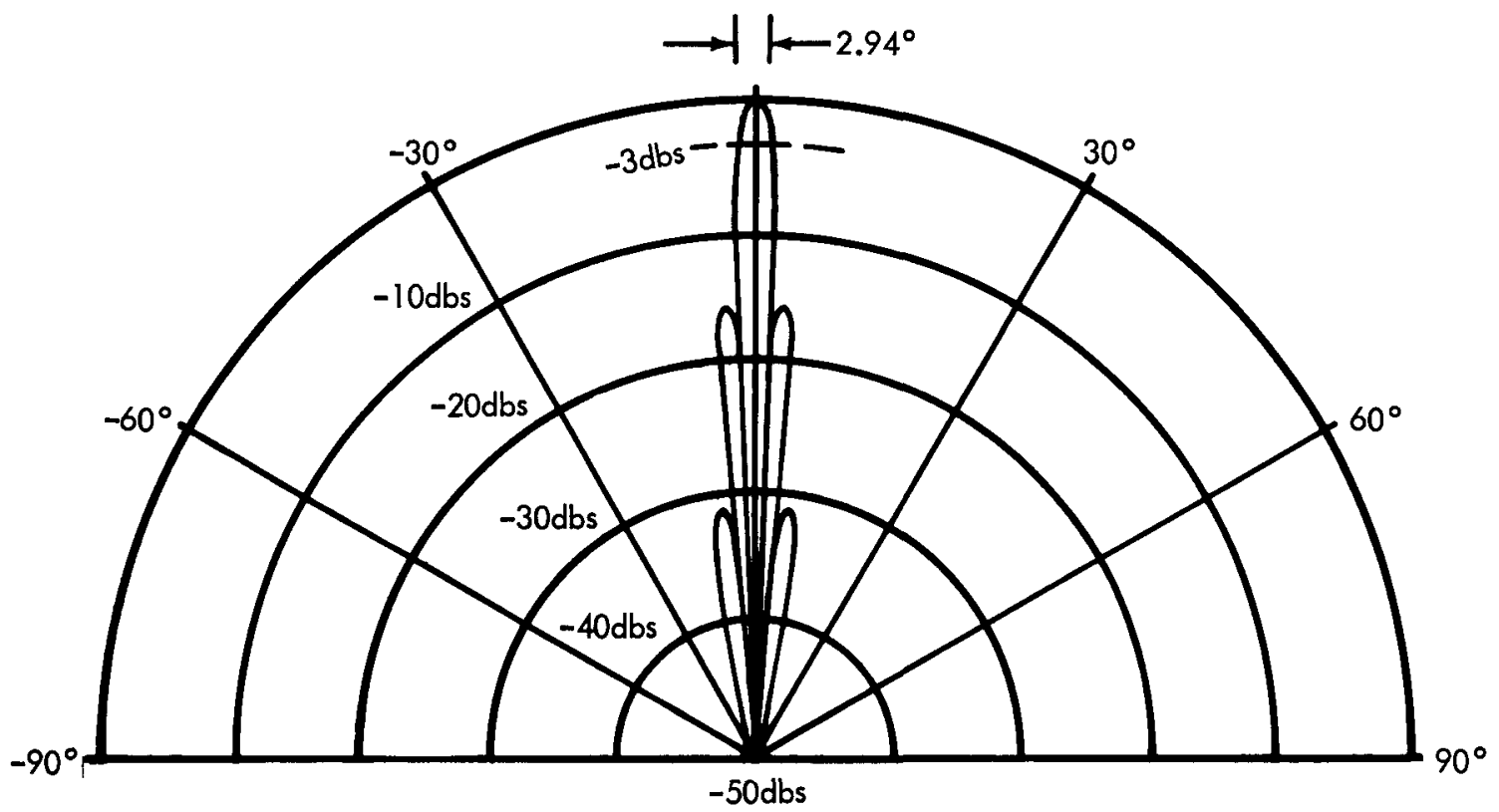

FIG. 12 CALCULATED RADIATION PATTERN FROM THEORY OF PISTON TRANSDUCER 
that side lobes can be suppressed to intensities that are negligible when compared to the main lobe.

Measurements were made to determine the widths of ultrasonic beams at different focal points (Figure 13). One-half-inch-diameter lead zirconatetitanate piezoelectric disks vibrating at frequencies of 2.25 and $5 \mathrm{Mc} / \mathrm{sec}$ were operated with zirconium lenses of different radii of curvature. The widths of the ultrasonic beams were larger at longer focal points for a given disk frequency. The beam widths were less for piezoelectric disks vibrating at higher frequencies at fixed focal points. In Figure 14 are indicated the experimental results obtained from lenses with different radii of curvature and piezoelectric disks operating at a frequency of $2.25 \mathrm{Mc} / \mathrm{sec}$ but with two diameters of disks. Figure 15 shows the widths of ultrasonic beams as functions of the diameters of piezoelectric disks vibrating at the same frequency and operating with the same lens.

Tests were conducted to determine beam width as a function of the radius of curvature of three different lenses at a distance of 16 inches from the transducers. The results shown in Figure 16 were derived from a $0.5-$ inch-diameter piezoelectric disk vibrating at $2.25 \mathrm{Mc} / \mathrm{sec}$. It was found that the smallest lens produced the sharpest acoustic beam at a fixed point. 


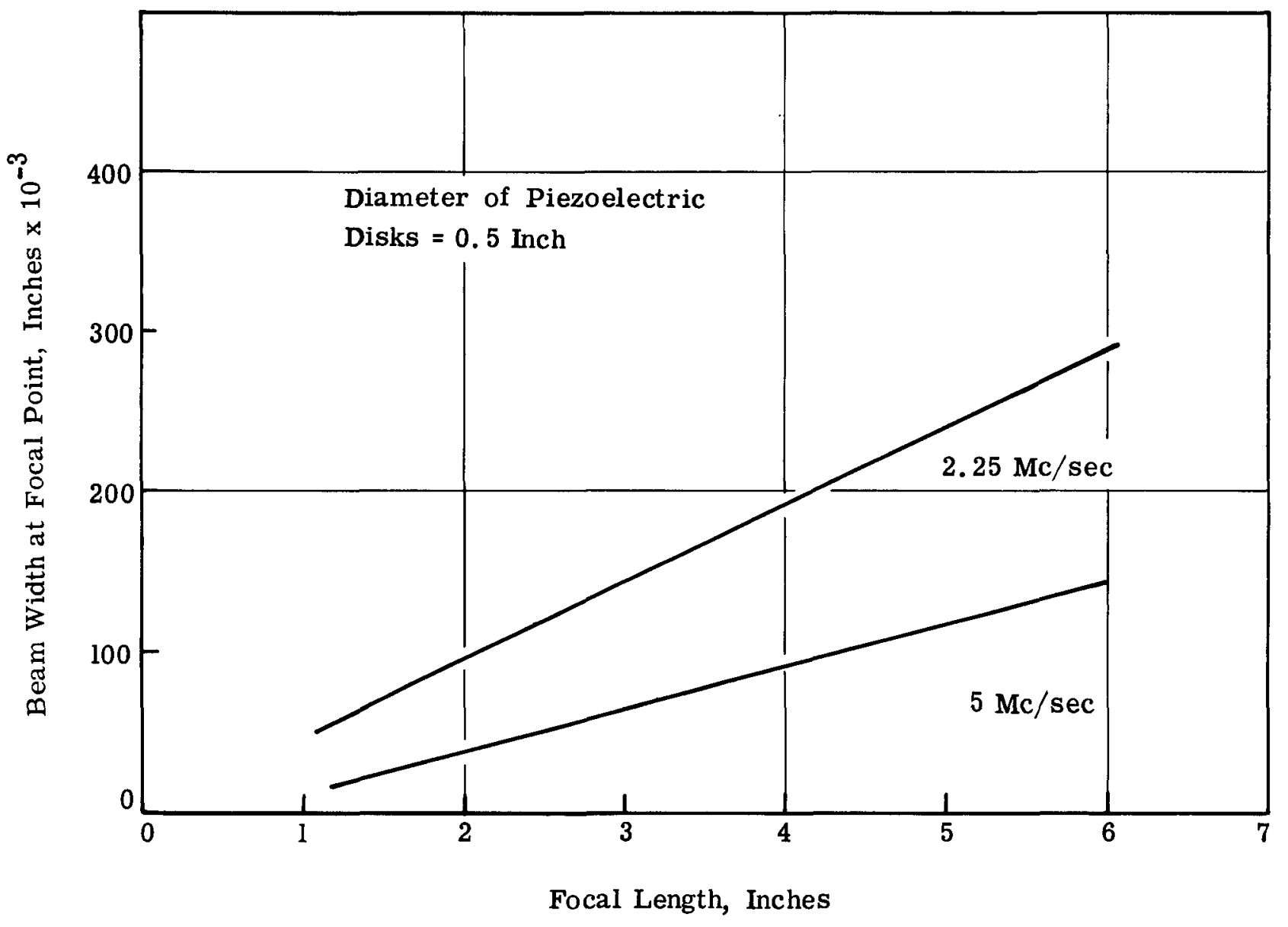

FIG. 13 BEAM WIDTH AT FOCAL POINT FOR VARIOUS FOCAL LENGTHS WITH FIXED DIAMETER PIEZOELECTRIC DISKS 


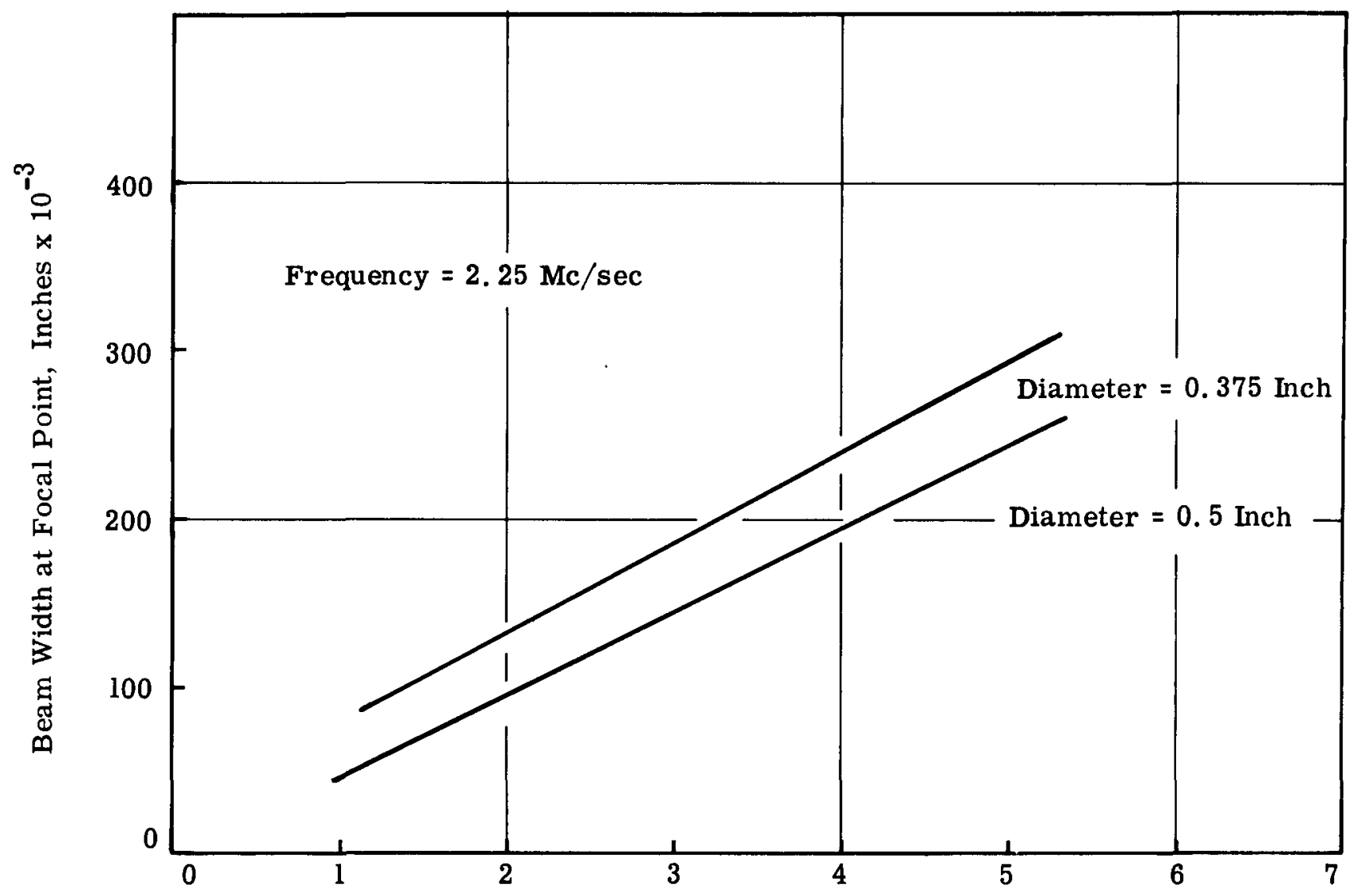

Focal Length, Inches

FIG. 14 BEAM WIDTH AT FOCAL POINT FOR VARIOUS FOCAL LENGTHS WITH A FIXED FREQUENCY 


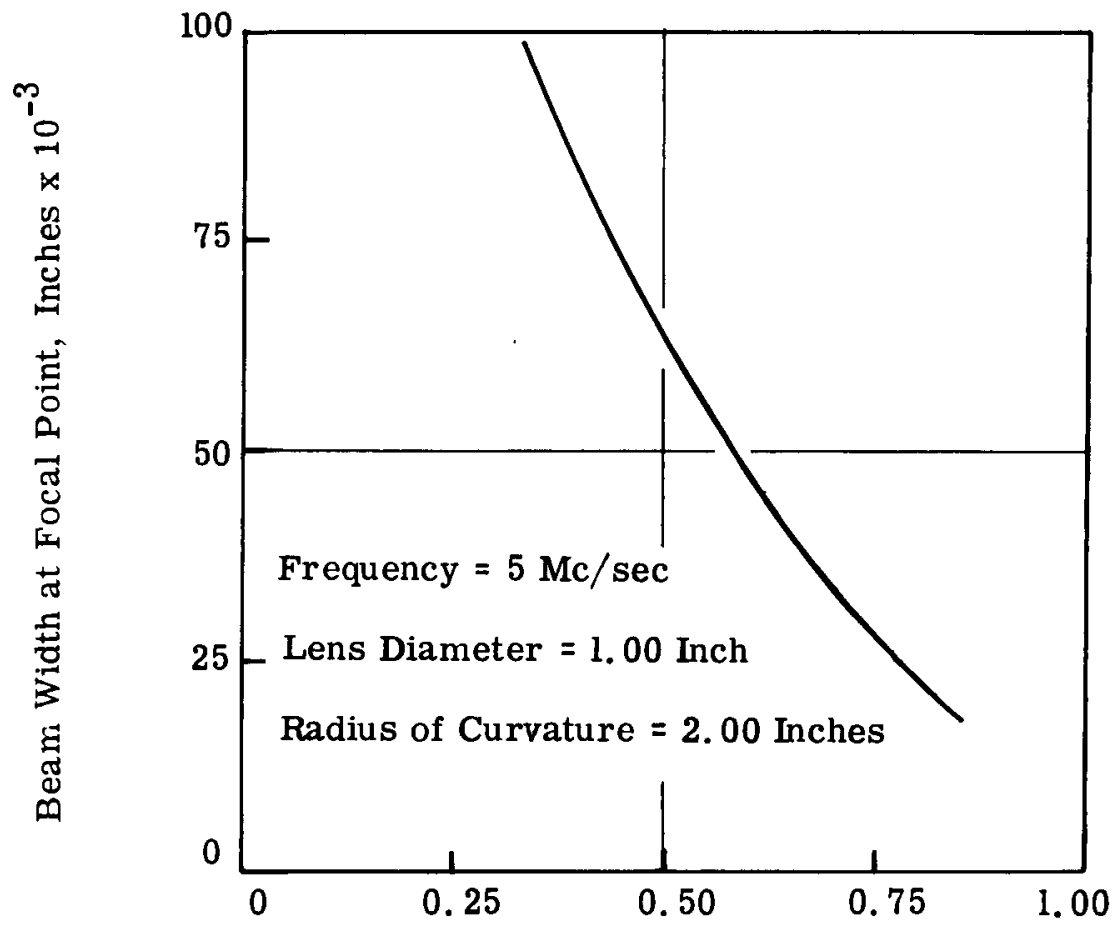

Diameter of Piezoelectric Disks, Inches

FIG. 15 BEAM WIDTH AT FOCAL POINT AS A FUNCTION OF THE DIAMETER OF THE PIEZOELECTRIC DISK 


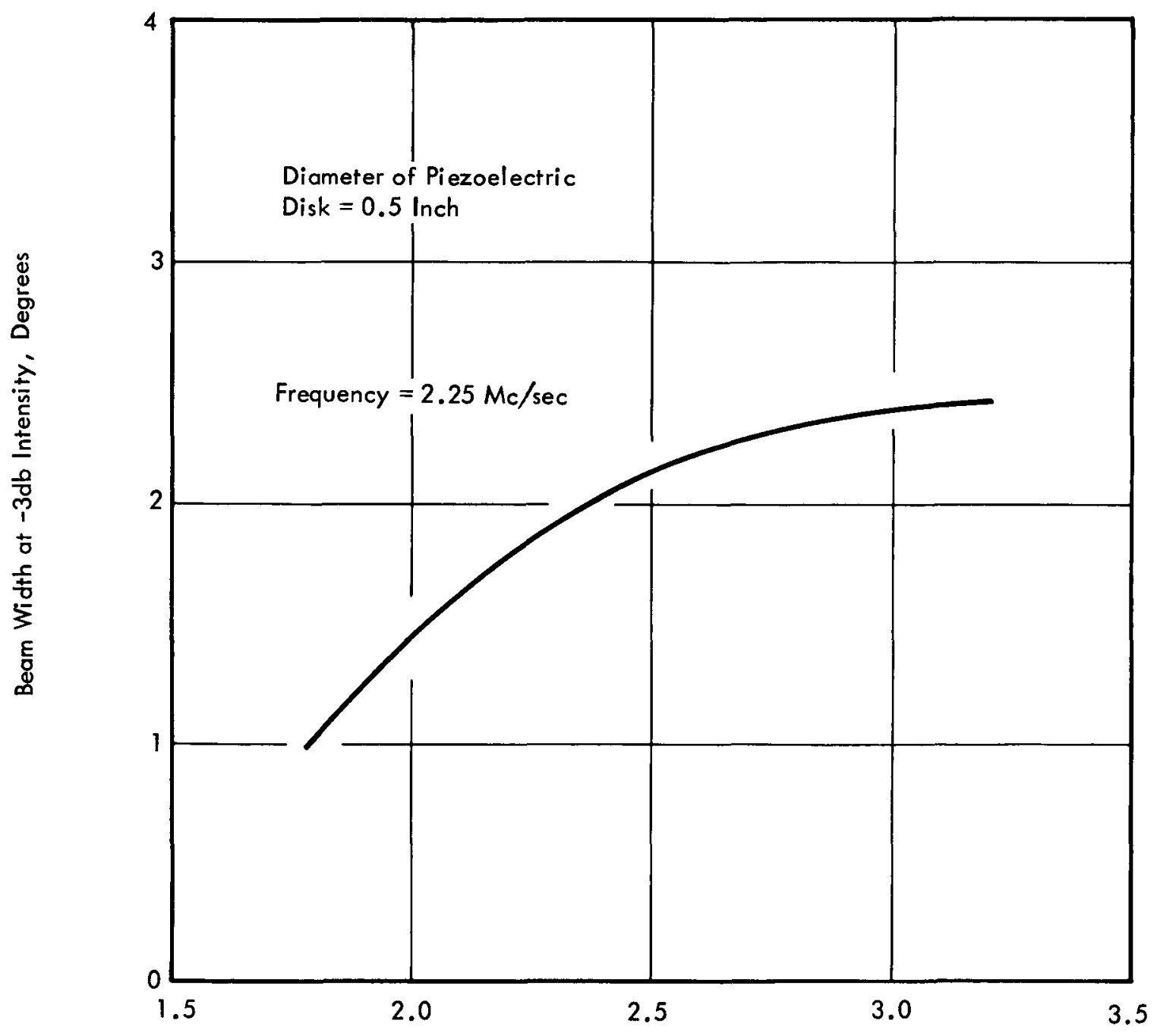

Lens Radius of Curvature, Inches

FIG. 16 BEAM WIDTH AT ABOUT 16 INCHES AS A FUNCTION OF THE RADIUS OF CURVATURE OF THE LENS 


\section{OPERATION OF UNDER-SODIUM SCANNER}

\section{A. LOCATING OBJECTS WITH A-SCAN SYSTEMS}

A-scan systems were used to locate objects in liquid sodium at temperatures ranging from sodium's melting point up to and including $600 \mathrm{~F}$. The intensity and the resolution of the transducers operating in that environment were entirely satisfactory. A thin layer of high-temperature Aeroshell grease No. 15 was applied to the surface of the piezoelectric disk of each transducer to provide good acoustic contact between the disk and the acoustic metal lens. A solid electrolytic copper $O$-ring was used to seal each of the transducers. The transducers were leak-tested with a helium mass spectrometer before immersion in sodium. Satisfactory sealing occurred when the covers of the transducers were tightened to a value of $900 \mathrm{lb}$-in, as indicated by a one-foot torque wrench.

The A-scan tests were conducted in the sodium facility that was discussed earlier. The maximum detection range for the systems was limited by the physical size of the sodium tank. The multiple reflection echoes between transducers and objects and the high signal-to-noise ratio, higher than $60 \mathrm{db}$, indicated that operating distances up to 10 feet are entirely feasible. A typical A-scope photograph obtained from the readout oscilloscope is presented in Figure 17. The scale of the horizontal axis in this photograph is $50 \mu \mathrm{sec} / \mathrm{div}$ and the distance between the transducer and the stainless steel target, as indicated by the separation of the transmitted and echo pulses, was 14.05 inches.

The width of the transmitted pulse shown in Figure 17 was $20 \mu \mathrm{sec}$. Based on the measured sound velocity in $600 \mathrm{~F}$ sodium, a total round trip distance of 1.895 inches is required to discern between the $20 \mu s e c$ trans mitted pulse and the echo pulse. Thus, the minimum distance between a transducer that is transmitting a $20 \mu \mathrm{sec}$ pulse and a target is 0.947 inch. However, the transmitted pulse width can be reduced to $5 \mu$ sec with proper and easily achieved damping of the piezoelectric disk. Therefore, an operating distance of less than $1 / 4$ inch between transducer and target can be readily achieved. Hence, A-scan systems can be used in liquid sodium at temperatures up to and including $600 \mathrm{~F}$ at distances between transducers and targets ranging from $1 / 4$ inch to 10 feet.

Tests were conducted to determine piezoelectric disk damping characteristics, and it was observed that all discernible multireflection signals resulting from acoustic impedance mismatching between the piezoelectric disks, the zirconium lenses, and sodium (or water) could be eliminated by a suitable backing block. 


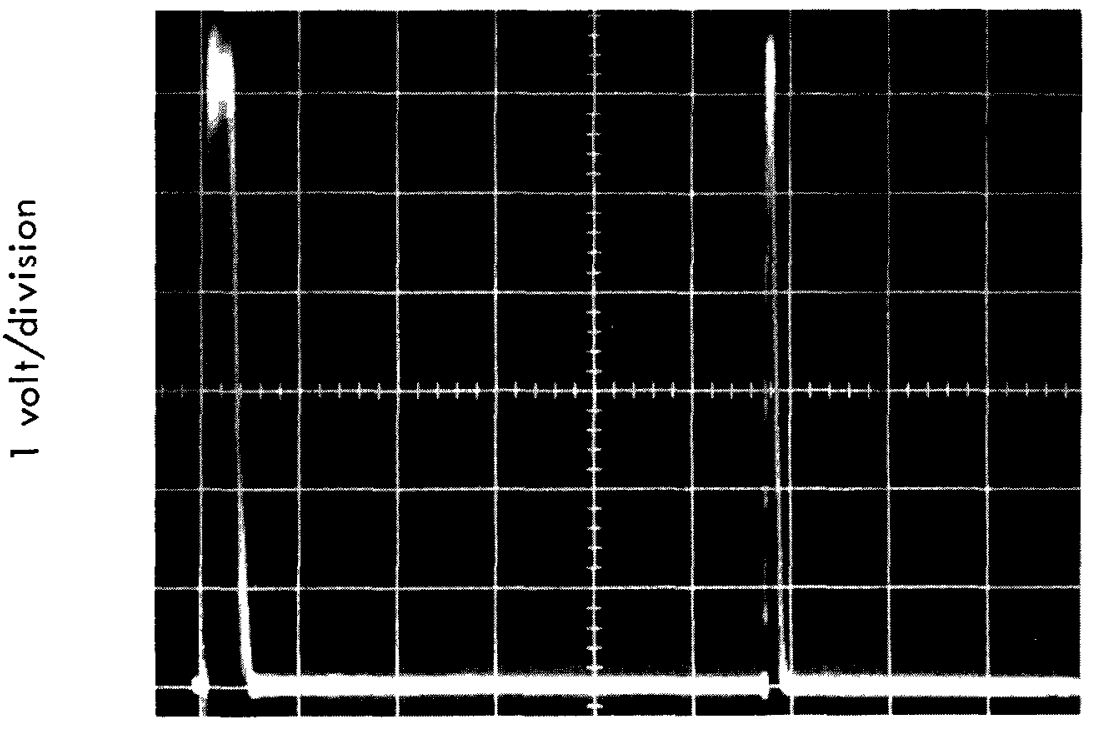

$50 \mu \mathrm{sec} /$ division

FIG. 17 TYPICAL A- SCAN DISPLAY 
Excellent distance discrimination was demonstrated using the Transigate unit and the A-scan presentation. The alarm circuits of the Transigate unit were triggered when a target located 30 inches from the transducer was moved less than 0.005 inch. The distance between the transducer and the target was limited to 30 inches by the sodium tank. An observation of pulse wave fronts in multiple reflections from transducers to the tank walls and back indicated that distance discrimination of 0.005 inch or less can be obtained with a distance of 5 feet between a transducer and a target.

The capability of the system to discriminate between objects that are adjacent to each other was demonstrated. The beam widths of transducers at or near their focal points are functions of the operating frequencies and the diameters of the piezoelectric disks and the diameters and radii of curvature of the lenses. By proper choice of these parameters, two flat objects, side by side, separated by a distance of 0.030 inch, can be individually identified.

\section{B. DISCERNING OBJECTS WITH C-SCAN SYSTEMS}

As indicated previously in this report, a complete C-scan system works satisfactorily for under-sodium scanning in the temperature range of 300 to $600 \mathrm{~F}$. By appropriate adjustment of the various parameters, a target can be selected on the basis of its distance from the transducer and on the amplitude of the echo received from the target. A target which protrudes as little as $1 / 16$ inch from another target can be selected and identified. Pattern recognition has been demonstrated by scanning characters that were recessed in metal bars. Scanning performance in $600 \mathrm{~F}$ liquid sodium was compared with that in room-temperature water. Figure 18 shows an under-water scan of an aluminum bar with milled flat-bottom characters, 1/4inch deep and 1/4-inch wide. The light area represents the 2 -inch-wide aluminum bar. The scan was obtained with a transducer having a 4.5-inch focal length, operating at $5 \mathrm{Mc} / \mathrm{sec}$, with the target approximately at the focal point of the transducer. Figure 19 shows an under-sodium scan at a temperature of $600 \mathrm{~F}$ of a stainless steel bar with $1 / 4-i n c h-w i d e$ and $1 / 4$ inch-high characters. The scan was made with a 1 -inch-diameter, $2 \mathrm{Mc} / \mathrm{sec}$ piezoelectric disk and a zirconium lens with a 4-inch radius of curvature. The results of the two scans indicate that the $C$-scan system has satisfactory and similar performance in water and in sodium. Figure 20 is a photograph of a stainless steel target with various milled grooves that was scanned to measure system resolution. A flat-bottomed groove, 1/8-inch deep and $1 / 8$-inch wide, was readily detected. A groove width of $1 / 4$ inch was accurately scanned and recorded. Good resolution of objects $1 / 32$-inch wide and $1 / 16$-inch deep was obtained. The bottom of a $1 / 8$-inch deep $V$-shaped groove was accurately detected and recorded. 


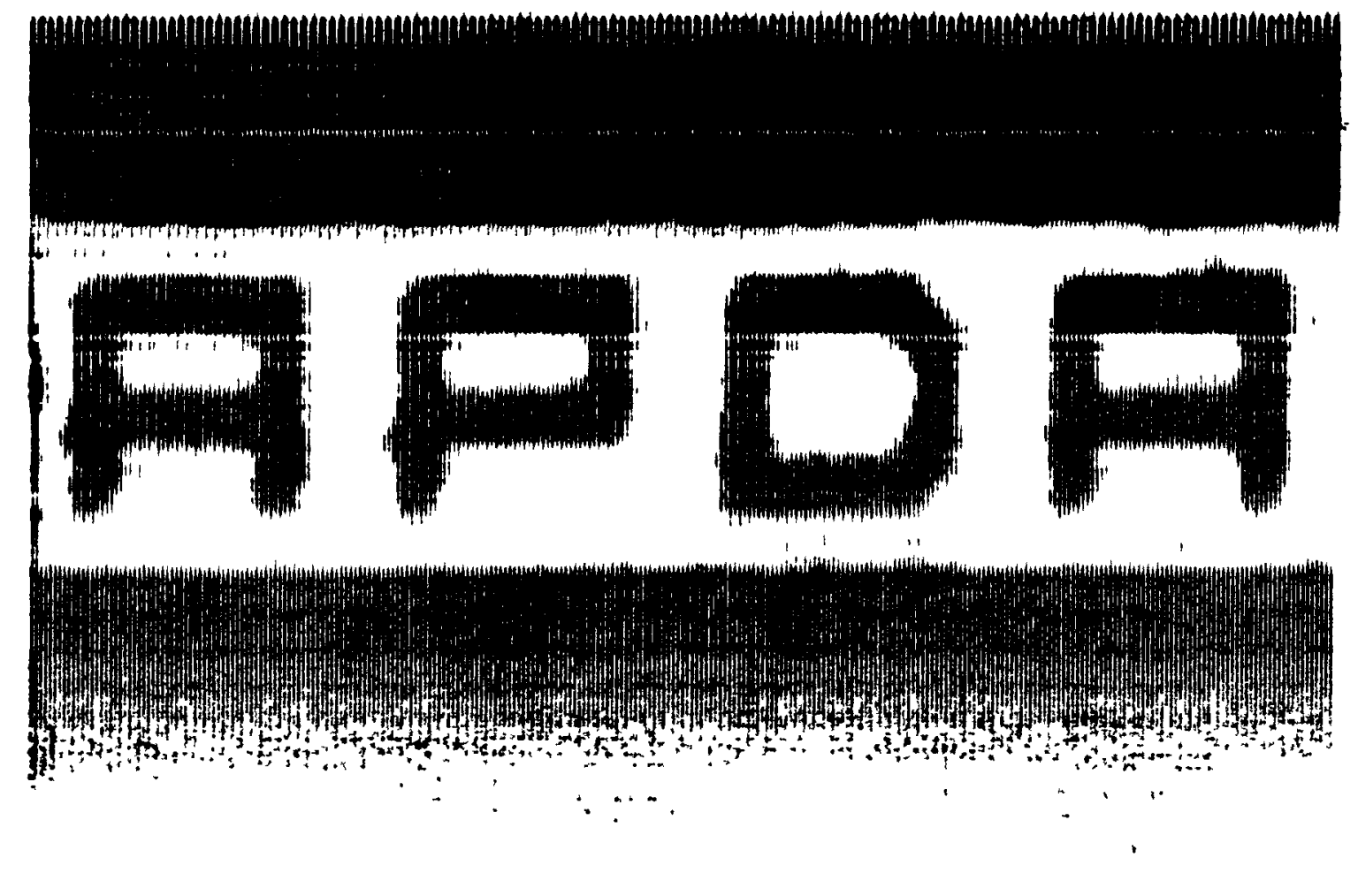




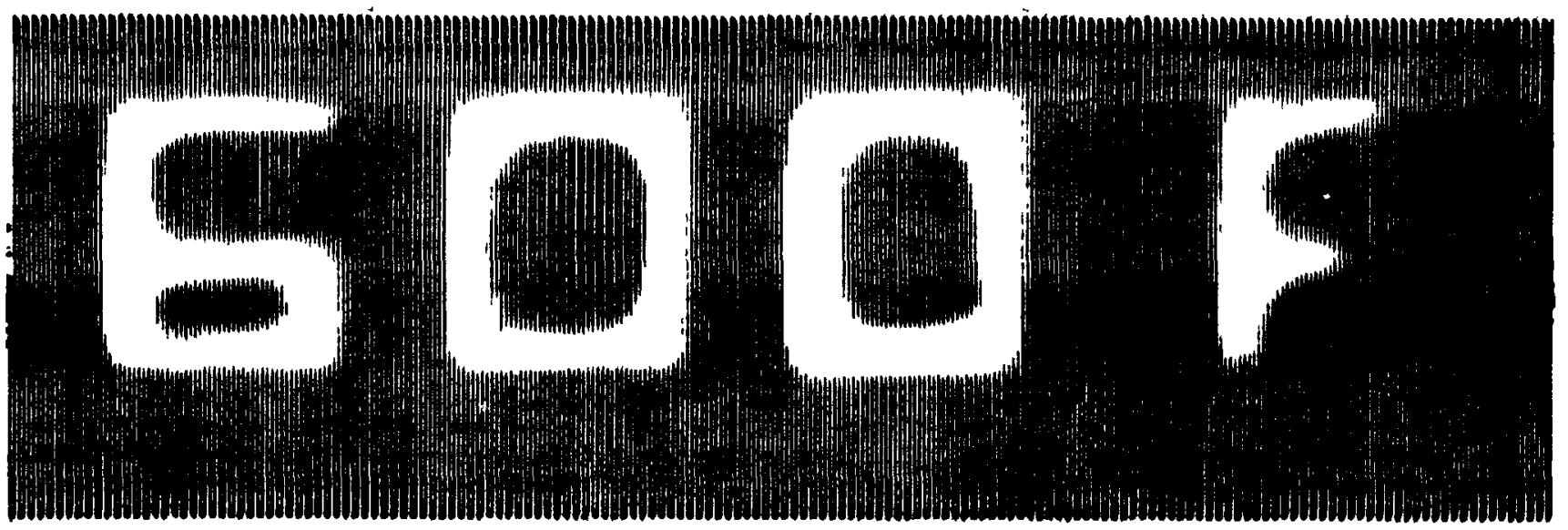

FIG. 19 C-SCAN REPRODUCTION OF TARGET IN $600 \mathrm{~F}$ SODIUM 




FIG. 20 STAINLESS STEEL TARGET FOR C-SCAN TESTING 


\section{CONCLUSIONS}

The feasibility of operating ultrasonic transducers immersed in liquid sodium at temperatures up to and including $600 \mathrm{~F}$ has been demonstrated. The characteristics of the transducers in liquid sodium have been experimentally defined and no anomalies were observed. A-scan techniques for finding objects and defining their locations have been demonstrated. C-scan principles have been applied, and satisfactory pattern recognitions have been obtained. In summary, the proof-of-principle for A-scan and C-scan systems in liquid sodium at temperatures to and including $600 \mathrm{~F}$ has been established. 
-

•. 


\section{REFERENCES}

1. Ying, Shuh-Pan, Scott, Clyde C., "Attenuation Measurements of Sound and Performance of Ultrasonic Transducers in 600 F Liquid Sodium," APDA-180, Atomic Power Development Associates, Inc., December 1965.

2. Ying, Shuh-Pan, Scott, Clyde C., "Concepts for General-Purpose Under Sodium Scanning Systems," APDA-179, Atomic Power Development Associates, Inc., November 1965.

3. Sokolov, S., Elek-Nachr.-Tek, 6, p. 451, 1929.

4. Firestone, F. A., U. S. Patent 2, 280,226 (1942).

5. Firestone, F. A., and Frederick, J. R., J. Acoust. Soc. Am., 18, p. $200,1946$.

6. Carlin, Benson, Ultrasonics, McGraw-Hill Book Company, New York, 1960.

7. Stokes, G. , Trans. Cambridge Phil. Soc. , 8, p. 287, 1845.

8. Kirchoff, G., Poggendorff's Ann. Phys., 134, p. 177, 1868.

9. Herafeld, K. F., Litovitz, T. A., Absorption and Dispersion of Ultrasonic Waves, Academic Press, Inc., New York, 1959.

10. Fox, F. E., Rock, G. D., Phys. Rev. 70, p. 68, 1946.

11. Pochapsky, T. E., Phys. Rev. 84, p. 553, 1951.

12. Sittig, M., Sodium - Its Manufacture, Properties, and Uses, Reinhold Publishing Corporation, New York, 1956.

13. Mason, W. P., Phys. Acoust., 1, Part A, Academic Press, New York and London, 1964.

14. Ernst, P., "Ultrasonic Lenses and Transmission Plates," J. Sci. Instrum, 22, p. 238, 1945.

15. Sette, D., "Ultrasonic Lenses of Plastic Materials," J. Acoust. Soc. Am. 21, p. 374,1949 . 
-

- 


\title{
APPENDIX A:
}

SCHEMATIC DRAWINGS OF UNDER-SODIUM SCANNER SYST EM COMPONENTS AND

\author{
TEST FACILITY
}


-

- 


\section{LIST OF DRAWINGS}

Figure

Page

A. 1

Focusing Transducer with Planospherical Lens . . . .

A. 2 Focusing Transducer Details - Sheet No. 1 . . . . .

A. 3 Focusing Transducer Details - Sheet No. 2 . . . . . .

A. 4 Sodium Scanner Test Tank and Sodium Pot Support

(Stock List) . . . . . . . . . . . . . . . . . 50

A. 5 Sodium Scanner Test Tank and Sodium Pot Support

(Fixture Layout) . . . . . . . . . . . . . . . . . . .

A. 6 Sodium Scanner Test Tank and Sodium Pot Support

(Detail Sheet)

A. 7 Sodium Scanner Test Tank and Sodium Pot Support (Detail Sheet) . . . . . . . . . . . . . . .

A. 8 Sodium Scanner Test Tank and Sodium Pot Support

(Detail Sheet)

A. 9 Sodium Scanner Test Tank and Sodium Pot Support (Detail Sheet) . . . . . . . . . . . . . . . . . . .

A. 10 Sodium Scanner Test Tank and Sodium Pot Support (Detail Sheet) . . . . . . . . . . . . . . .

A.11 Sodium Scanner Test Tank and Sodium Pot Support (Assembly Drawing). . . . . . . . . . . . . . .

A. 12 Sodium Scanner Test Tank and Sodium Pot Support (Tank Details). . . . . . . . . . . . .

A. 13 Sodium Scanner Test Tank and Sodium Pot Support. . . .

A. 14 Sodium Scanner Test Tank and Sodium Pot Support. . .

A. 15 Sodium Scanner Test Loop Glove Box and Sodium Pot

Support . . . . . . . . . . . . . . . . . . 
A.16 Sodium Scanner Test Tank and Sodium Pot Support . . . . 62

A. 17 Ultrasonic Scanner Tank Electric Heater Schematic. . . . 63

A. 18 ' C-Scan Mechanism-Power Drive . . . . . . . . . . . 64

A. 19 ᄀ C-Scan Drive Block . . . . . . . . . . . . . . 66

A. 20 m C-Scan Drive Mechanism Details . . . . . . . . . . . 67

A. $21 \times$ C-Scan Mechanism Plate Base . . . . . . . . . . 68

A. 22 in C-Scan Drive Mechanism Rail-Support. . . . . . . . . . 69

A. 23 y C-Scan Drive Mechanism Rail-Support . . . . . . . 70

A. 24 C-Scan Drive Mechanism Details . . . . . . . . . . 71

A. 25 C-Scan Drive Mechanism Details . . . . . . . . . 72

A.26 G C-Scan Drive Mechanism Details . . . . . . . . . 73

A. 27 C-Scan Drive Mechanism Details . . . . . . . . . . 74

A. 28 : C-Scan Drive Mechanism Details . . . . . . . . . 75

A. 29 Sodium C-Scan Device Wiring Schematic . . . . . . . . 76

A. 30 C-Scan Mechanism Manual Drive . . . . . . . . . . 77

A. 31 Scan Block-C-Scan Mechanism Manual Drive. . . . . . 79

A. 32 C-Scan Mechanism Manual Drive . . . . . . . . . 80

A.33 C-Scan Mechanism Manual Drive . . . . . . . . . . 81 


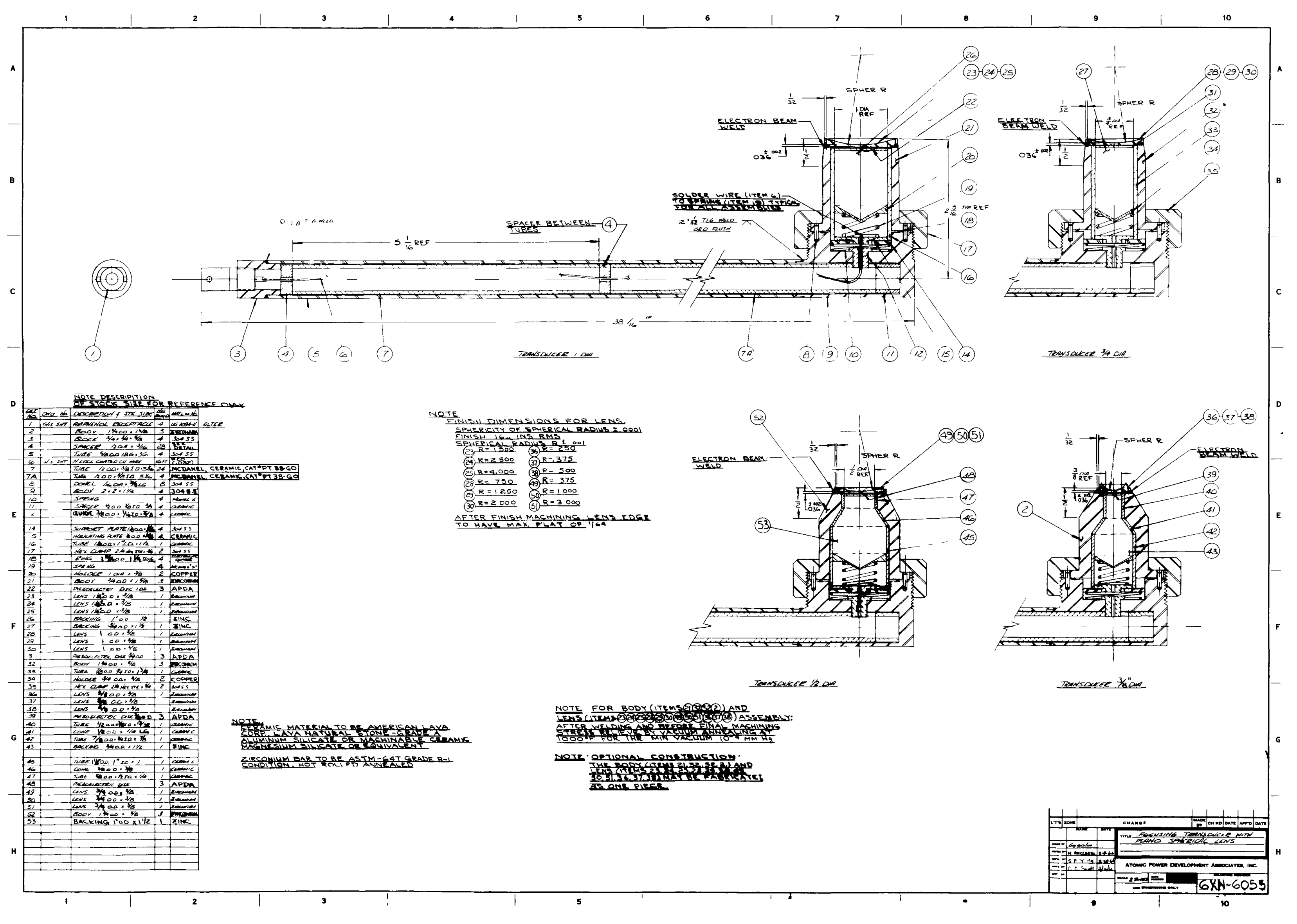

FIG. A.1 FOCUSING TRANSDUCER WITH PLANOSPHERICAL LENS 


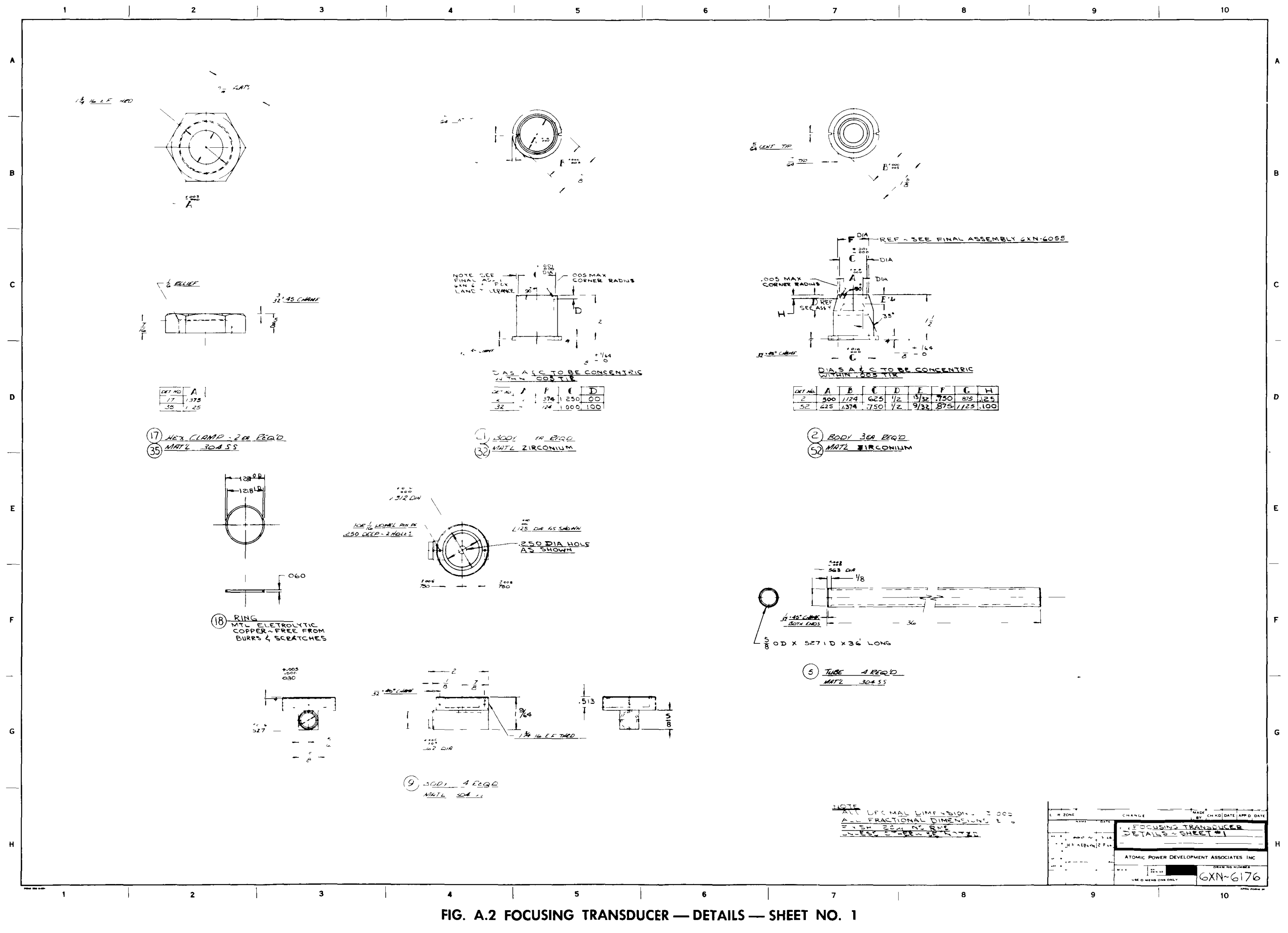

48 




FIG. A.3 FOCUSING TRANSDUCER - DETAILS - SHEET NO. 2 




FIG. A.4 SODIUM SCANNER TEST TANK AND SODIUM POT SUPPORT (STOCK LIST) 


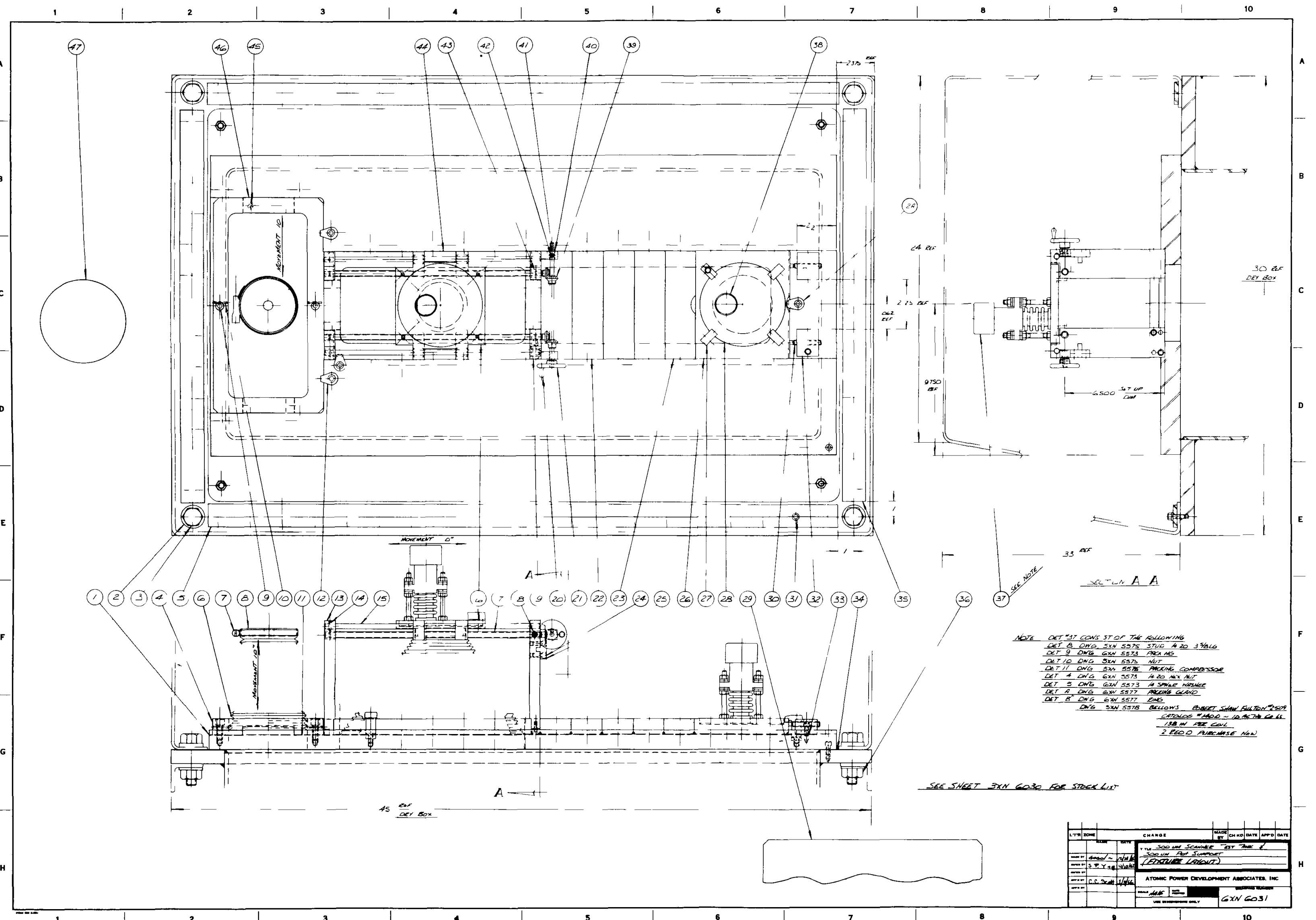

FIG. A.5 SODIUM SCANNER TEST TANK AND SODIUM POT SUPPORT (FIXTURE LAYOUT) 


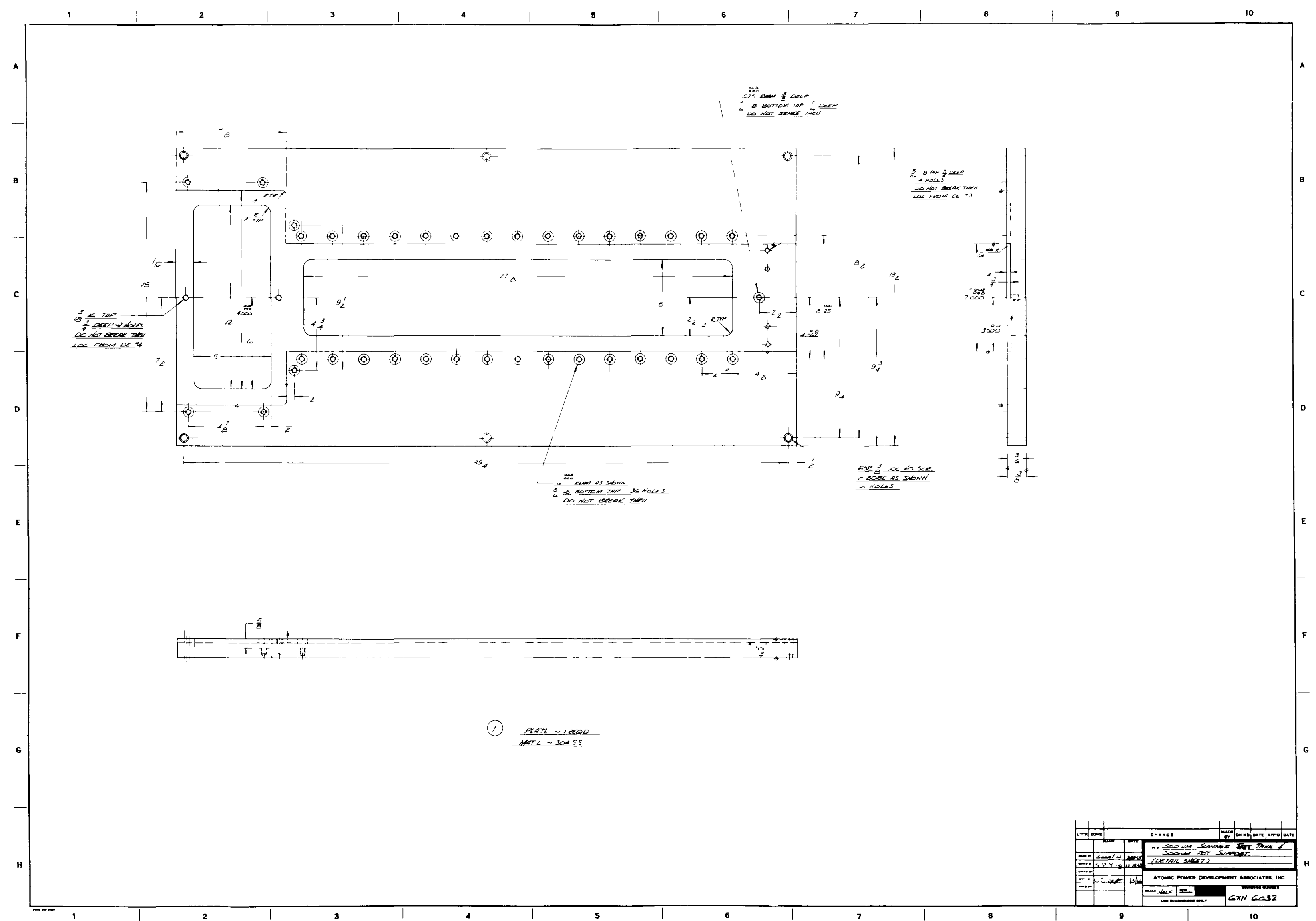

FIG. A.6 SODIUM SCANNER TEST TANK AND SODIUM POT SUPPORT (DETAIL SHEET) 

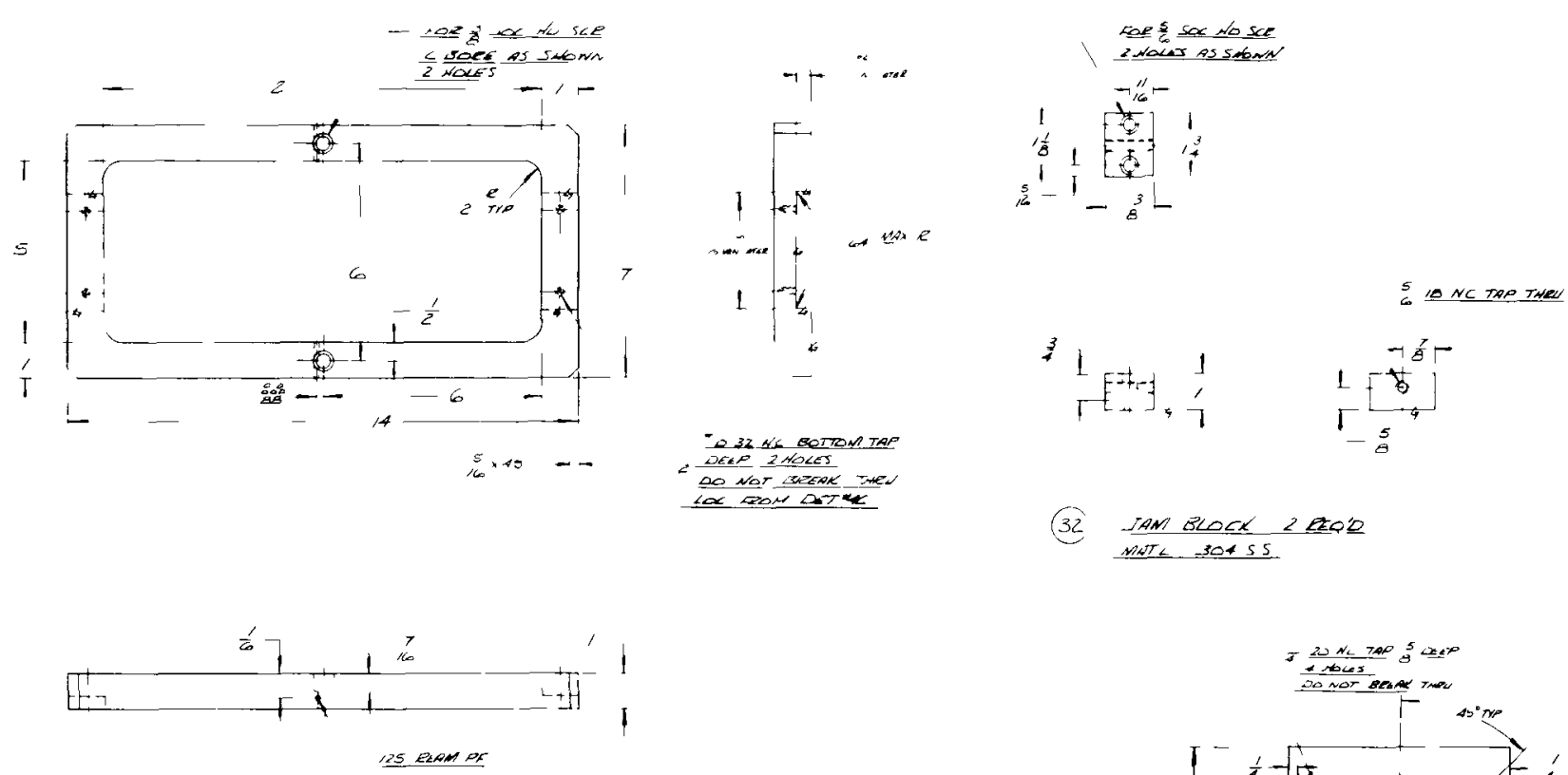

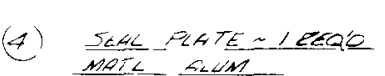
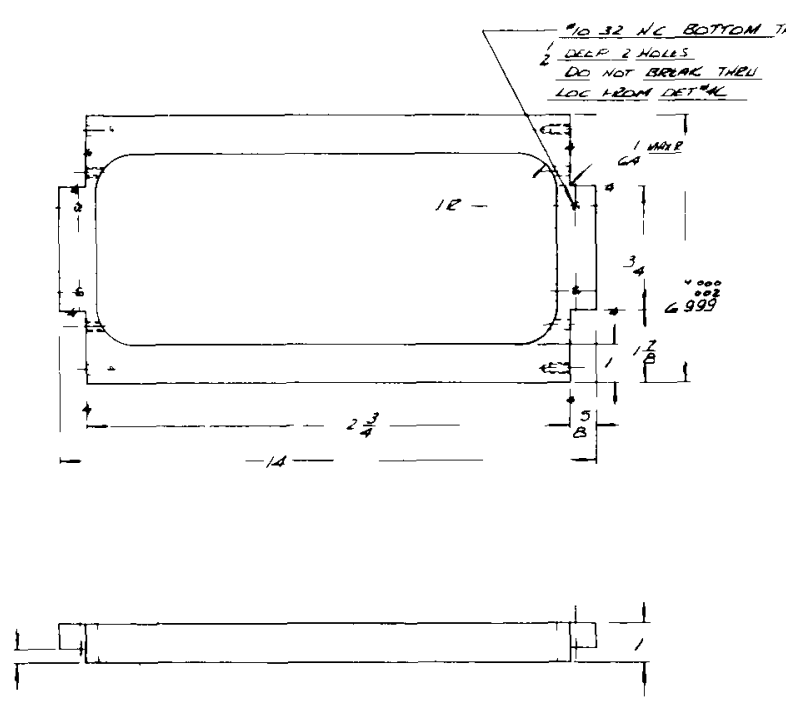

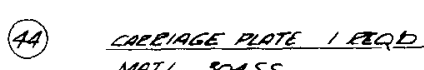

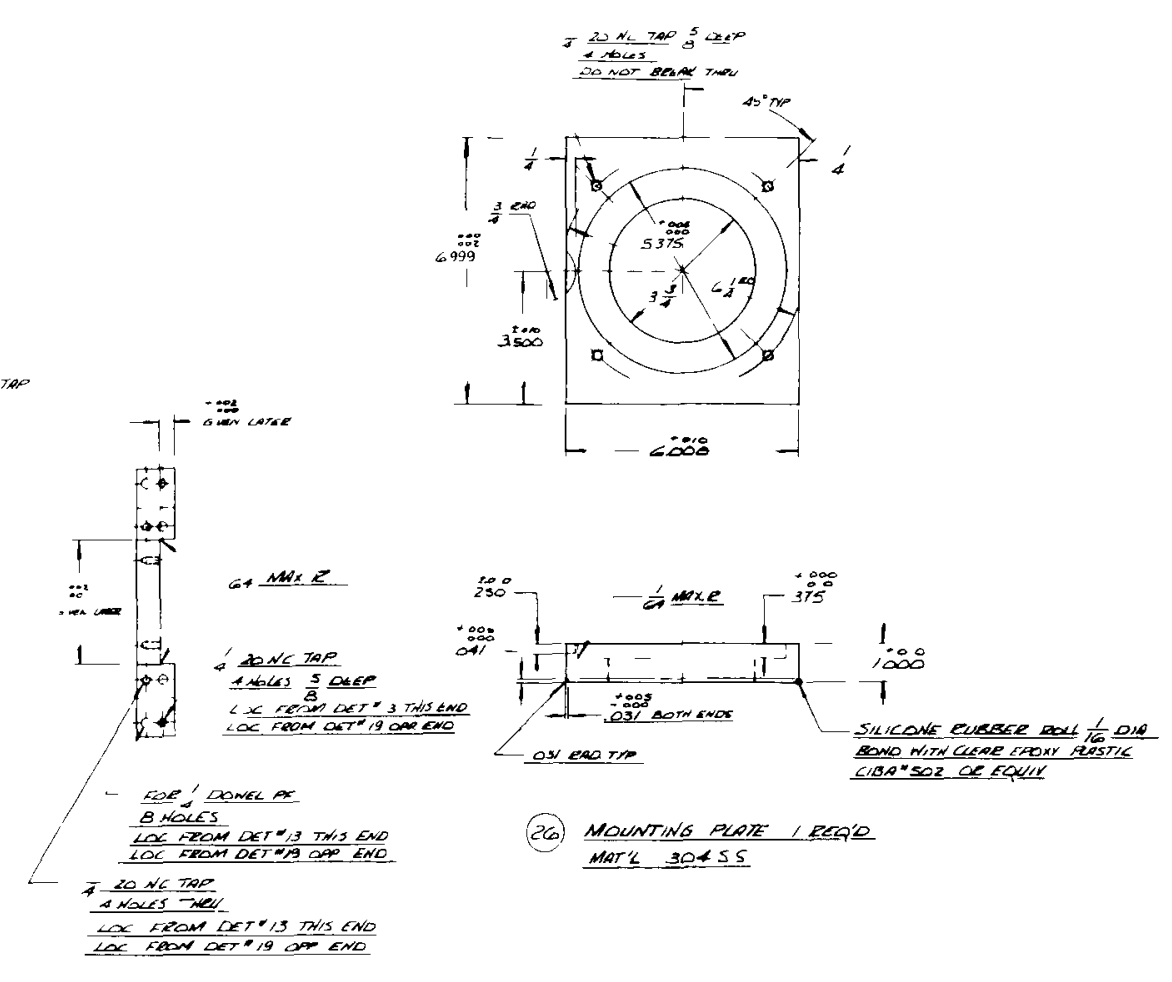

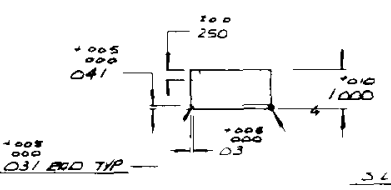

(23) Smace nate, lecas

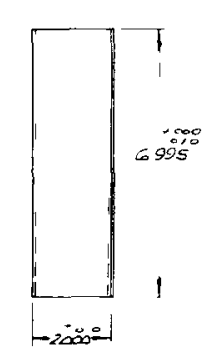

$1 \sqrt{-1000}$

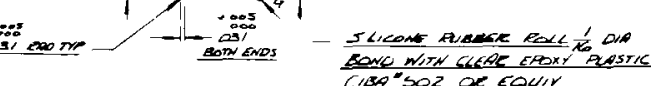

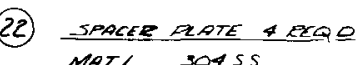




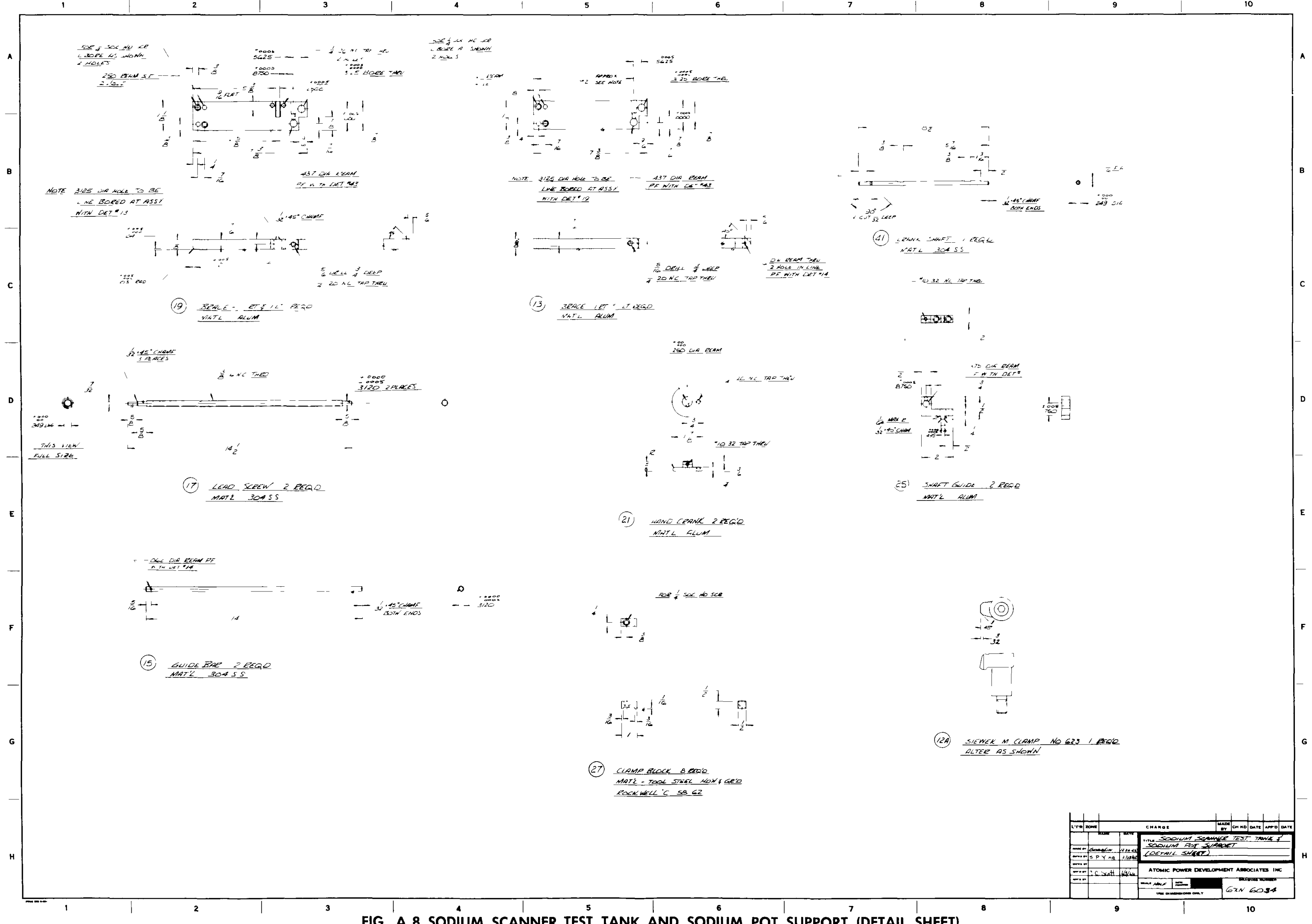

54 


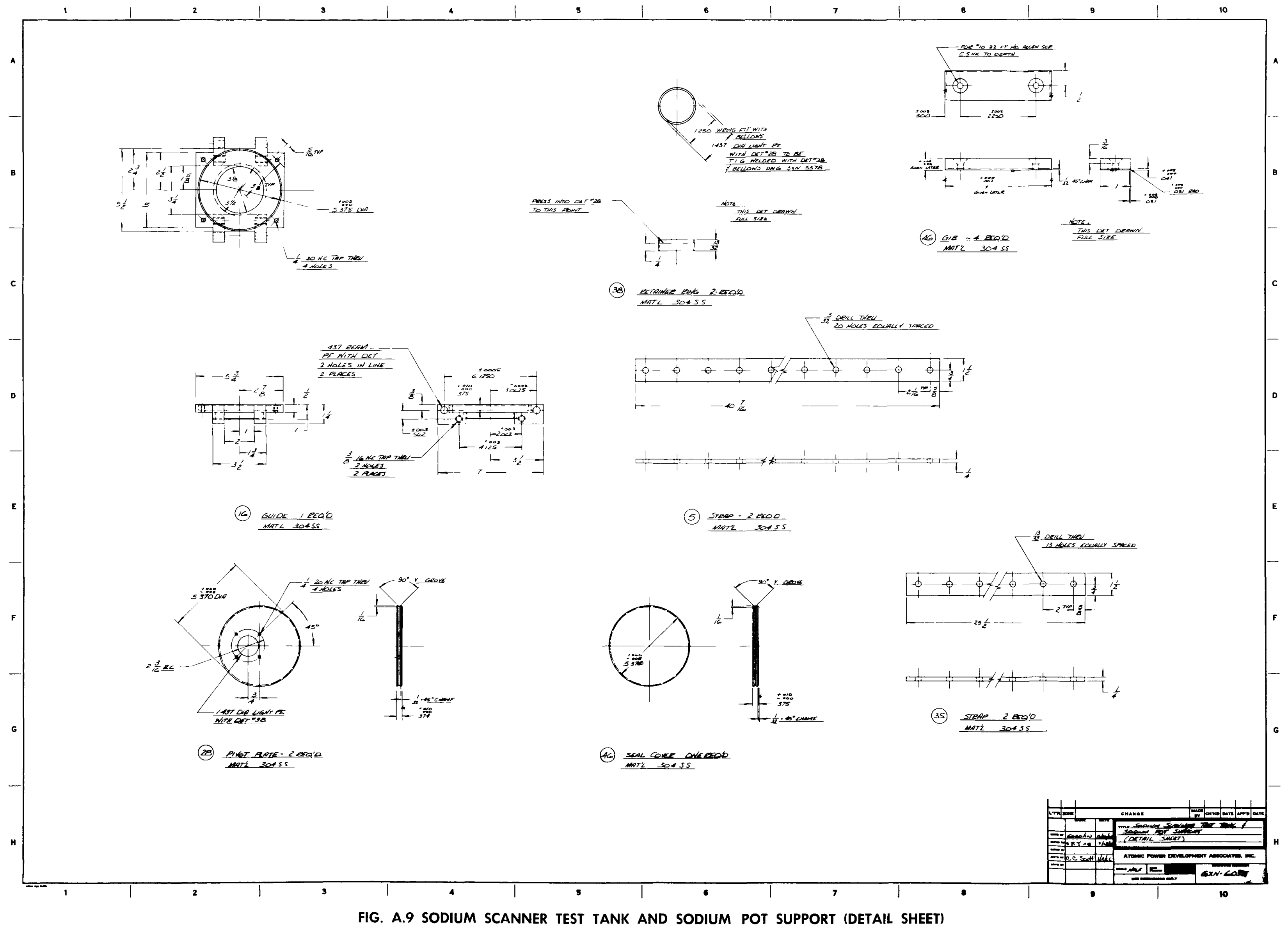

55 


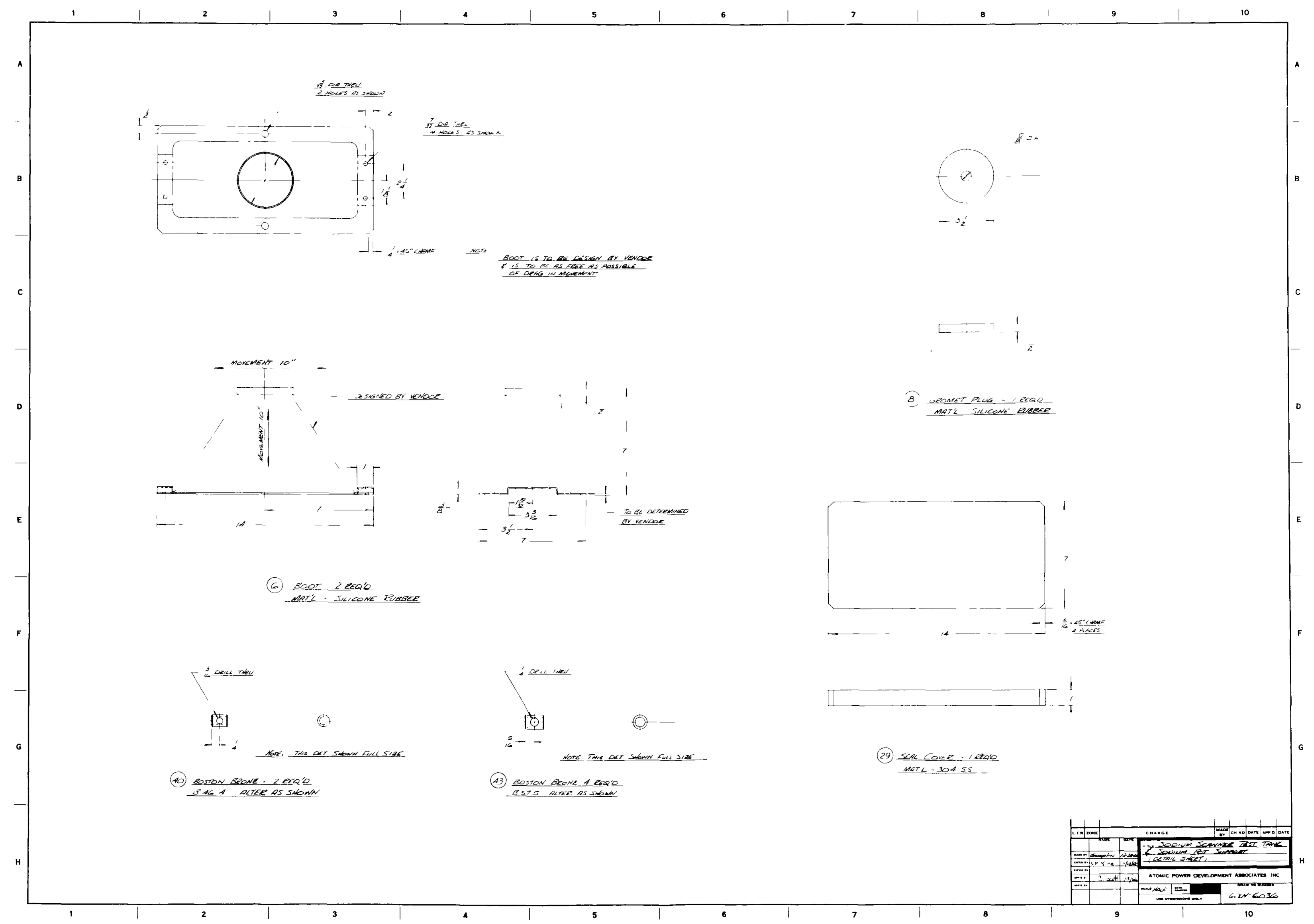

FIG. A.10 SODIUM SCANNER TEST TANK AND SODIUM POT SUPPORT (DETAIL SHEET) 


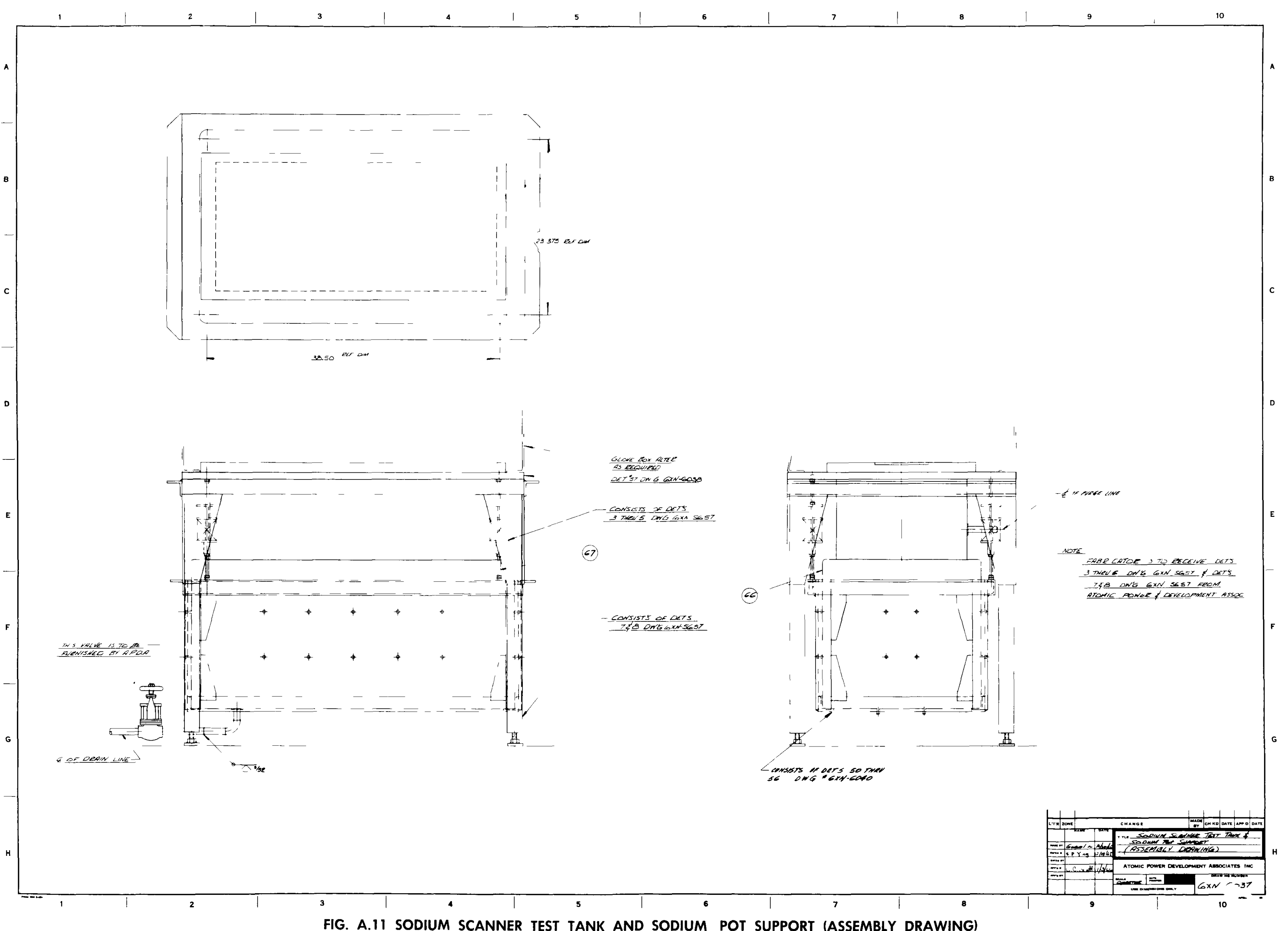

FIG. A.11 SODIUM SCANNER TEST TANK AND SODIUM POT SUPPORT (ASSEMBLY DRAWING) 


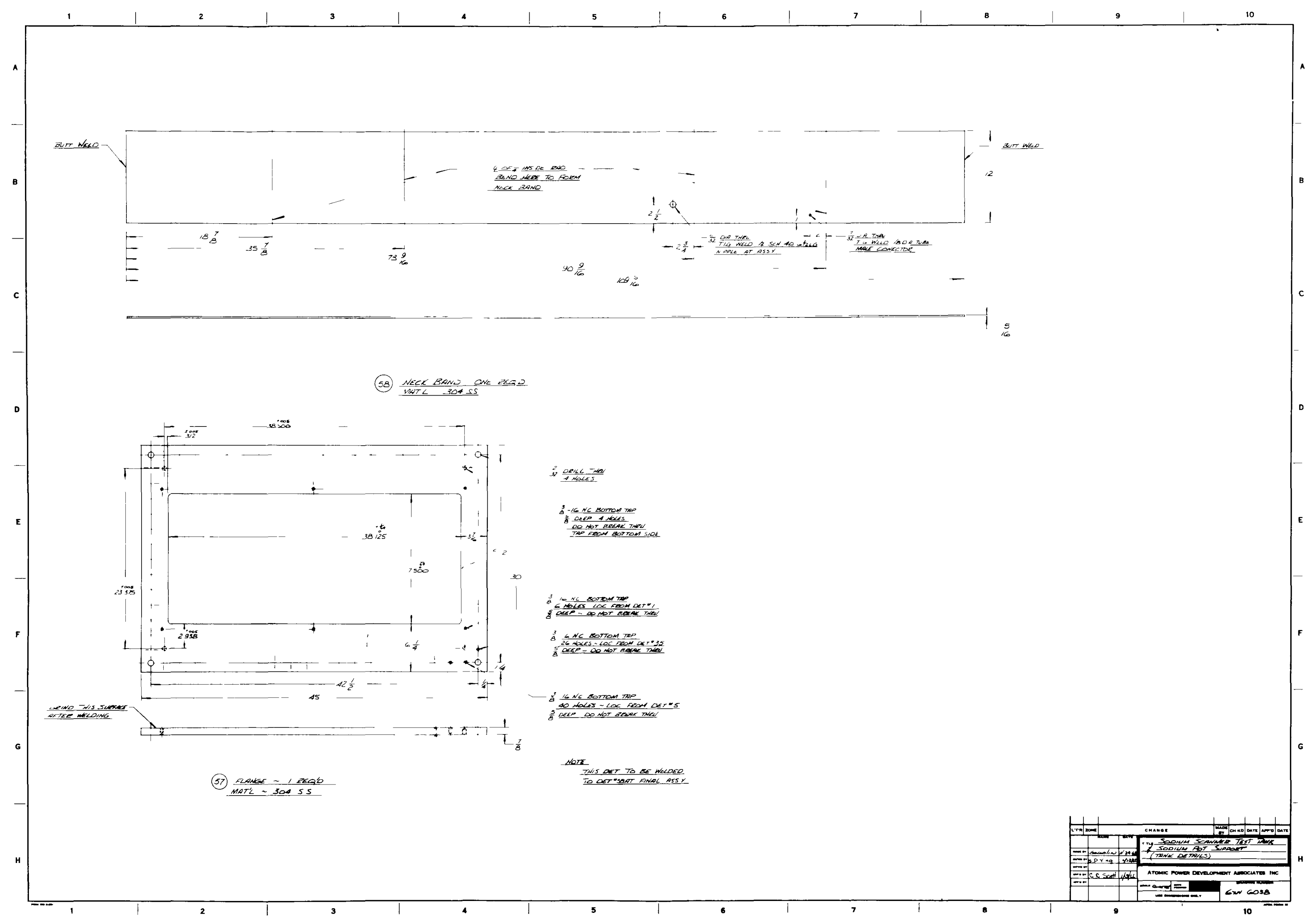

FIG. A.12 SODIUM SCANNER TEST TANK AND SODIUM POT SUPPORT (TANK DETAILS) 


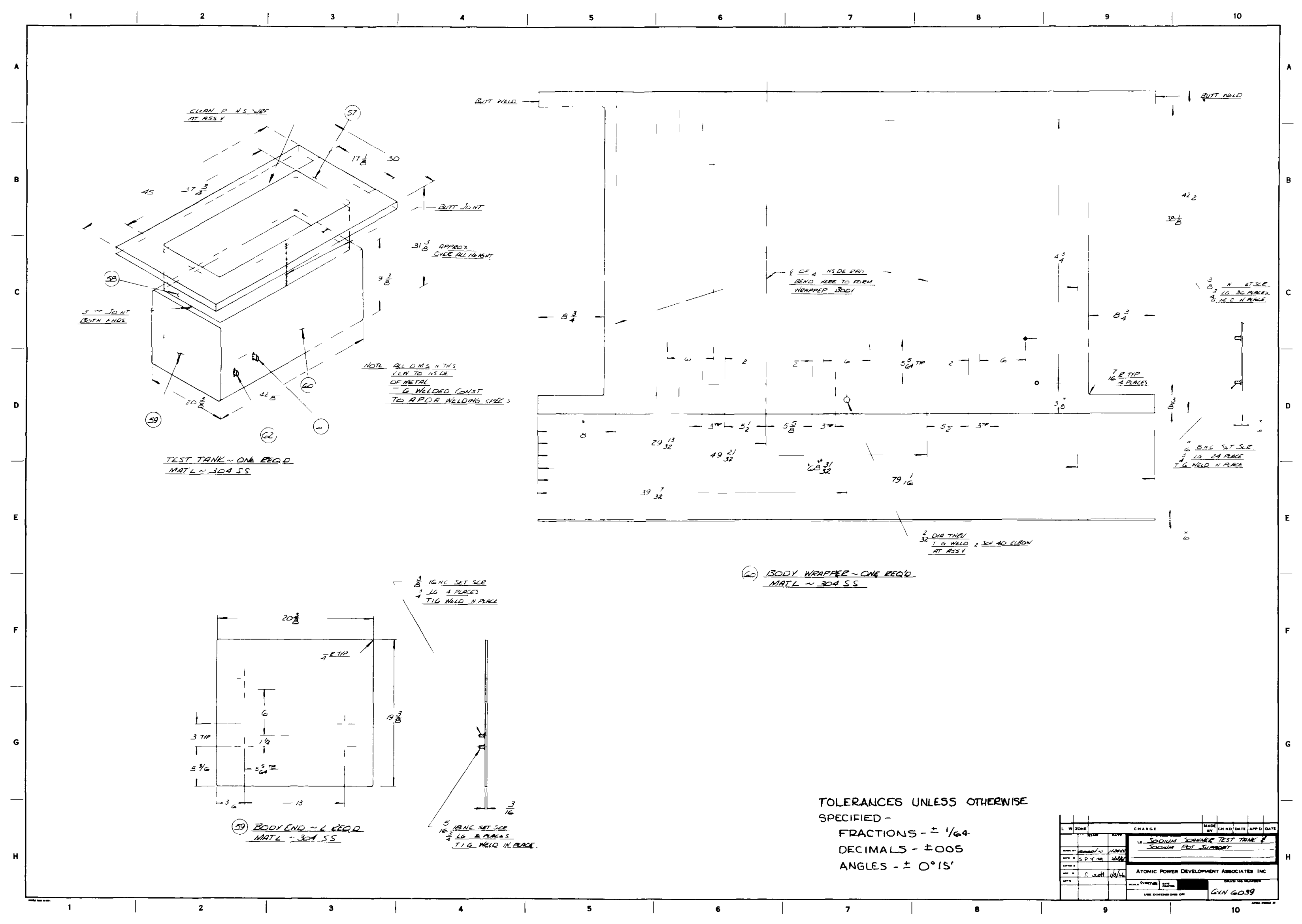

FIG. A.13 SODIUM SCANNER TEST TANK AND SODIUM POT SUPPORT 


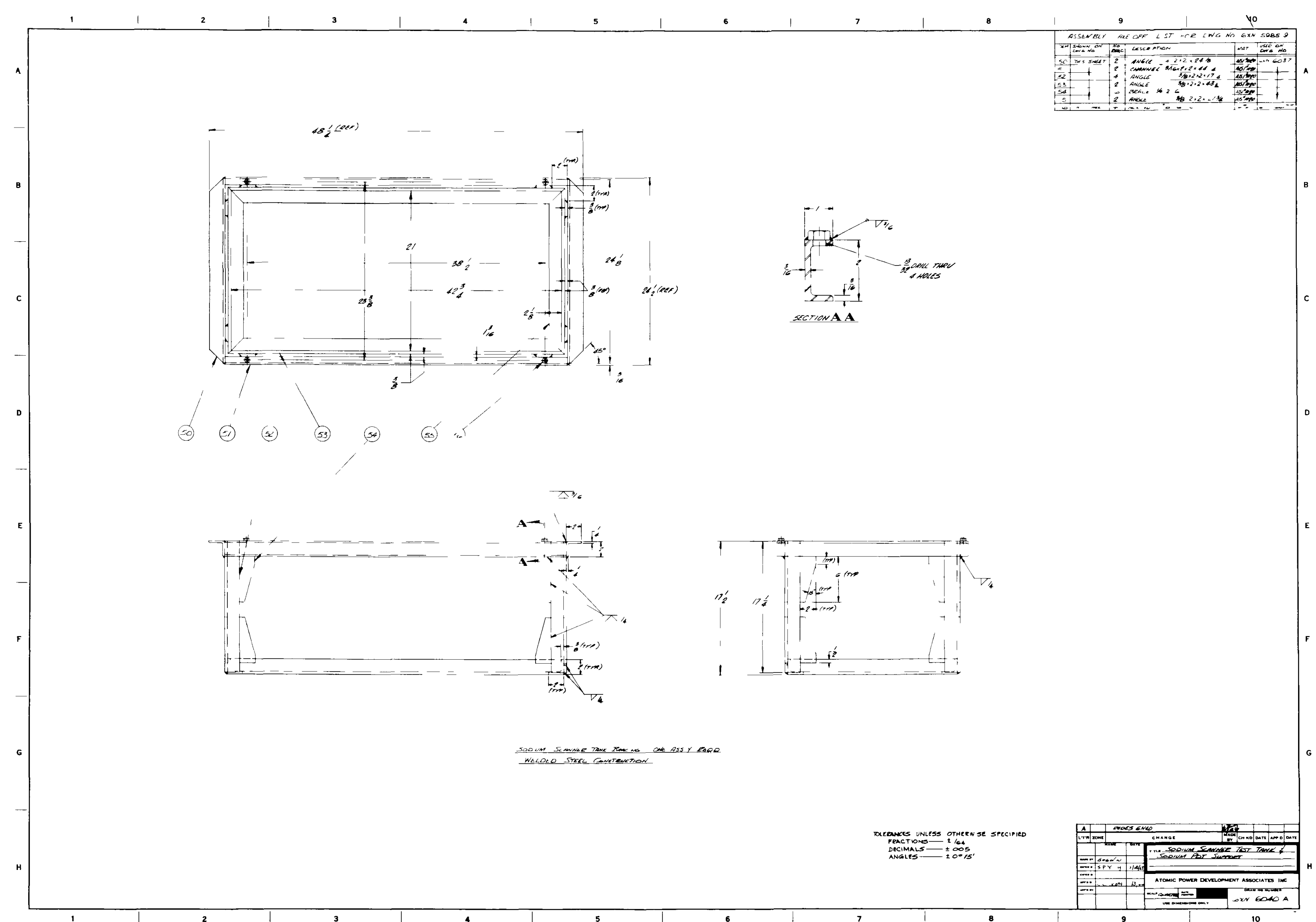

FIG. A.14 SODIUM SCANNER TEST TANK AND SODIUM POT SUPPORT 


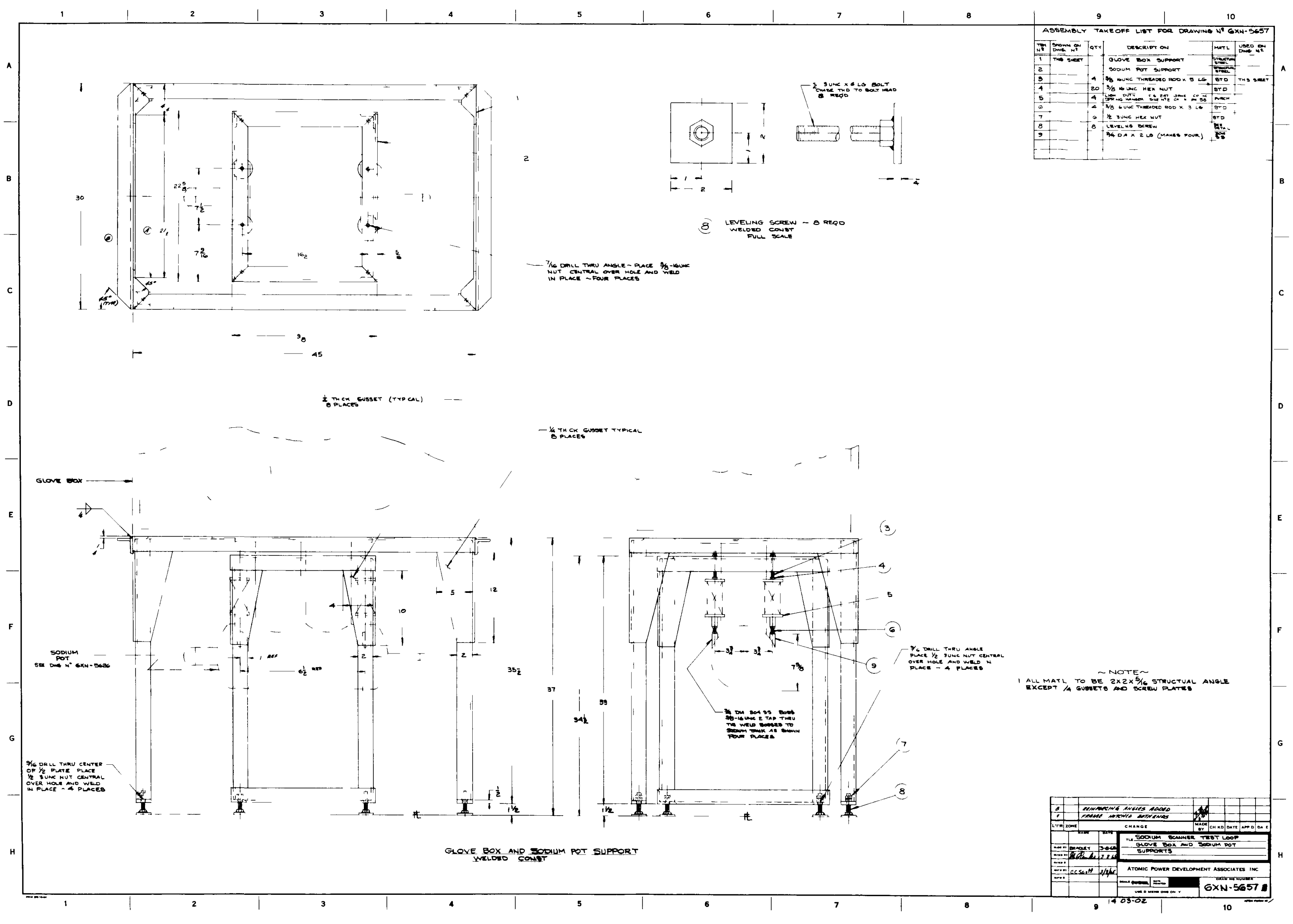

FIG. A.15 SODIUM SCANNER TEST LOOP GLOVE BOX AND SODIUM POT SUPPORT 


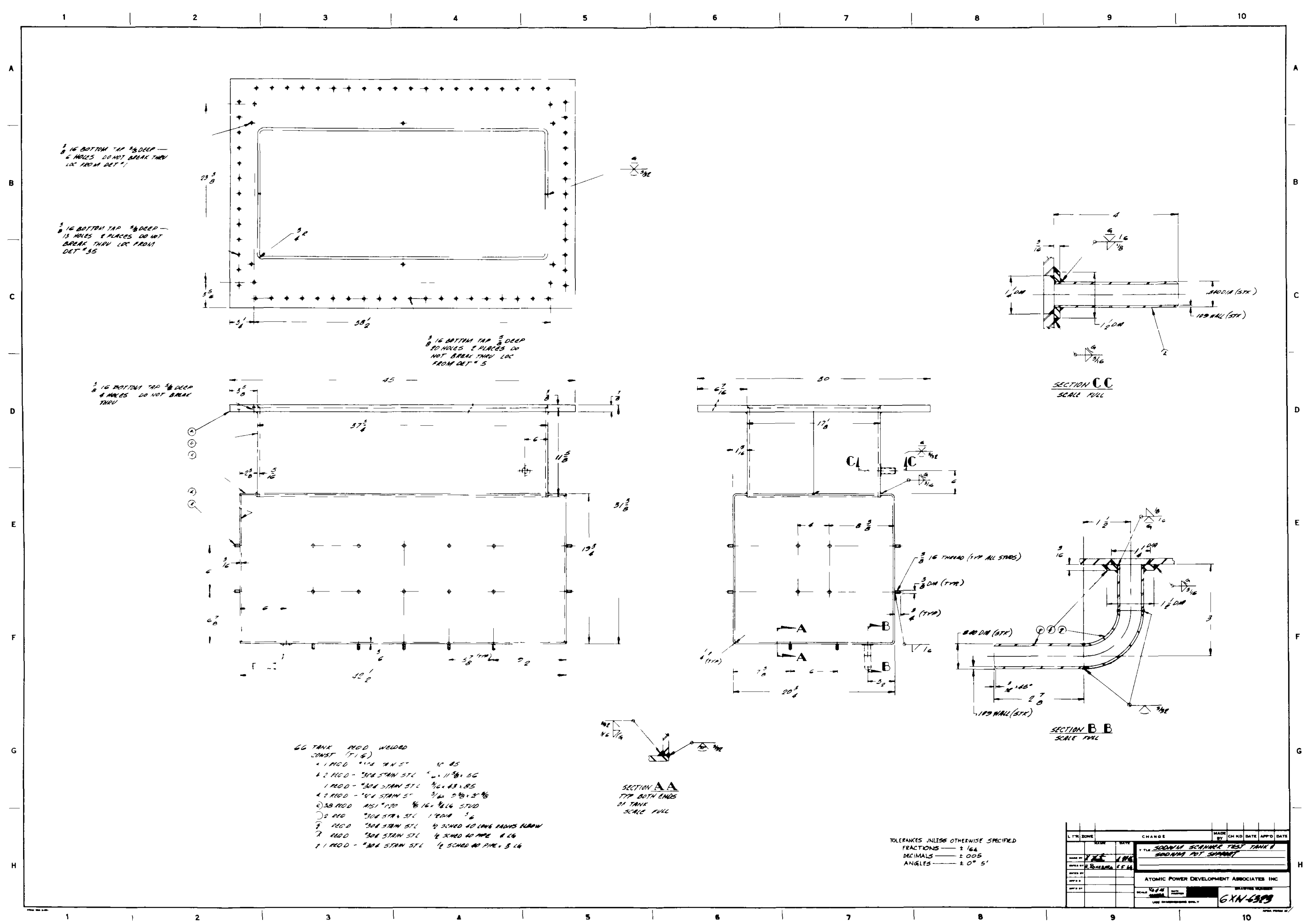

FIG. A.16 SODIUM SCANNER TEST TANK AND SODIUM POT SUPPORT 


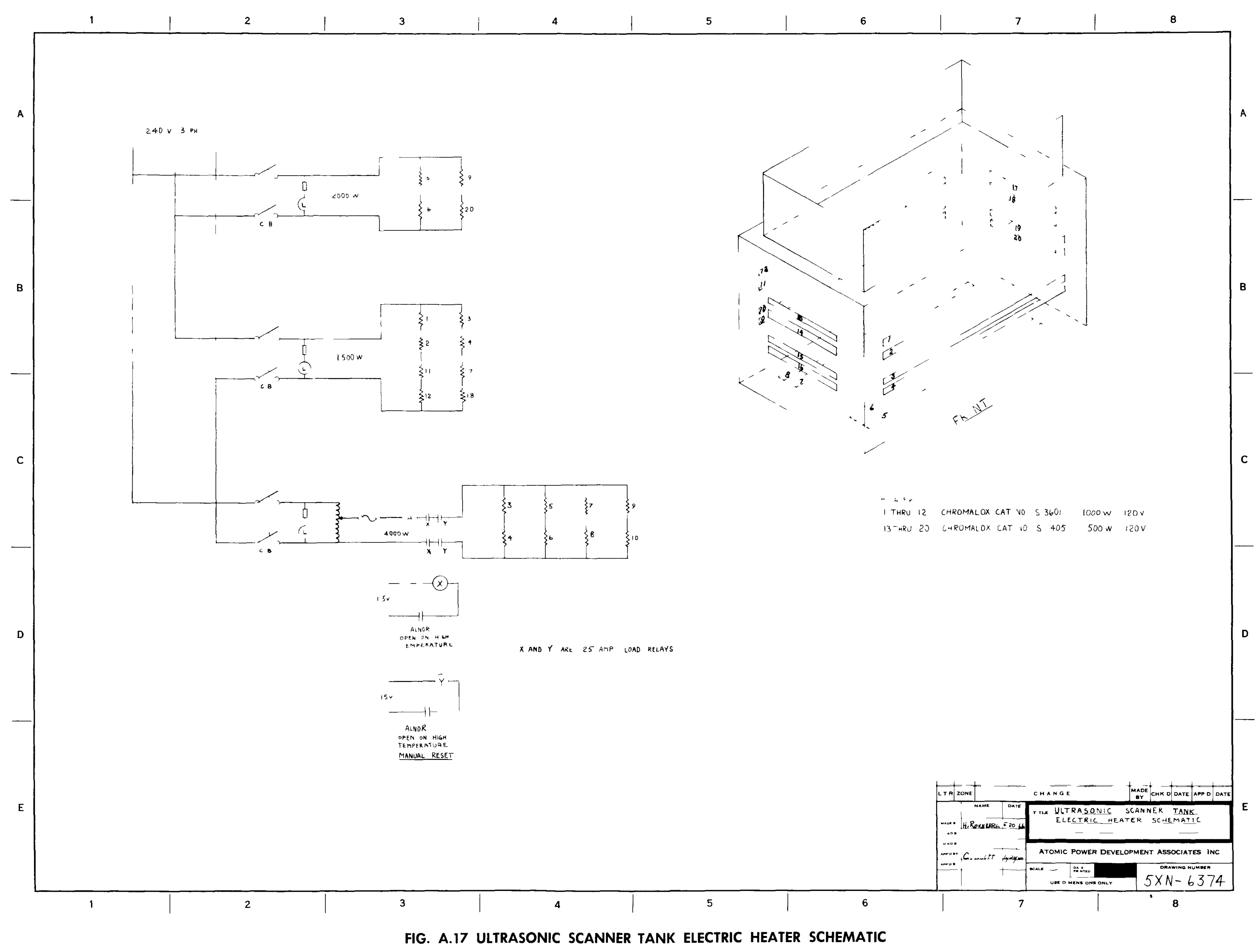



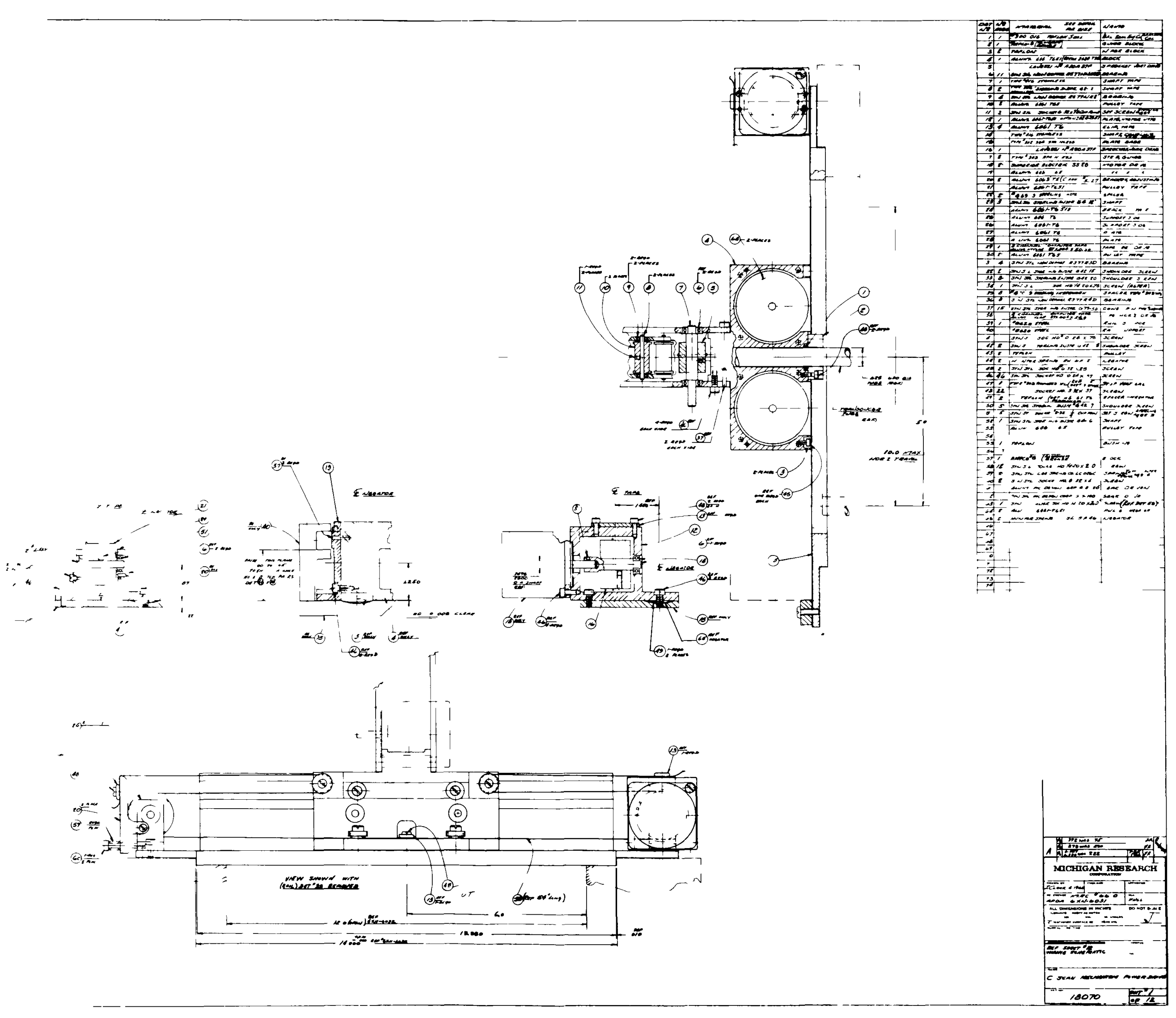


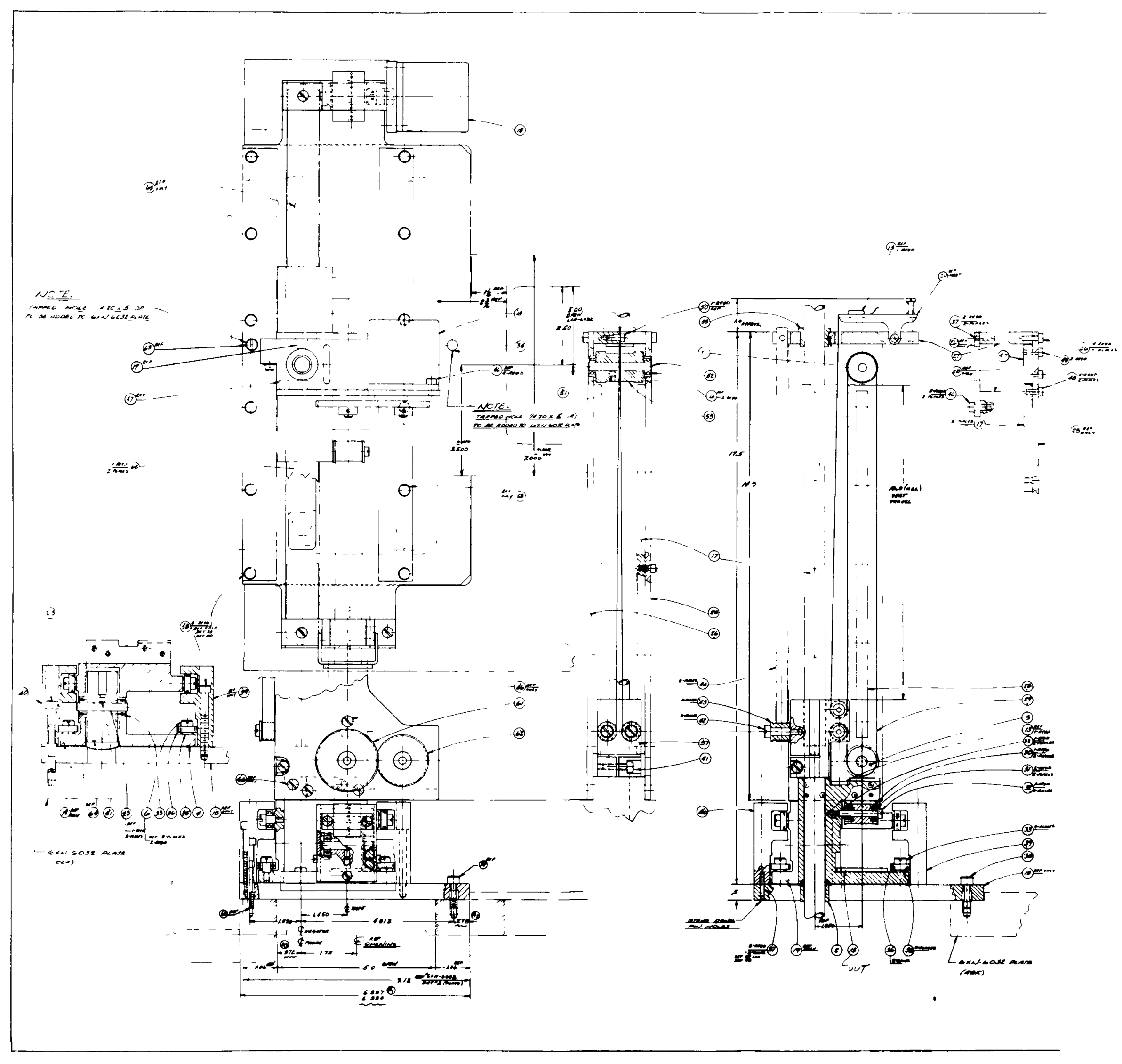




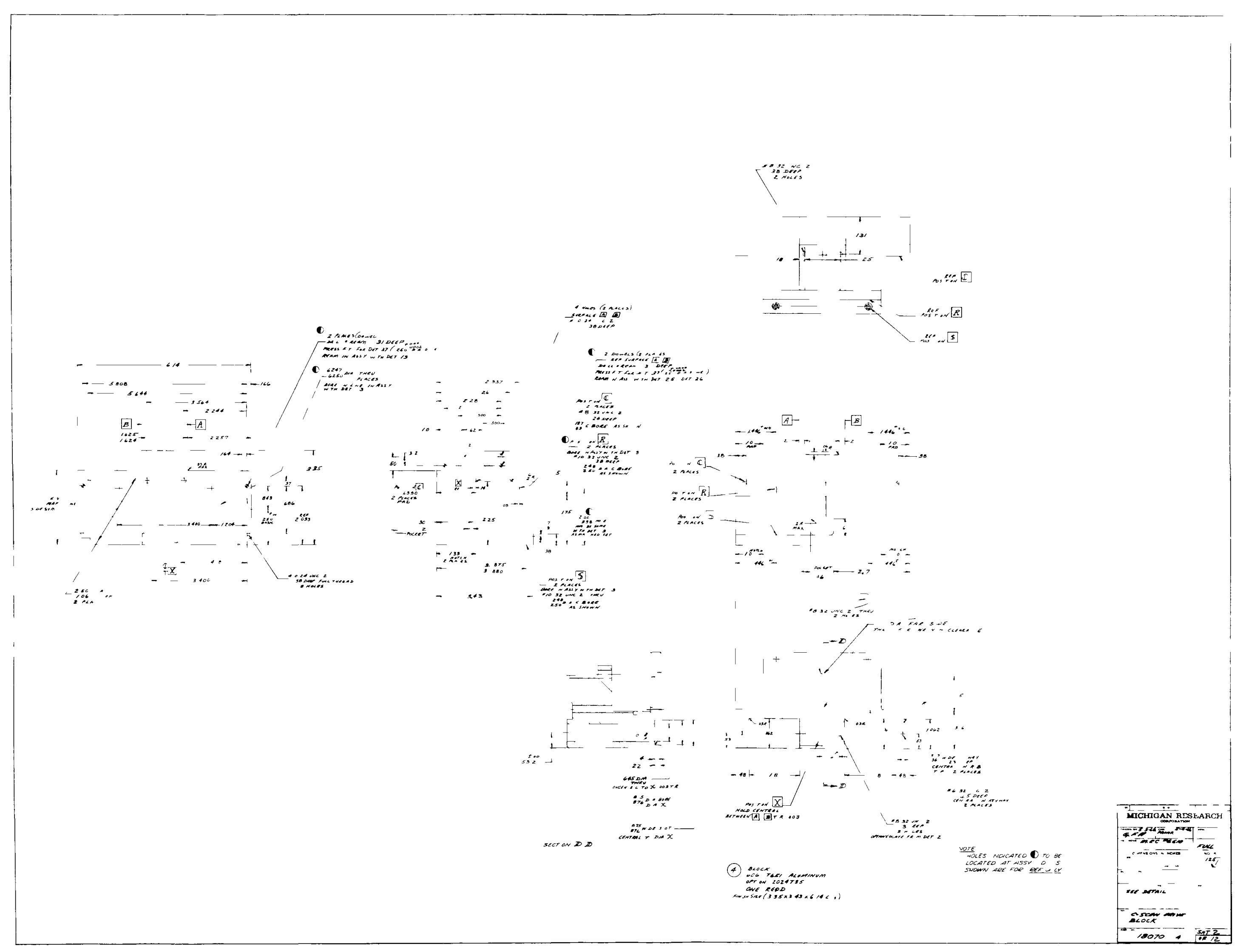

FIG. A.19 C-SCAN DRIVE BLOCK 


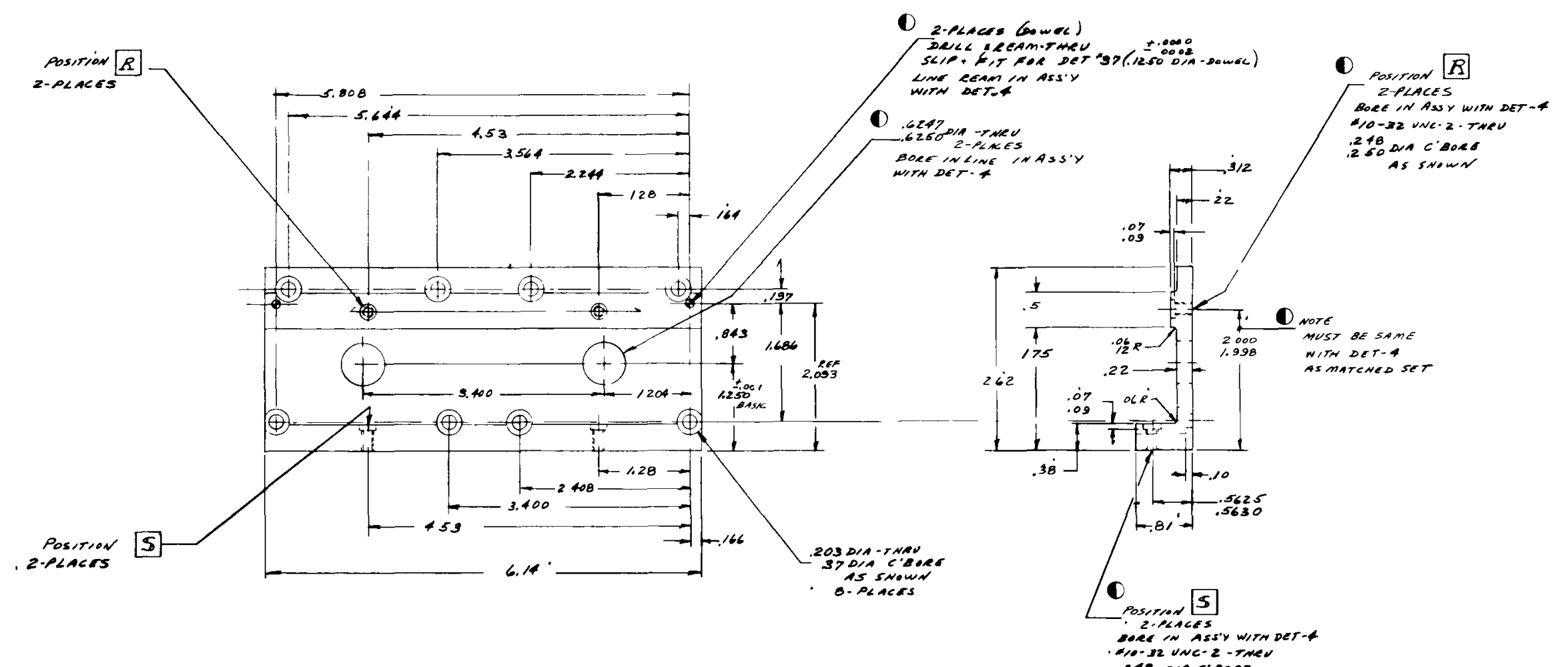

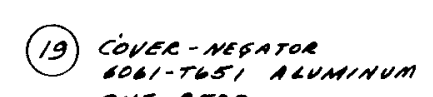

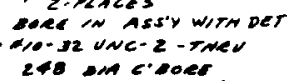

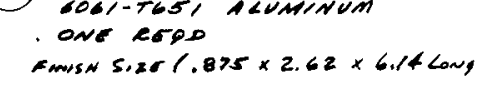

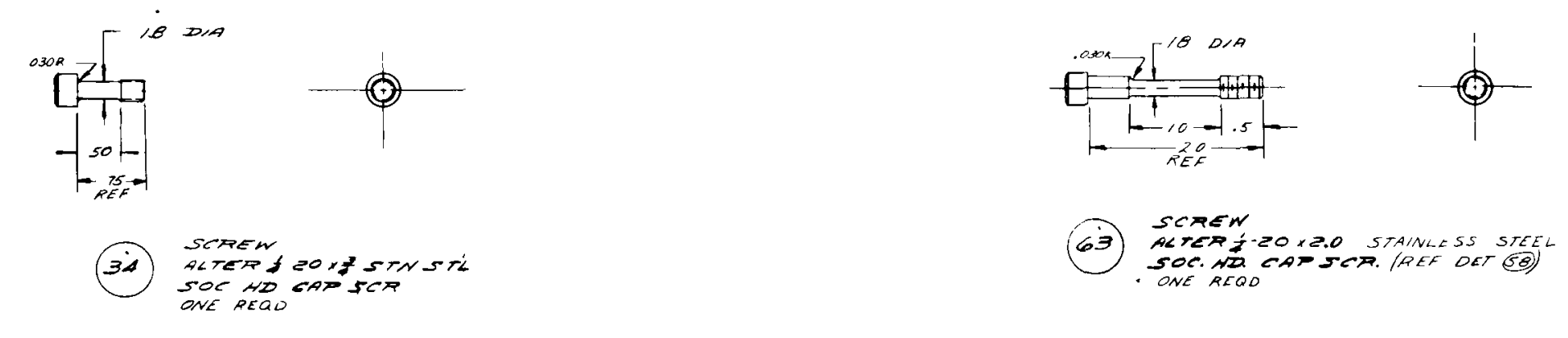

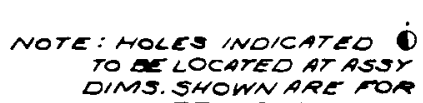

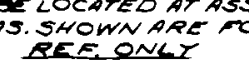

MCHIGAN RESEARCH

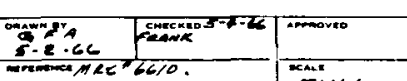

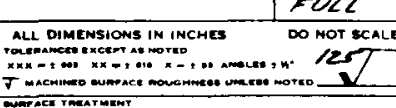
ser orrall MTSCAN DRIVE MECHANISM
DETAILS $18070-i 9 \cdot 34-6 \cdot 3 \mid \frac{5 n T 3}{0.612}$ 

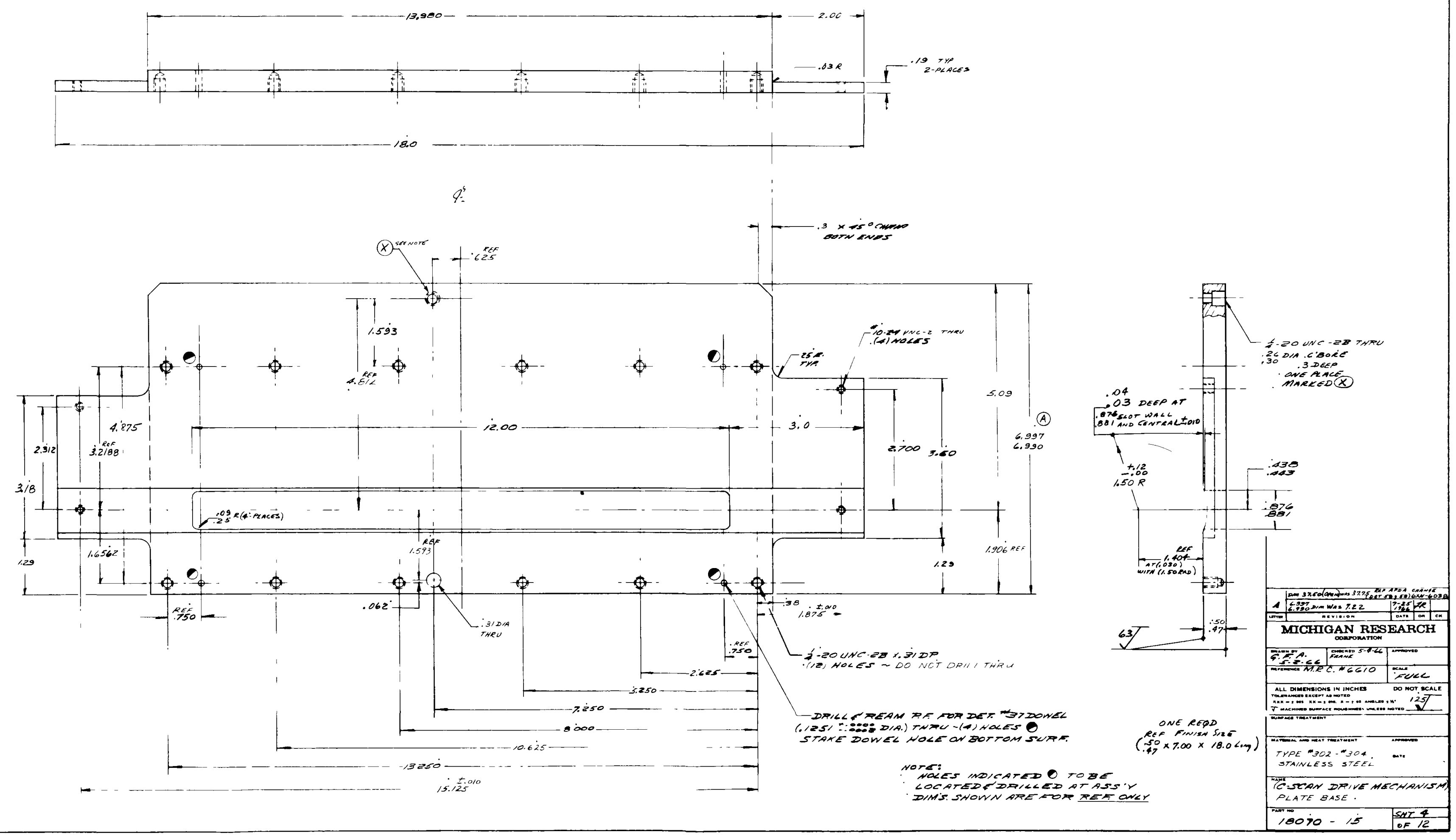

FIG. A.21 C-SCAN MECHANISM PLATE BASE 

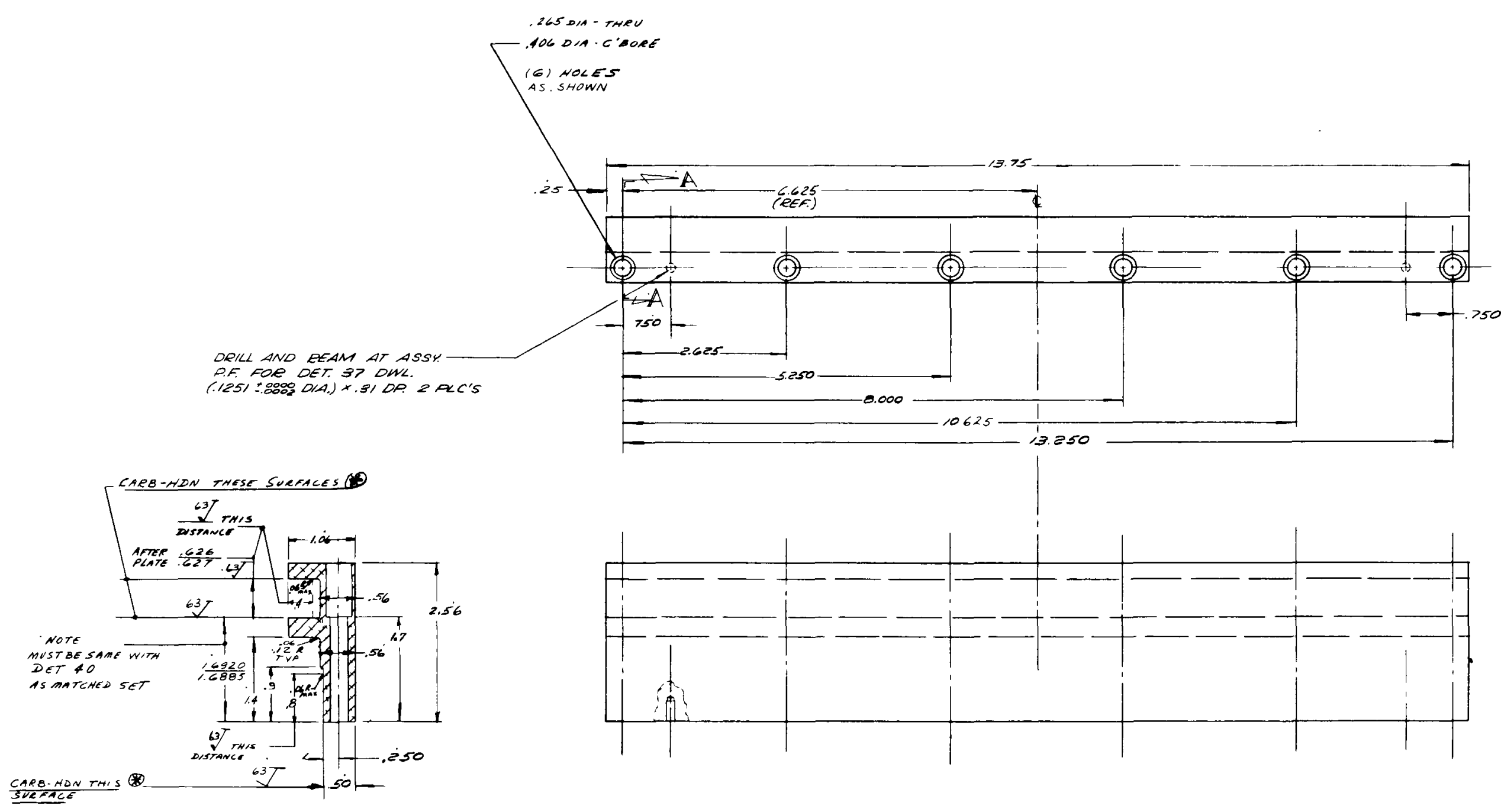

section A A

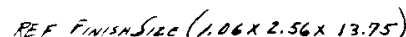
ONE REQD
MICHIGAN RESEARCH

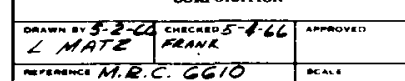

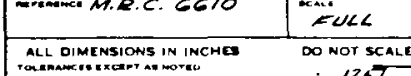
$7=-\ldots+\ldots$

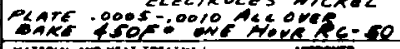

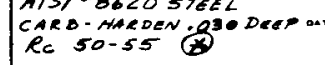

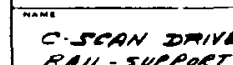

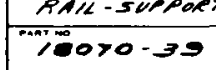

FIG. A.22 C-SCAN DRIVE MECHANISM RAIL-SUPPORT 


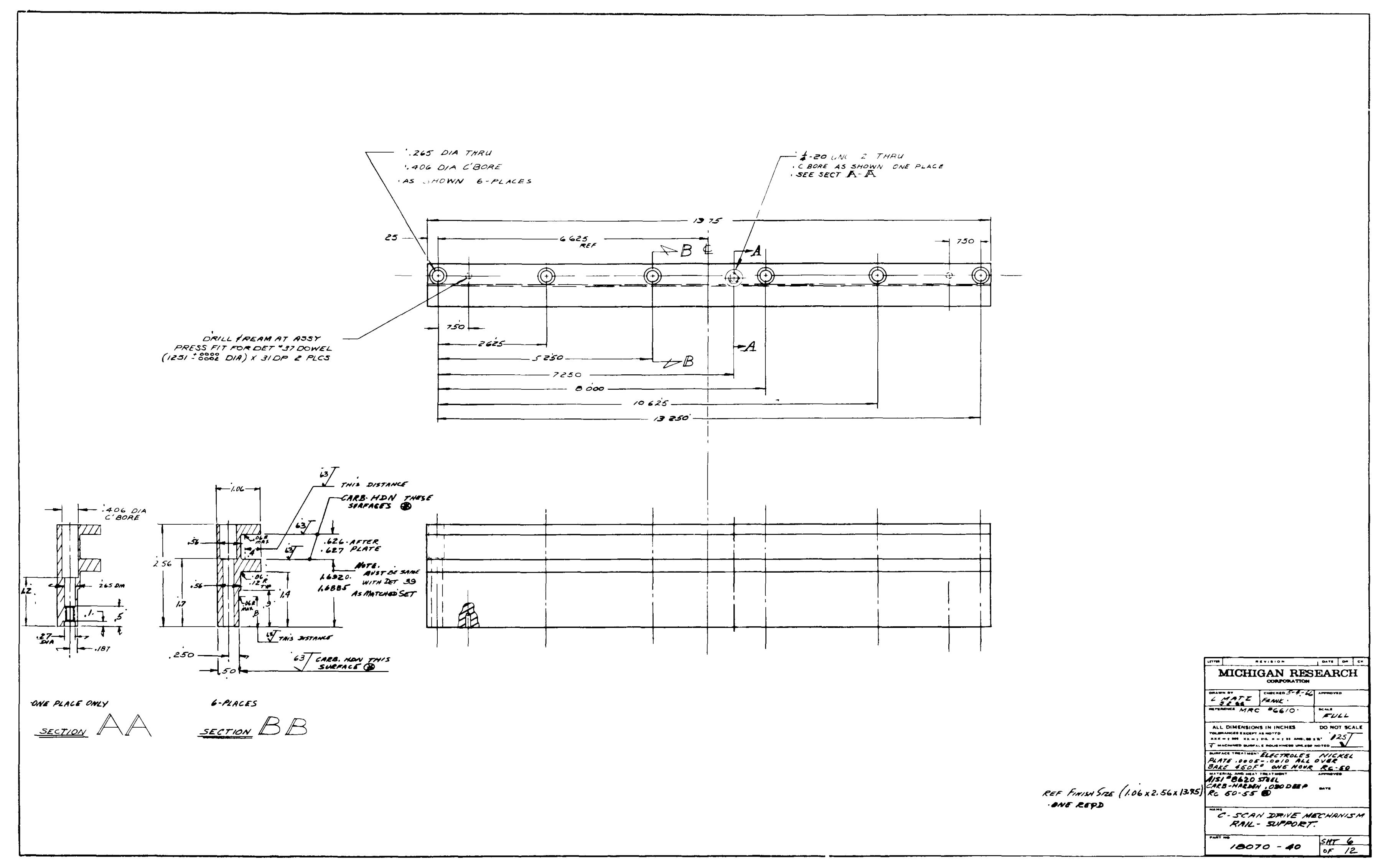

FIG. A.23 C-SCAN DRIVE MECHANISM RAIL-SUPPORT 


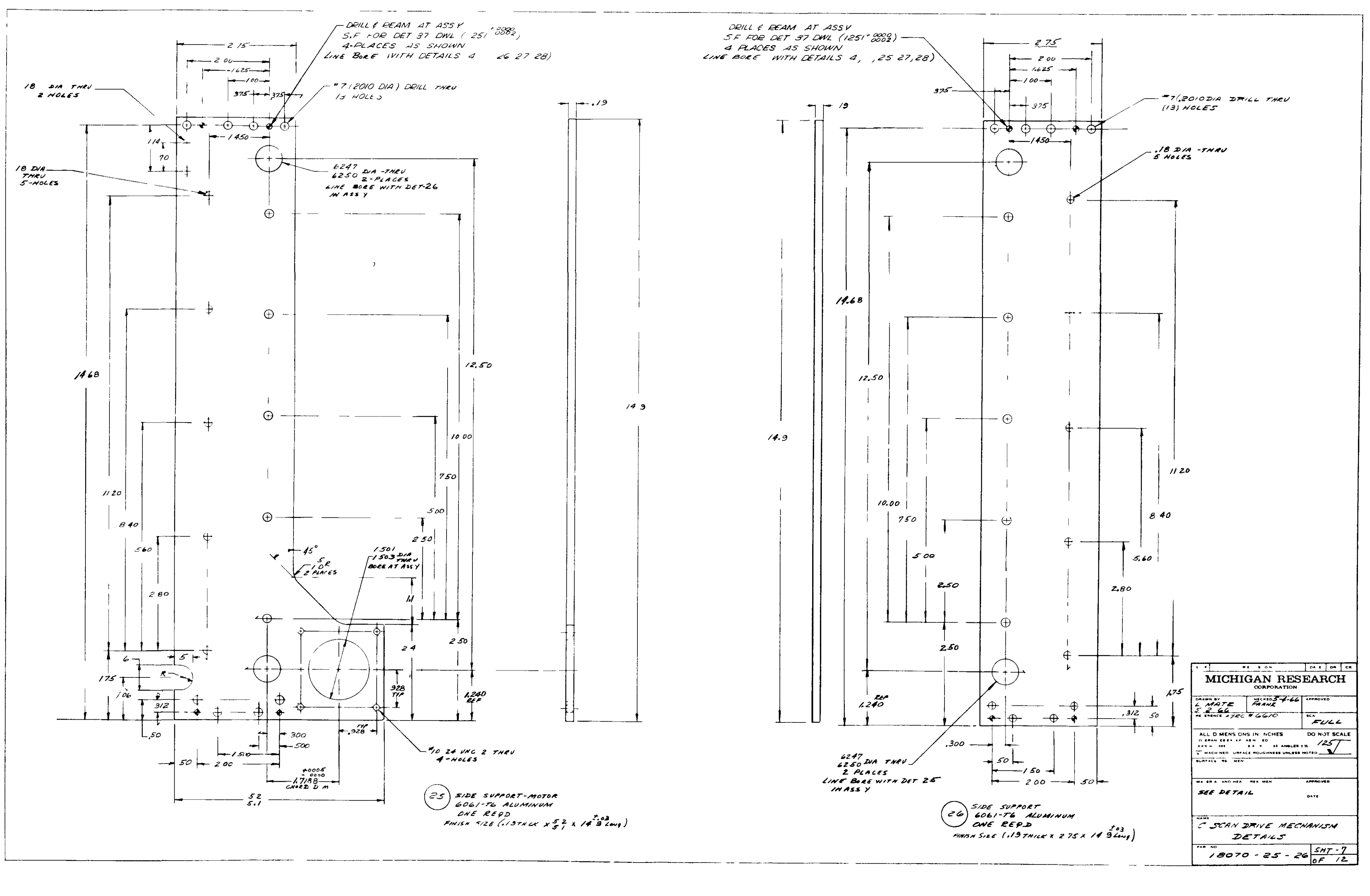

FIG. A.24 C-SCAN DRIVE MECHANISM DETAILS 


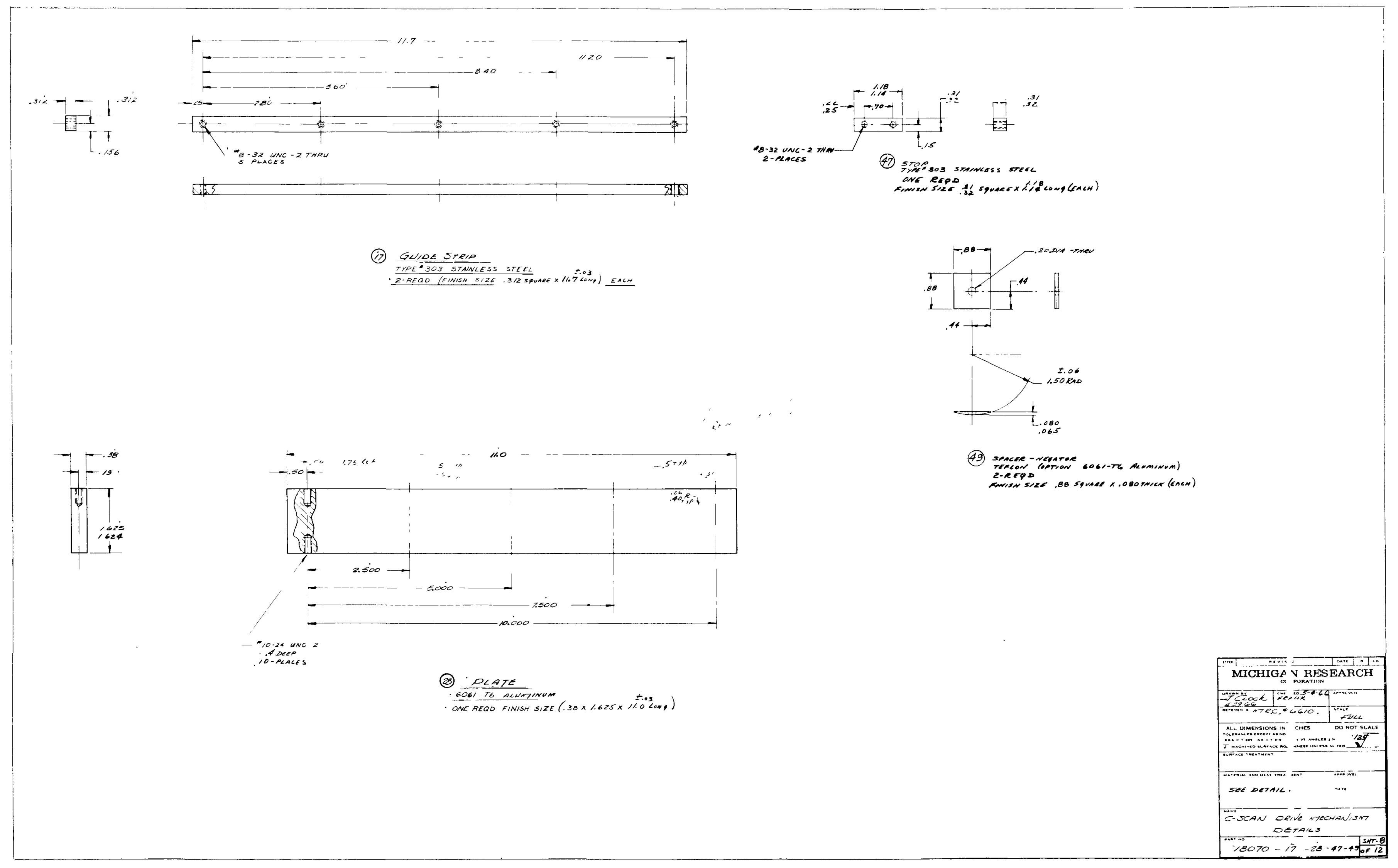




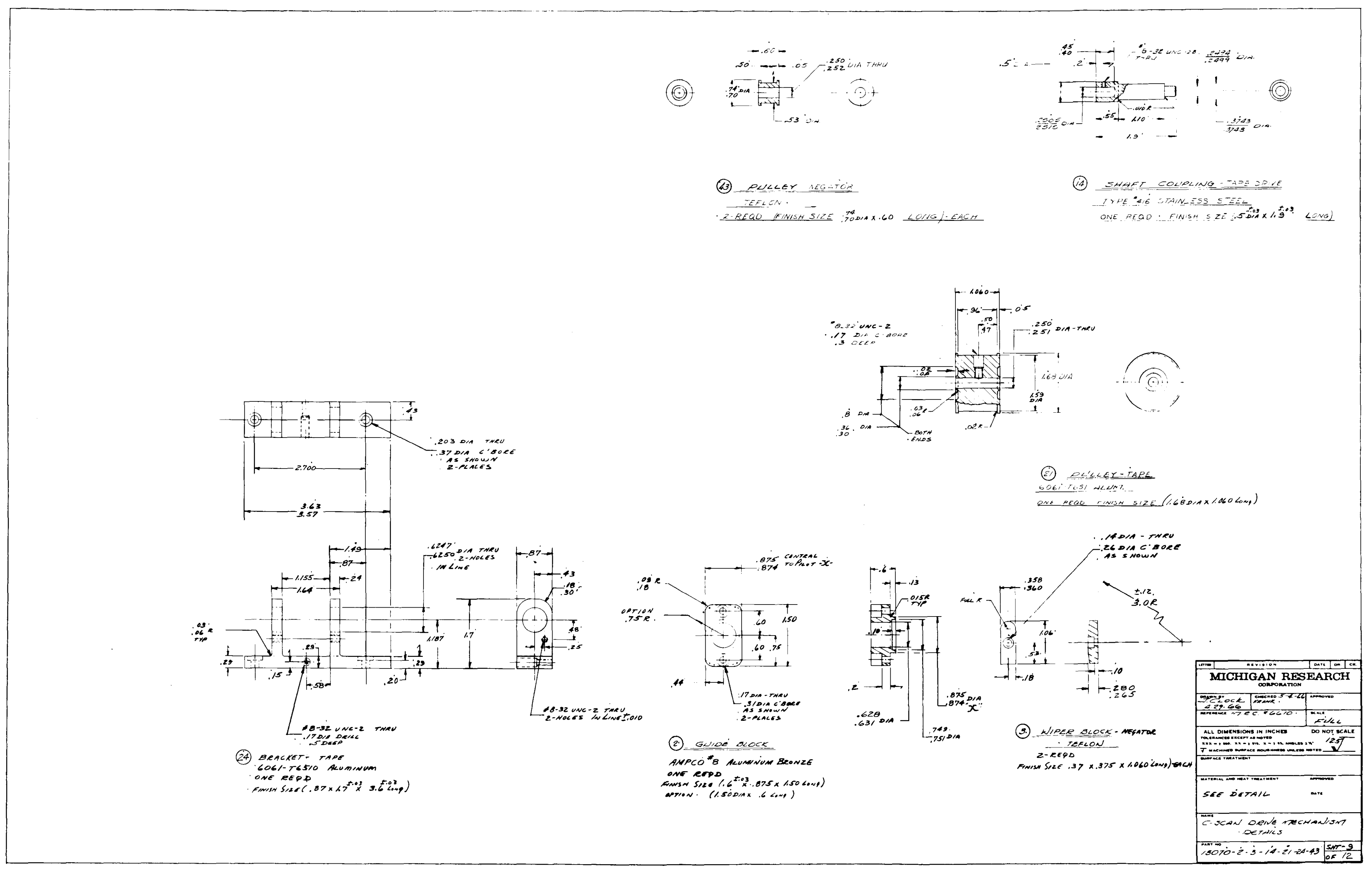

FIG. A.26 C-SCAN DRIVE MECHANISM DETAILS 


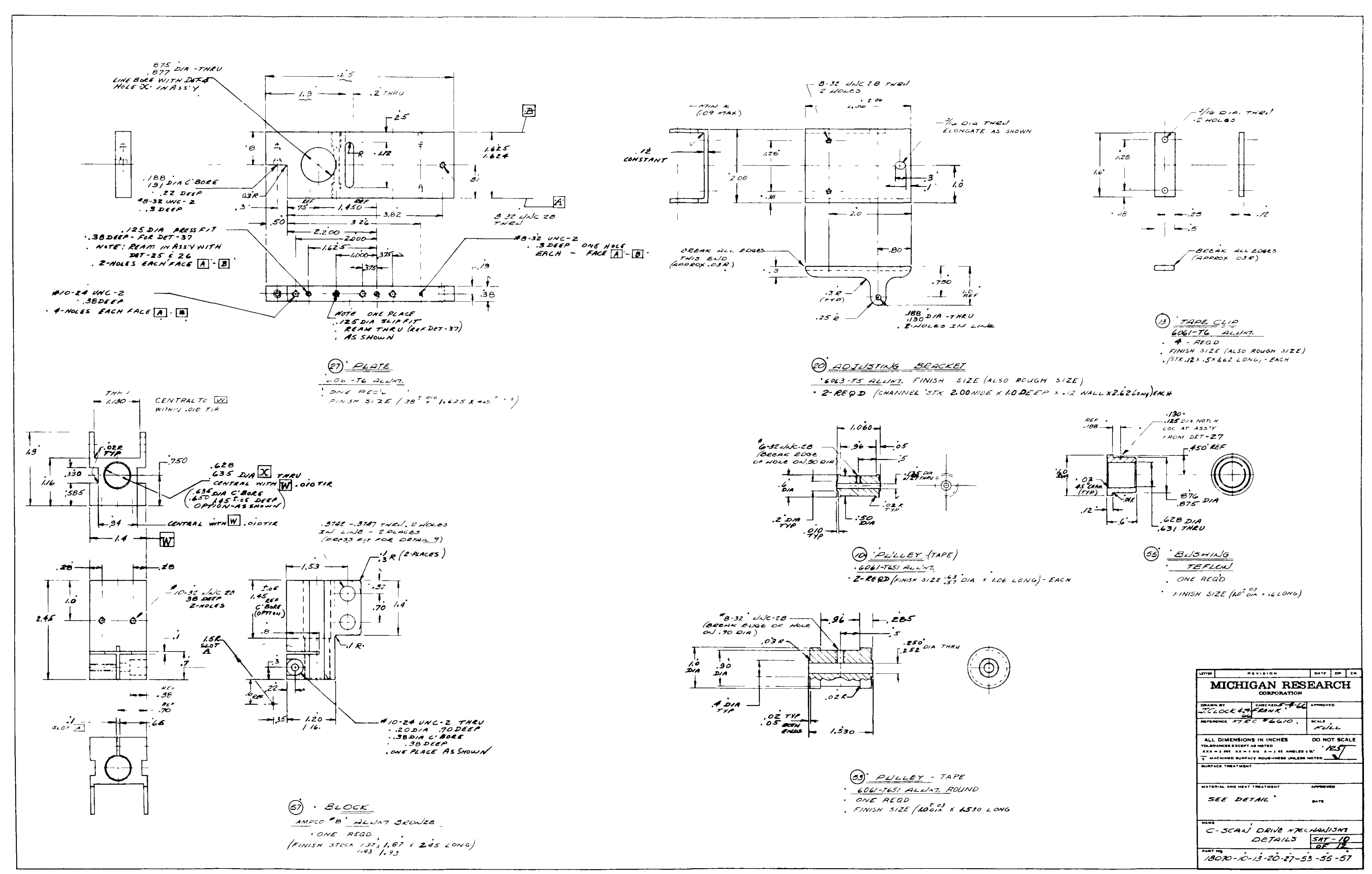

FIG. A.27 C-SCAN DRIVE MECHANISM DETAILS 

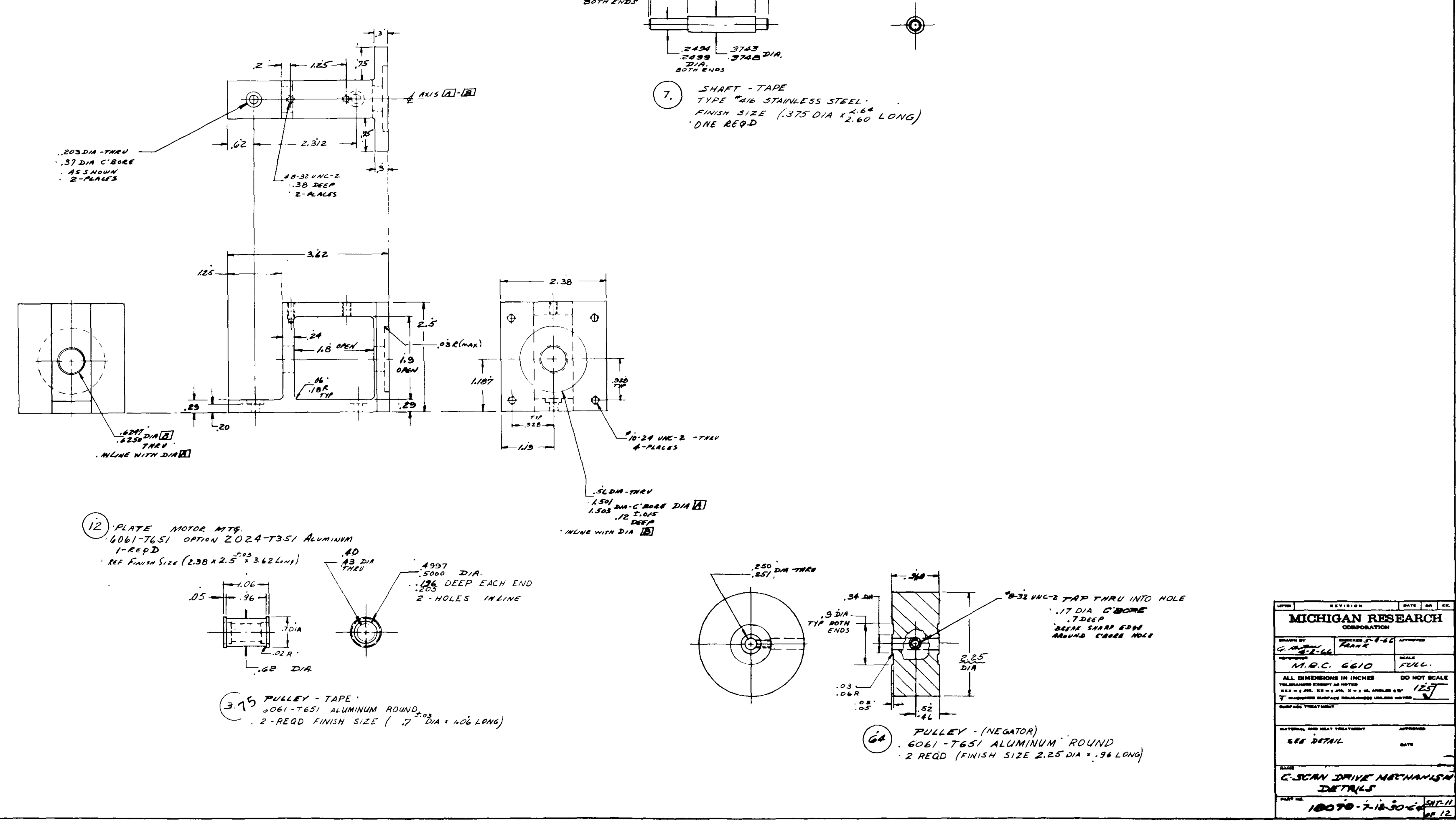


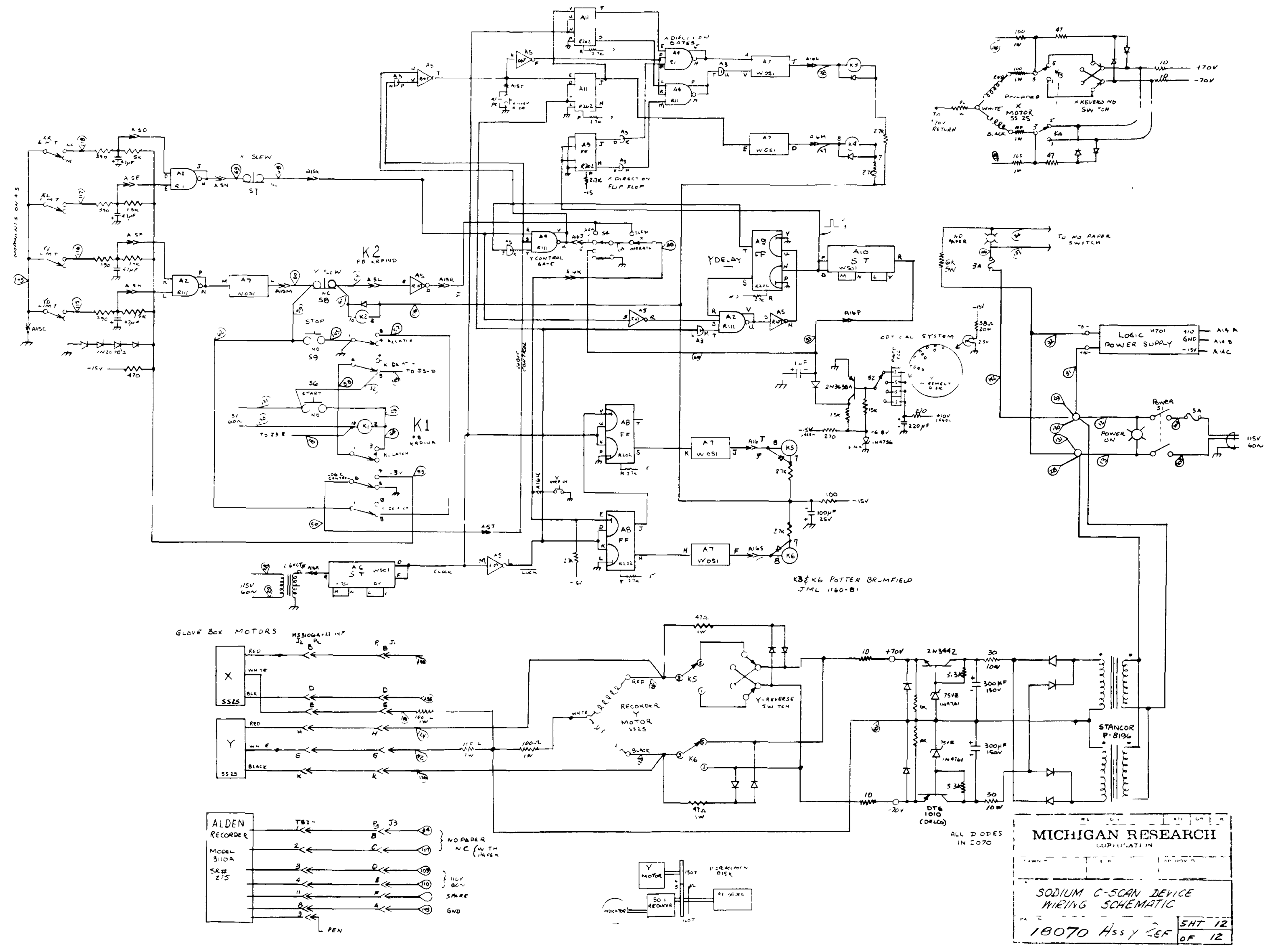

FIG. A.29 SODIUM C-SCAN DEVICE WIRING SCHEMATIC 


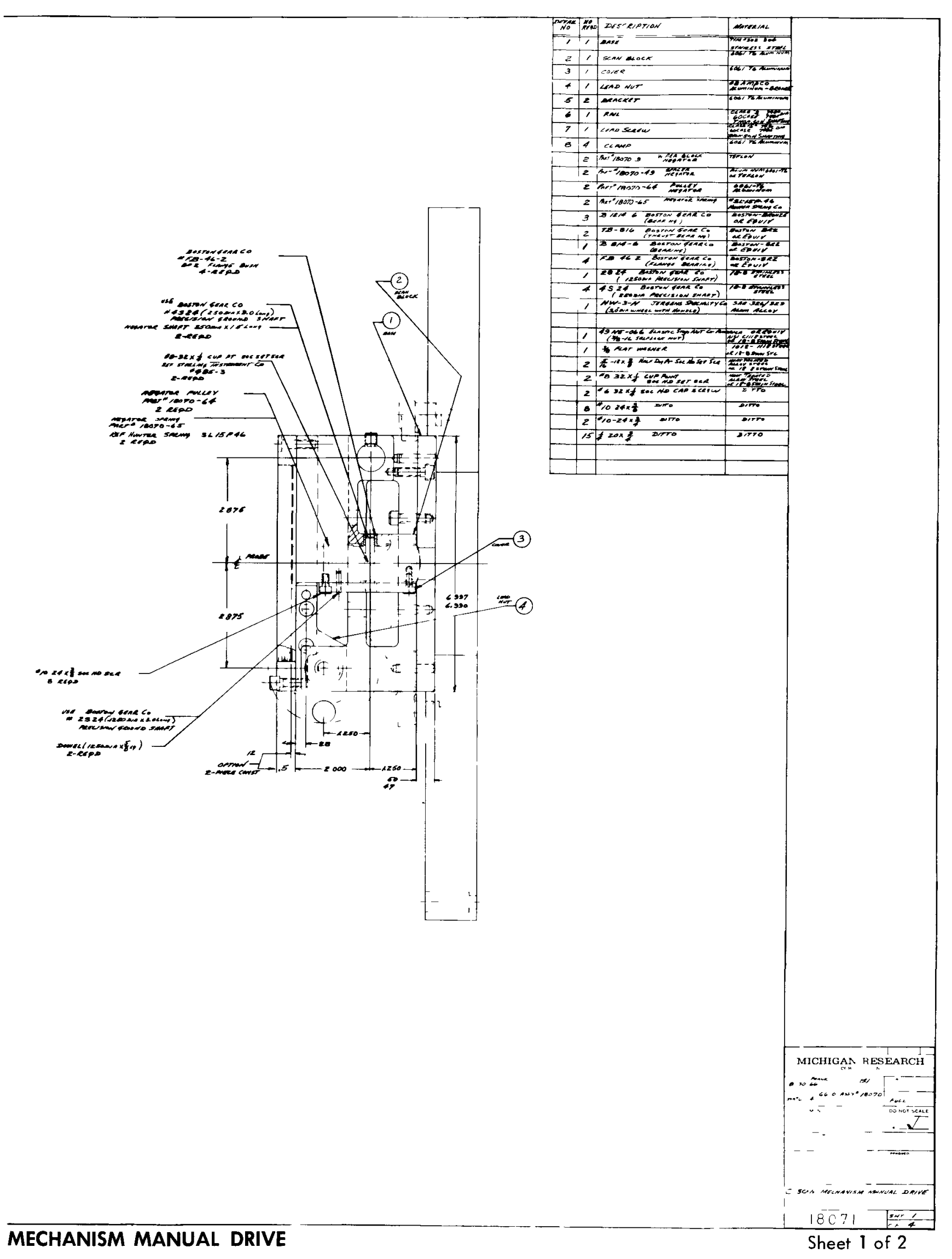




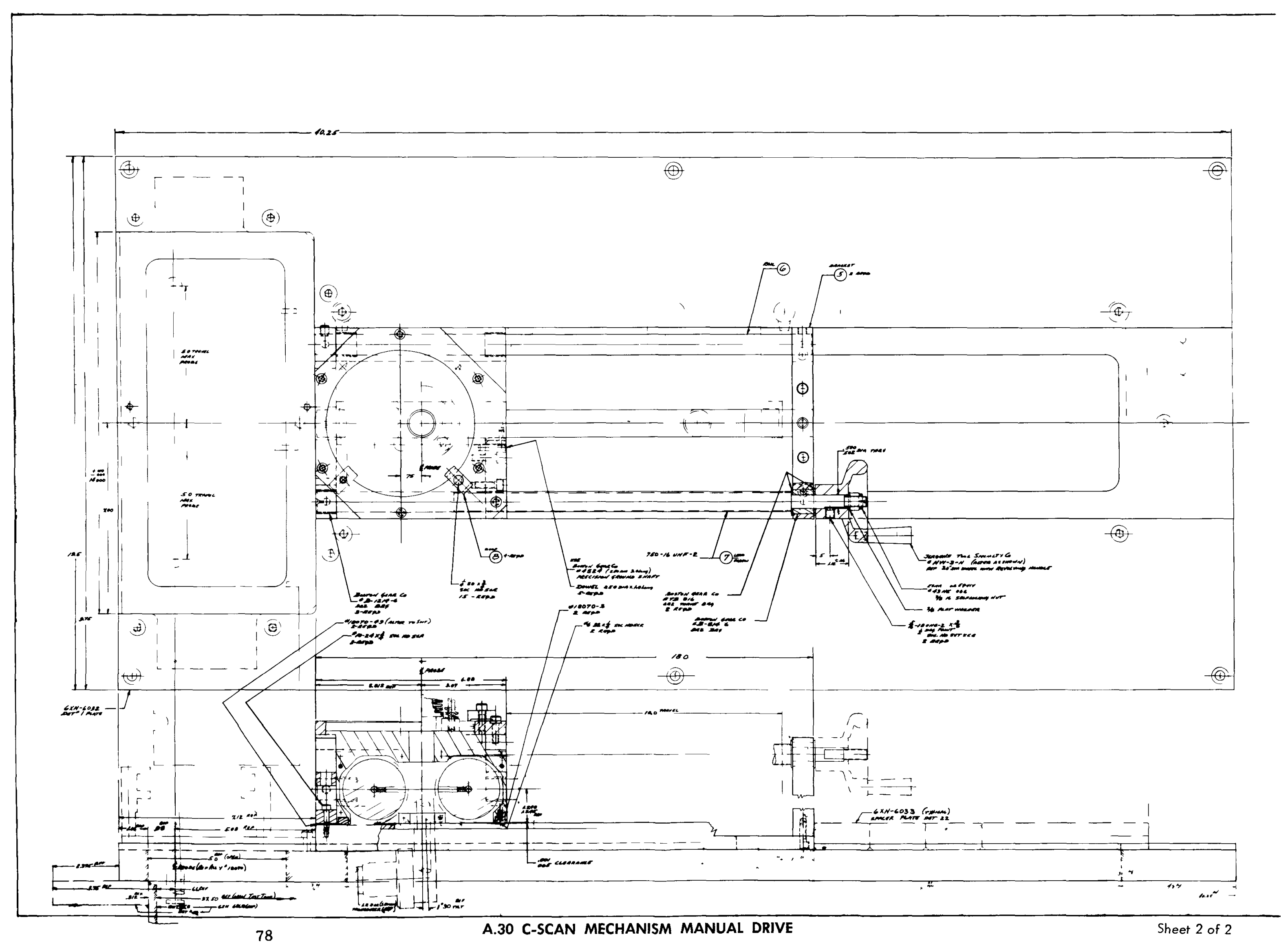




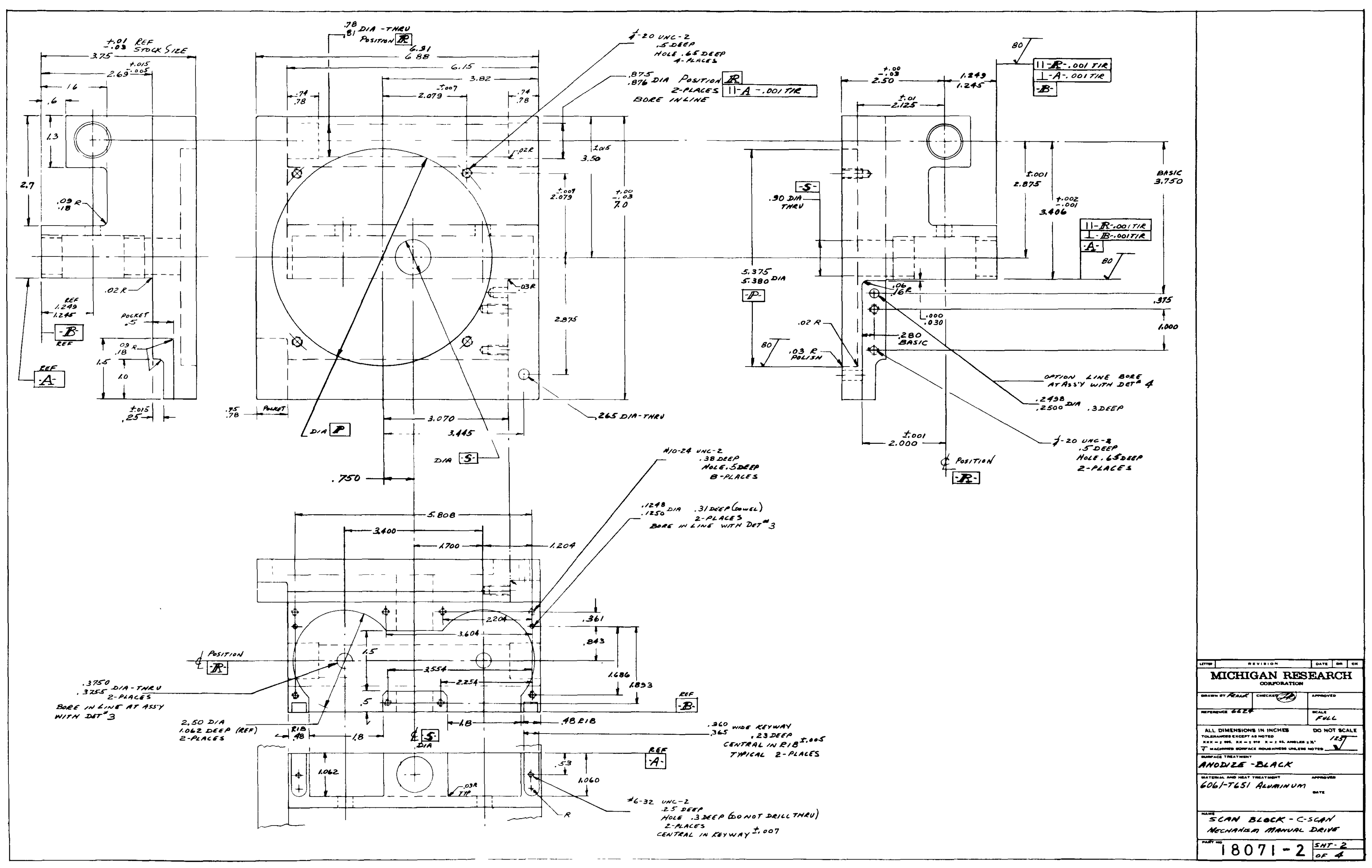




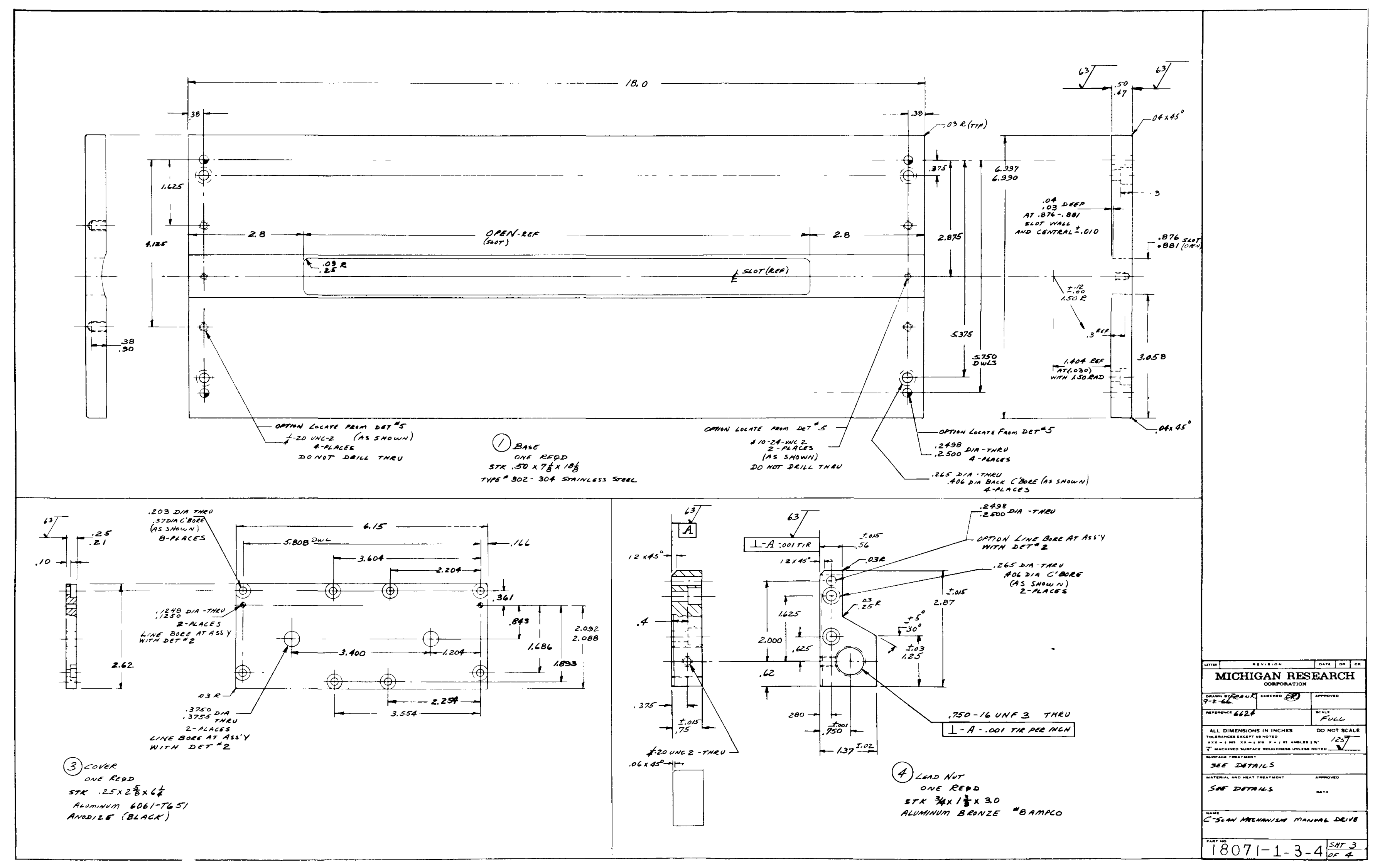




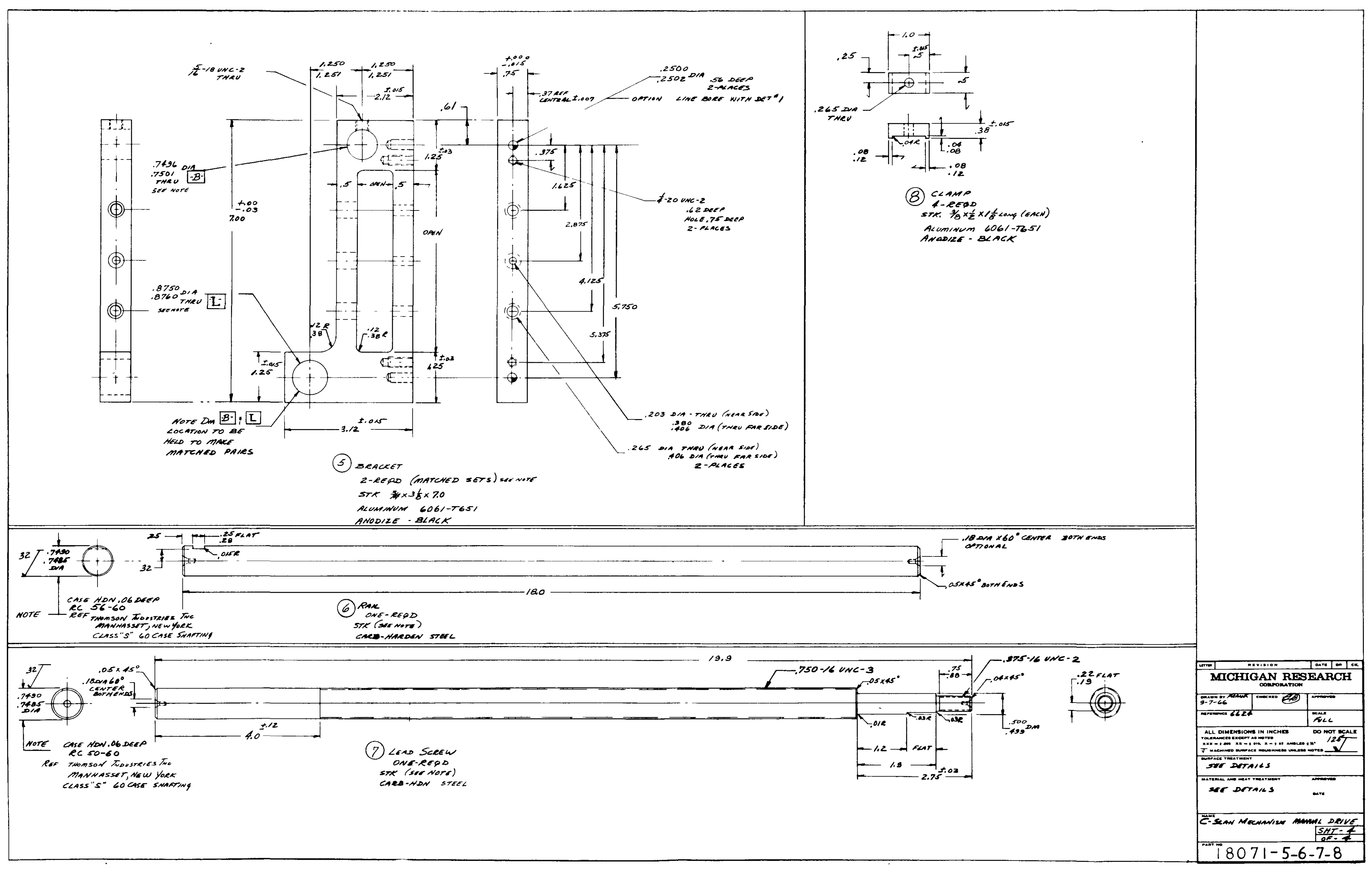


$\bullet$ 


\section{DISTRIBUTION LIST}

No. of Copies

USAEC - Chicago Operations Office

2

Director, Contracts Office

G. H. Lee

R. J. Gariboldi

USAEC - Washington

1

N. Grossman

R. H. Jones

W. R. Kornack

J. A. Lieberman

J. J. Morabito

J. M. Simmons

S. A. Szawlewicz

G. W. Wensch

M. Whitman

D. J. Wille

USAEC - DTIE

3

R. L. Shannon

USAEC - New York Operations Office

1 J. Dissler

1 J. Wise

USAEC - San Francisco Operations Office

1

J. Holliday

USAEC - Canoga Park Area Office

2

W. G. Armstrong

USAEC - MCRP, Indiana polis

1 S. Meyers 
No. of Copies

Argonne National Laboratory

R. Bane

S. Greenberg

L. Kelman

L. J. Koch

K. Kuczen

S. Lawroski

R. E. Macherey

M. Novick

W. R. Simmons

F. Smith

Brookhaven National Laboratory

1 O. E. Dwyer

2 D. Gurinsky

1 K. Hoffman

1 C. Klamut

1 L. Newman

1 A. Romano

Los Alamos Scientific Laboratory

2 D. B. Hall

1 G. Waterbury

1 L. E. Whinery

1 W. R. Wykoff

LMFBR - Argonne National Laboratory

A. Amorosi

Oak Ridge National Laboratory

F. L. Culler

1 J. H. Devan

1 D. Gardiner

1 R. E. MacPherson

1 J. White

Pacific Northwest Laboratory, BMI

5 E. Astley

1 S. L. Fawcett 
No. of Copies

NASA, Lewis Flight Propulsion Laboratory

1

C. A. Barrett

Aerojet - General Corporation

1

H. Derow

Allis-Chalmers Mfg. Co. (Bethesda, Md.)

1

W. S. Farmer

L. E. Phillips

Library

Atomics International

1 D. T. Eggen

2 D. C. Fulton

1

Liquid Metals Information Center

Babcock \& Wilcox Company

1

P. B. Probert

Baldwin-Lima-Hamilton Corporation

1 J. G. Gaydos

1 R. A. Tidball

Combustion Engineering, Inc.

1 W. H. Zinn

General Atomics, Div. of General Dynamics

$1 \quad$ P. Fortescue

General Electric Company

3 K. Cohen

M. W. Kellogg Company

1 E. W. Jesser

MSA Research Corporation

1 C. H. Staub 
No. of Copies

Nuclear Materials \& Equipment Corporation

1

Z. M. Shapiro

Power Reactor Development Company

1 A. S. Griswold

Southwest Atomic Energy Associates

1

J. R. Welsh

United Nuclear Corporation

2

A. Strausser

Westinghouse Corporation

2 J. Wright

US-EURA TOM Exchange

10

A. DeStordeur, Brussels

10 W. Haefele, Karlsruhe

4 F. Pierantoni, CNEN, Bologna

10 G. Vendryes, CEN Saclay

US-UKAEA Exchange

12 R. Nicholson

Total 135

September 8, 1966 